University of Rhode Island

DigitalCommons@URI

Open Access Dissertations

1995

\title{
The Influence of Formulation and Device Variables on the Intransasal Absorption of Salmon Calcitonin
}

Ramneik Dua

University of Rhode Island

Follow this and additional works at: https://digitalcommons.uri.edu/oa_diss

\section{Recommended Citation}

Dua, Ramneik, "The Influence of Formulation and Device Variables on the Intransasal Absorption of Salmon Calcitonin" (1995). Open Access Dissertations. Paper 181.

https://digitalcommons.uri.edu/oa_diss/181

This Dissertation is brought to you for free and open access by DigitalCommons@URI. It has been accepted for inclusion in Open Access Dissertations by an authorized administrator of DigitalCommons@URI. For more information, please contact digitalcommons-group@uri.edu. 
THE INFLUENCE OF FORMULATION AND DEVICE VARIABLES ON THE INTRANASAL ABSORPTION OF

\section{SALMON CALCITONIN}

BY

RAMNEIK DUA

A DISSERTATION SUBMITTED IN PARTIAL FULFILLMENT OF THE REQUIREMENTS FOR THE DEGREE OF DOCTOR OF PHILOSOPHY

IN

PHARMACEUTICAL SCIENCES 


\section{DOCTOR OF PHILOSOPHY DISSERTATION \\ OF}

\section{RAMNEIK DUA}

\section{APPROVED:}

Dissertation Committee

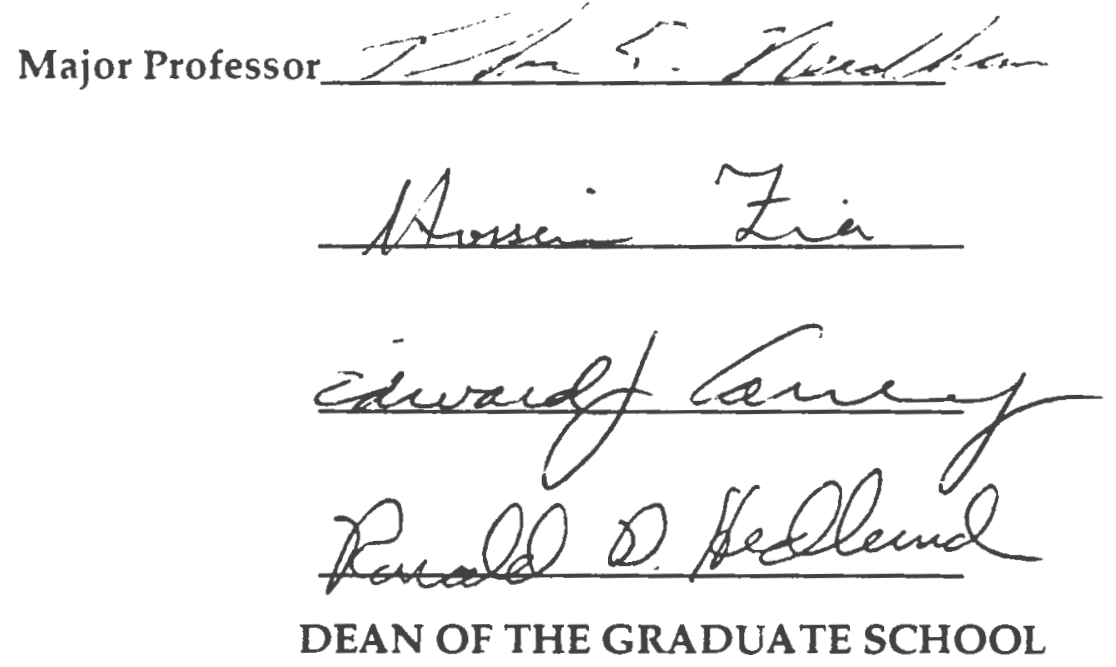

UNIVERSITY OF RHODE ISLAND 


\begin{abstract}
The nasal administration of drugs, particularly peptides, is very beneficial but like other mucosal routes, suffers from low bioavailability for the higher molecular weight compounds. The nasal bioavailability of peptides and proteins is influenced by the dosage form as well as the devices used for administration. In the present study an effort was made to investigate the effect of formulation and device variables on the intranasal delivery and absorption of salmon calcitonin $(\mathrm{sCT})$. The formulations were designed as nasal sprays with viscosity of 1 and $76 \mathrm{cps}$ using methylcellulose as a viscosity enhancing agent at 0 and $1 \%$ $\mathrm{w} / \mathrm{w}$; tonicity of $100 \mathrm{mOsm}, 300 \mathrm{mOsm}$ and $600 \mathrm{mOsm}$ using sodium chloride as a tonicity adjusting agent; an acidic phospholipid, Dimyristoylphosphatidylglycerol (DMPG), as an absorption enhancer at $1 \%$ $\mathrm{w} / \mathrm{w}$ and chlorobutanol as the preservative. The formulations were investigated for viscosity by using a cone and plate viscometer and for droplet size distribution with a Malvern laser sizer. The selected formulations were delivered to the nasal cavity of healthy male New Zealand rabbits using a commercially available metered spray pump and a prototype device, nasal micron spray pump, to facilitate a uniform distribution of the spray in the nasal cavity. The components of the devices, mechanism of pump and actuator design were evaluated for dose accuracy as well as their ability to generate a uniform distribution of spray in the nasal cavity. A full factorial design with tonicity at three levels, viscosity at two levels and concentration of enhancer at two levels was used as the experimental design. Serum levels of SCT were determined using a double antibody radioimmunoassay. The area under the curve (AUC) and bioavailability were determined using pharmacokinetic software MKDATA. The pharmacodynamic effect of salmon calcitonin of lowering of calcium was
\end{abstract}


measured, by complexation with arsenazo III, using a visible spectrophotometric technique at $650 \mathrm{~nm}$. The data was analyzed using ANOVA and the comparisons among the treatments were performed using'Scheffe's multiple comparison analysis and Fisher's least significance test. Deviation from isotonicity (300 mOsm) enhanced the intranasal bioavailability of sCT by $4-5$ fold while the addition of DMPG at a concentration of $1 \% \mathrm{w} / \mathrm{w}$ doubled the bioavailability. Variation in the viscosity of formulations did not influence the bioavailability of salmon calcitonin. The data was interpreted using response surface methodology (RSM) with canonical analysis parameters demonstrating that optimum formulations could be designed. 


\section{ACKNOWLEDGMENTS}

I want to express my thanks for the succor and direction in all my endeavors to my major Professor Dr. Thomas E. Needham.

I would like to extend thanks to my Committee members, Dr. Hossein Zia and Dr. Edward Carney, for their fine suggestions and useful comments during the critique of this dissertation.

I also would like to express my appreciation to Rhone Poulenc Rorer Inc., for

partially supporting this project; especially Dr. Michelle Duncan, who provided an exceptional scientific guidance during the course of my research at Rhone Poulenc Rorer Inc.,

Graduate studies would not have been imaginable without the reassurance and unfailing support of my father, and my sisters, Puneit and Sumeit. 


\section{PREFACE}

I elected to write this dissertation following the format of the manuscript plan described in section 11-3 of the graduate manual at the University of Rhode Island. This option was most appropriate to present my results in various sections.

Section I consists of a general introduction of the topic and the objectives of my investigation. The three manuscripts, in Section II are the core of this study. Section III contains a set of appendices $\mathrm{A}$ to $\mathrm{C}$ giving experimental details and supporting data for the three manuscripts presented in Section II. 


\section{TABLE OF CONTENTS}

APPROVAL PAGE........................................................................ i

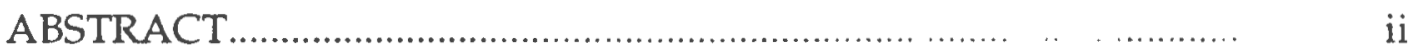

ACKNOWLEDGMENT............................................................... iv

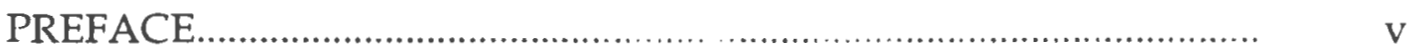

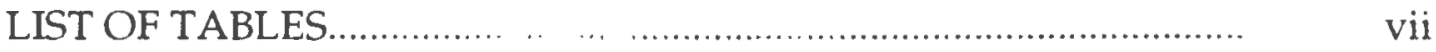

LIST OF FIGURES..................................................................... ix

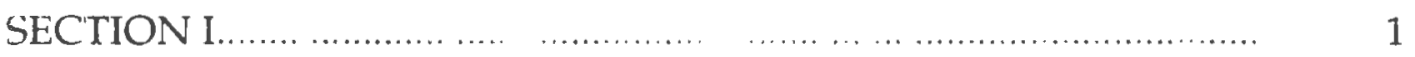

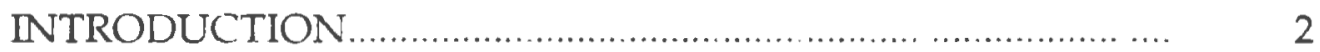

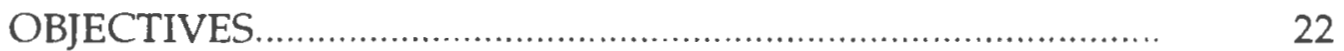

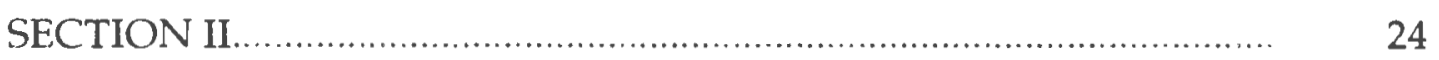

MANUSCRIPT 1 1..................................................................... 25

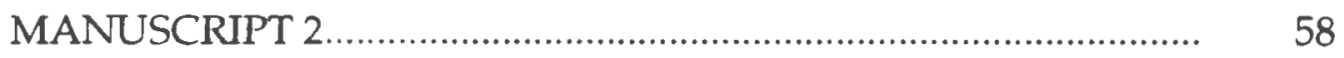

MANUSCRIPT 3

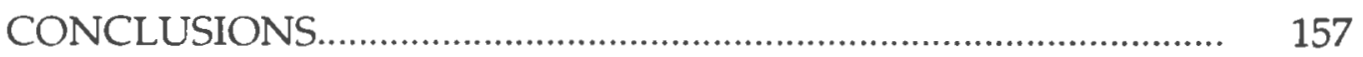

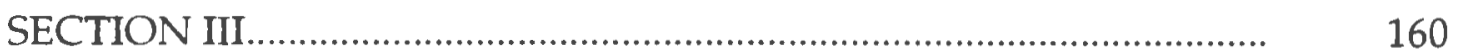

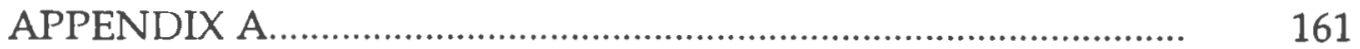

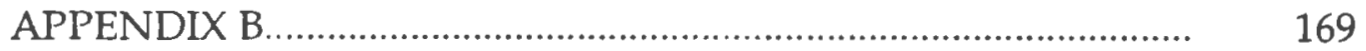

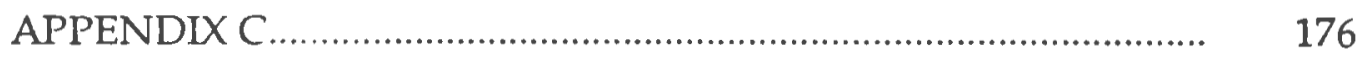

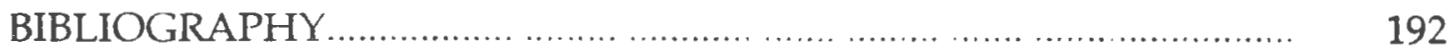




\section{LIST OF TABLES}

\section{MANUSCRIPT II}

Pharmacokinetic parameters after intranasal administration of

salmon calcitonin to New Zealand rabbits.

Pharmacodynamic parameters after intranasal administration of 75 salmon calcitonin to New Zealand rabbits.

\section{MANUSCRIPT III}

Pharmacokinetic parameters of low viscosity after intranasal

Pharmacodynamic parameters of low viscosity after intranasal administration of salmon calcitonin in $\mathrm{New}$ Zealand rabbits

Pharmacokinetic parameters of high viscosity after intranasal administration of salmon calcitonin in New Zealand rabbits

Pharmacodynamic parameters of high viscosity after 138 intranasal administration of salmon calcitonin in New Zealand rabbits

\section{APPENDIX B}

Analysis of Variance of Malvern data for viscosity

Analysis of Variance of Malvern data for tonicity

Analysis of Variance of Malvern data for concentration of enhancer

Analysis of Varance of Malvern data for mechanism of pump 
Scheffe's multiple comparison test for viscosity

Scheffe's test multiple comparison test for tonicity

178

Scheffe's multiple comparison test for concentration of 179 absorption enhancer

Fisher's Least Significance difference test for viscosity

Fisher's Least Significance difference test for tonicity

181

Fisher's Least Significance difference test for concetration of

182 absorption enhancer

Computer output for General linear modeling for 183 ANOVA

Computer output for General linear modeling for 184 RSM procedure

Canonical analysis of response surface analysis

Response surface analysis parameters 186

Simulated data for the response surface analysis 


\section{LIST OF FIGURES}

\section{MANUSCRIPT I}

View of interior of nasal micron spray pump

View of the spray nozzle

Configuration of Malvern laser sizer

Non-Newtonian flow' exhibited by methylcellulose

Dose reproducibility studies of nasal devices

The influence of viscosity on the droplet size distribution using metered nasal spray pump

The influence of tonicity on the droplet size distribution using metered nasal spray pump

The influence of concentration of absorption enhancer on the droplet size distribution using metered nasal spray pump

The influence of mechanism of pump on the droplet size distribution for metered nasal spray pump

The influence of orifice diameter of spray insert in a actuator on the droplet size distribution for metered nasal spray pump

The influence of spray angle of a actuator on the droplet... size distribution for a metered nasal spray pump

The influence of viscosity on the droplet size distribution using nasal micron spray pump as the nasal device.

\section{MANUSCRIPT II}

Concentration time profile of salmon calcitonin after iv administration.

The influence of iv administration of salmon calcitonin on the calcium level 
The influence of viscosity on the intranasal absorption of salmon calcitonin in isotonic solutions

The influence of viscosity on the intranasal absorption of

The influence of viscosity on the intranasal absorption of salmon calcitonin for hypotonic solutions

The influence of viscosity on the calcium level after intranasal administration of isotonic salmon calcitonin solutions

The influence of viscosity on the calcium level after

The influence of viscosity on the calcium level after intranasal administration of salmon calcitonin hypotonic solutions

Three dimensional surface plot of tonicity and viscosity versus area under the curve

\section{MANUSCRIPT III}

The influence of a salt concentration of $0.045 \mathrm{M}$ and

DMPG on the intranasal absorption of salmon calcitionin

The influence of a salt concentration of $0.15 \mathrm{M}$ and DMPG on the intranasal absorption of salmon calcitionin

The influence of a salt concentration of $0.3 \mathrm{M}$ and DMPG on the intranasal absorption of salmon calcitionin

The influence of a salt concentration of $0.045 \mathrm{M}$ and

DMPG on the calcium level after intranasal absorption of salmon calcitionin

The influence of a salt concentration of $0.15 \mathrm{M}$ and

DMPG on the calcium level after intranasal absorption of salmon calcitionin

The influence of a salt concentration of $0.3 \mathrm{M}$ and

DMPG on the calcium level after intranasal absorption of salmon calcitionin 
The influence of a salt concentration of $0.045 \mathrm{M}$ and

DMPG on the intranasal absorption of salmon calcitionin at a high viscosity

The influence of a salt concentration of $0.15 \mathrm{M}$ and DMPG on the intranasal absorption of salmon calcitionin at a high viscosity

The influence of a salt concentration of $0.3 \mathrm{M}$ and DMPG on the intranasal absorption of salmon calcitionin at a high viscosity

The influence of a salt concentration of $0.045 \mathrm{M}$ and DMPG on the calcium level after intranasal absorption of salmon calcitionin at a high viscosity

The influence of a salt concentration of $0.15 \mathrm{M}$ and DMPG on the calcium level after intranasal absorption ofsalmon calcitionin at a high viscosity

The influence of a salt concentration of $0.3 \mathrm{M}$ and

DMPG at a higher viscosity on the calcium level after intranasal absorption of salmon calcitionin

Three dimensional surface plot of salt concentration and

DMPG versus area under the curve

\section{APPENDIX A}

Standard curve of radioimmunoassay of salmon

calcitonin 
Dedicated to memory of my mother 


\section{SECTION I}


INTRODUCTION 
Recent years have seen enormous advances in the field of protein and peptide engineering and a greater understanding of the way in which biological response modifiers function in the body. It is now possible through the use of recombinant DNA techniques, or by solid phase protein synthesis, to produce significant quantities of a wide variety of proteins and polypeptide hormones that are therapeutically active. The list of these response modifiers includes interferons, macrophage activation factors, neuropeptides and proteins that may have potential in cardiovascular diseases, inflammation, contraception etc Prospects of using some of these materials in medicine have reached the stage where products have either been approved by regulatory authorities or are the subject of applications as investigational drugs or as new therapeutic agents In most cases these agents are administered by injection, however those agents which are indicated for chronic therapy need to be administered by appropriate delivery systems.

Unfortunately the research technology for development of delivery systems for peptides and proteins has not kept pace with the rapid progress in biotechnology and consequently there are presently few systems that are entirely appropriate for the administration of macromolecules. Furthermore essential pharmacokinetic and correlative pharmacodynamic data is often missing, for example questions like where and how does the peptide function?, what dose is needed and how often should it be given?

Many of these obstacles are related to the properties that set peptides and picteins apart from the vast majority of drug substances in use today. These properties include molecular size, susceptibility to proteolytic breakdown, rapid plasma clearance, peculiar dose-response curves, immunogenicity, 
biocompatibility and the tendency of peptide or protein to undergo aggregation, adsorption and denaturation. Therefore existing drug delivery systems must be modified and novel ones must be developed to overcome these obstacles 1 .

Although the biotechnology industry has prompted a resurgence of interest in noninvasive delivery systems, there have been studies performed as early as 1922 investigating the efficacy of insulin by intranasal, oral, rectal and vaginal routes 2 . This early work and that of others up to the 1960's met with little success. Fiowever these studies served to illustrate the major problems of noninvasive delivery which are low bioavailability, unreliable dosing, and acute local toxicity of formulations using permeation enhancers; these problems still remain the major challenges $3-7$.

Some of the noninvasive routes investigated in the recent years are oral, ocular, buccal, pulmonary, transdermal, rectal, vaginal and nasal. For each route of delivery, there are two potential barriers to absorption, poor permeability and enzymatic barriers. The problems of poor permeability, high inter subject variability and acute toxicity associated with delivering protein and peptide drugs by noninvasive routes may be minimized by using enzymatic inhibitors and/or novel absorption enhancers. The delivery by these routes may not be bioequivalent to invasive methods, however the convenience to patient will, in some cases, outweigh the demand for complete bioequiralenced.

The main emphasis is to rationally evaluate the problems for peptide and protein drug delivery systems and the options available for rational and 
optimal drug delivery.

\section{Oral Delivery}

A wide variety of routes of administration and delivery systems exist, but by far the most popular approach is oral delivery where the drug is intended to be absorbed from the gastrointestinal tract (GIT). However the delivery of peptides and proteins via the GIT is difficult because of their inherent instability due to the presence of proteolytic enzymes and the poor permeability of the intestinal mucosa to high molecular weight polypeptides and proteins 9 .

Although generally unsuccessful at present, the potential therapeutic and commercial benefits of successful oral delivery of peptides and proteins are sufficiently compelling to sustain research. The principal strategy has been the protection of a given peptide or protein from the proteolytic enzymes in the lumen of the gastrointestinal tract. Insulin was encapsulated with an impervious azopolymer film that remains intact in the GIT until it reaches the large intestine. Once in the colon, the azo bonds of the polymer are reduced by the indigenous microflora releasing the peptide. This strategy was used for vasopressin and insulin and biologically active amounts were absorbed into the blood stream of the rat. In spite of these encouraging results, the general utility of this approach in oral delivery is far from certain and requires additional information on the effects of both bacterial proteolytic enzymes on peptide stability and fecal matter on peptide absorption within the colon 10 .

The less than successful delivery of oral dosage forms for proteins and 
polypeptides has led to the investigation of alternative noninvasive routes such as transdermal or mucosal routes. Peptides and proteins when delivered via these alternative routes may be exposed to a smaller surface area, hence a smaller fraction of enzymes are present, as compared to the oral route. Peptides and proteins are subjected to less dilution via these routes since the resident fluid volume is less, thereby maximizing the concentration gradient for absorption

\section{Transdermal Delivery}

The skin is composed of two major tissue layers. The outermost layer of the epidermis, the stratum corneum, is composed of thin flat, layered keratinized cells, 15 to 20 laver - thick and is major barrier to skin permeation. The epidermis is much thinner than the dermis and is made up of stratified keratinized cells. The underlying layer, or dermis is extensively vascularized and contains a nerve network. While the stratum corneum lacks in enzymes, the next viable layers contain numerous enzymes that can degrade peptide and protein drugs 11-12.

The transdermal route has been successful in systemically delivering small drug molecules, such as scopolamine, nitroglycerine, clonidine, and estradiol. The delivery of peptide and protein has shown a greater resistance to absorption, primarily because of impermeability to the stratum corneum. At the present time it seems highly unlikely that the simple application of a peptide in a vehicle to the skin will produce suitable clinical effects 13 . The enhancement of peptide/protein skin permeation via electric current, iontophoresis, has shown some promise for the transdermal delivery of these 
drugs. This mode of delivery may have the potential to deliver the drug in a pulsaltile manner, which is critical for the desired physiological response of some of the hormonal drugs 14-15.

However the iontophoretic transport of gonadotrophin-releasing hormone $(\mathrm{GnRH})$, produced erratic results $\mathbf{1 6}$. The LHRH analog, leuprolide, was explored for iontophoretic facilitated transport and there was no measurable flux at $0.5 \mathrm{~V}^{17}$. Results obtained with the thyrotropin releasing hormone in nude mouse skin $\mathbf{1 8}$ and insulin in albino rabbit skin $\mathbf{1 9}$ indicated that iontophoresis offers henefits only when the integrits of the stratum corneum is compromised. In contrast, Siddiqui et al, reported iontophoretic facilitated transport of insulin across the skin of diabetic rats without first stripping the stratum corneum, although there were significant inter-animal variations in the extent of blood glucose lowering 20 .

No explanation has been suggested for these discrepancies in the role of the stratum corneum in limiting transdermal insulin absorption during iontophoresis. These equivocal results, coupled with the uncertain long-term effects of applied current on the skin cast doubt on the viability of iontophoresis as a routine, noninvasive technique to improve transdermal peptide and protein delivery $\mathbf{2 1}$.

\section{Ocular Delivery}

The visible part of the eye consists of the iris and the sclera. The iris is covered by cornea and the sclera is covered by a conjunctival membrane. Absorption primarily occurs through the cornea or the conjunctival membrane. 
The systemic absorption of peptides and proteins may occur through contact with the conjunctiva and the nasal mucosa, the latter occuring as the result of drainage through the nasolacrimal duct. For optimal systemic delivery the absorption through the conjuctival and nasal mucosa must be maximized.

The main difficulty in the delivery of drugs to the eye is the rapid removal of the substances by blinking and drainage through the lacrimal duct and the low permeability of the cornea 22. There is a significant level of aminopeptidases in the eye fluids and tissue: which may degrade the peptides 23

Several investigators have studied the delivery of peptides and proteins into the systemic circulation by the ocular route $24-29$. It has been demonstrated that it is not possible to achieve therapeutic levels of insulin without the use of a permeation enhancer. The bioavailability of insulin was improved by coadministration of permeation enhancers such as polyoxyethylene-9-lauryl ether, sodium deoxychlolate, sodium glycocholate. Over $80 \%$ of the insulin reaching the systemic circulation was found to be absorbed through the nasal mucosa and the absorption pattern followed that reported for nasal delivery quite closely 30 . The coadministration of permeation enhancers offers promising results but their long term effects on the ocular physiology and histology need further characterization.

\section{Pulmonary Delivery}

Pulmonary delivery systems have also been considered as a method of improving the bioavailability of peptide and proteins because of certain 
advantageous features offered by the lung The walls of the alveoli in the deep lung are extremely thin $(0.1$ to $1 \mu \mathrm{m})$ as compared to the capillary walls $(7 \mu \mathrm{m})$ or red blood cells $(8 \mu \mathrm{m})$. They are an order of magnitude thinner than typical mucosal or epithelial membranes, which are several milllimeters thick. In addition the surface area of the lung is extremely large, approximately $75 \mathrm{~m}^{2}$ for a $70 \mathrm{~kg}$ male. Furthermore one puff of an aerosol administered correctly can cover this surface area within seconds 31 .

However the lungs are rich in enzymes. Virtually all known peptide hydrolases (exopeptidases and proteinases) are present in the lung tissue. Several membrane-bound peptidases exist on pulmonary vascular surfaces and a wide variety of proteinases are present in other lung cells. Several peptidases are distributed throughout the lung and they may be impossible to saturate and can cause rapid degradation of peptides 32 .

The particle size distribution of aerosolized drug is very critical to the bioavailability of the aerosol formulations. The particle size often defined as mass median aerodynamic diameter (MMAD), must be approximately $5 \mu \mathrm{m}$ or less in order for drug particles to reach lung. A major concern with aerosol formulations is the denaturation of peptides and proteins during shaking and aerosolization, the dispersibility, the particle size as well as the more common concerns of chemical stability, safety and efficacy. A typical distribution of dose delivered from a meteren dose inhaler indicated that only $4.7 \%$ of the delivered dose actually raclit's the peripheral lung and $6.3 \%$ reaches the central lung 33 .

The absorption of the fraction of the drug that is able to reach the lung 
depends upon factors singular to respiratory system, such as tidal volume, respiratory rate, respiratory pause, respiratory distress syndrome, lung volume, emboli, total lung burden, solubilization in alveolar macrophages,

recirculation, pancreatitis, exercise, interstitial lung diseases etc ${ }^{34}$. Thus a lot of variables besides the formulation variables have to be taken into account for optimal delivery by pulmonary route

\section{Buccal Delivery}

The buccal membrante is similar to the skin in that it is a stratified squamous epithelium, with cellular extrusion products filling the intercellular spaces. The buccal enzymatic barrier is greater than other routes and enzyme activity has been reported to be greater than at the vaginal or nasal mucosa.

However, the buccal route offers convenience and is generally more acceptable to the patient than other routes. This route of delivery offers a much larger and easily accessible area for placement of delivery systems such as adhesive tablets, but there may be a risk of drug degradation by accidental swallowing or by the salivary wash-out of the tablet. Therefore the preferred dosage form for buccal delivery is bioadhesive patches. The formulation aspects of bioadhesive patches include variables such as the type of polymers used, the viscosity grade of the polymers, and the amount of polymer per patch which can further aid in optimizing the formulation 35

Permeability offered by buccal route is often poor as compared to other mucosal routes. Investigation of the buccal delivery of protirelin indicated the buccal dose required to achieve an equivalent pharmacodynamic response 
was about 200 times higher than that for iv injection of the peptide. Thus bioadhesive patches alone may not improve bioavailability sufficiently to reach therapeutic levels and may require the coadministration of permeation enhancers 36 .

\section{Rectal Delivery}

The human rectum offers a surface area of 200 to $400 \mathrm{~cm}^{2}$. It is abundant in blood, lymphatic vessels, and microflora and has a fairly constant environment with respect to temperature, $\mathrm{pH}$, and viscosity of rectal fluid 37 .

The enzymatic degradation of model enkephalin peptides has been shown to be greatest in rectum and an absorption enhancer is required to achieve therapeutic levels.

The dosage forms for rectal delivery of peptides and proteins are usually more conventional such as solutions, gels, and suppositories. Of these, gels are the most efficient because they offer a proper balance between retention at the site of administration and the rate of peptide release 38 . It was demonstrated that the rectal bioavailability of $\left[\mathrm{Asu}^{1,7}\right]$-eel calcitonin in the rat was best from a $0.1 \%$ polyacrylic acid gel when compared with other dosage forms such as saline, a triglyceride fatty acid mixture base, and a polyethylene glycol 1000 base. Following administration, solutions tend to spread away from the rectum into the aswencing colon and from there into portal rather than general circulation 39 thereby resulting in reduced peptide and protein bioavailability. Recently, more sophisticated systems such as the osmotic pumps and hydrogel cylinders have been investigated as rate-controlled rectal 
drug delivery systems, and while the results have been positive, these dosage

forms have not yet been tested with peptide and proteins $\mathbf{4 0 - 4 1}$.

There does not seem to be significant absorption via rectal route without the use of a permeation enhancer as demonstrated by the delivery of desglycinamide arginine-vasopressin which when enhanced with STDHF reached an optimum concentration of $4 \% \mathbf{4 2}$.

However the lack of acceptability of this route by many patients and the interruption of delivery by defecation makes this route less desirable than other routes 43 .

\section{Nasal Delivery}

The epithelial cells of the nasal mucosa are covered with numerous microvilli and increase the surface available for drug absorption. The nasal cavity offers a high surface area of approximately $150 \mathrm{~cm}^{2}$ for absorption. Furthermore the subepithelial layer is highly vascularized with large and fenestrated capillaries specially designed for the rapid passage of fluid through the vascular wall. The venous blood draining from the nose passes directly into the systemic circulation and is well suited for the absorption of drugs that are extensively metabolized 44 .

Nasal administration of nonpeptide drugs or peptides of ten residues or less has been very successful. Some examples are oxytocin, vasopressin and its analog desmopressin acetate (DDAVP); and luteinizing hormone-releasing hormone (LHRH) and its superanalogs buserelin, leuprolide, and nafarelin. 
However when the number of amino acids is increased to 20 or greater, as in insulin, glucagon or growth hormone releasing hormone, low bioavailability results except when delivered with an enhancer $45-46$.

The nasal hioavailability of peptides and proteins is influenced by the dosage form as well as the technique of administration. The most popular dosage form has been the aqueous solution, although gels, powders and microspheres have been investigated

The nasal administration of drugs, particularly peptides, is very advantageous but like other routes suffers from low bioavailability. To achieve reproducibility with dosing and provide acceptable economy in the treatment, a bioavailability of $1-2 \%$ for an expensive recombinant peptide must be improved. It is necessary to optimize both the techniques of administration and the nasal formulations to provide a sufficient level of drug absorption.

The optimal nasal absorption delivery system should be well tolerated, inexpensive, should have low toxicity and reasonable bioavailability. Starch microspheres, water insoluble and swellable powders and phospholipids are novel absorption systems which have promising properties but need further characterization 47 .

There are a number of noninvasive routes available for the delivery of polypeptides and proteins but all suffer from the obvious disadvantage of proteolytic activity and poor permeability to higher molecular weight molecules. However, with the administration of either enzymes inhibitors or protective polymers, or perhaps permeation enhancers, bioavailability can be 
substantially improved. Even though bioavailability by these routes may still be fairly low, the advantages of noninvasive therapy certainly outweigh the disadvantages.

A comparison of different routes for the delivery of protirelin via nasal, buccal, peroral and iv demonstrated that nasal administration was 10-times more efficient than the buccal route. Based on the pharmacodynamic effects observed, the nasal dose had to be five times higher than iv dose, whereas the buccal dose had to be forty times the nasal dose 48 .

Of all the alternative routes, the nasal route has received the most attention to date. Nasal delivery has the potential of being an extremely effective route for systemic administration of peptides and proteins. The selection of proper formulation parameters such as the $\mathrm{pH}$ of the vehicle, buffer species and concentration, ionic strength, viscosity, charge, osmolarity, type and concentration of preservatives as well as delivery with an appropriate device such as nasal spray pump, compressed air nebulizer, instillation catheter and dry powder insufflator could further influence and optimize the absorption of peptide and proteins. 


\section{REFERENCES}

1. Lee, V. H. L., Peptide and Protein Drug Delivery Systems., Biopharm., 1(3) (1988) 24-31.

2. Woodyatt, R.T., The clinical use of insulin, J. Metab. Res., 2 (1922) 793.

3. Collens, W.S. and Goldziehr, Absorption of insulin by the nasal mucous membrane, Proc. Soc. Exp. Bio. Med., 29 (1932) 756.

4. Gansslen, M., Ueber, Inhalation van insulin, Klin Schnschr, 4 (1925) 71.

5. Hanskiss, J. and Hadhazy, C.S., Resorption von insulin and asthmolysin von der nasenschleimhaut, Acta. Med. Acad.Sci-Hung. 12 (1958) 107.

6. Heubner, W., deJough, S.E., and Laquer, E., Ueber inhalation von insulin, Klin Schnshr. 3 (1924) 2342.

7. Major, R. H., The intranasal application of insulin, experimental and clinical experiences, Am. J. M. Sci, 192 (1936) 257.

8. Wearley, L. L., Recent Progress in Protein and Peptide Delivery by Noninvasive Routes., Critical Reviews in Therapeutic Drug Carrier Systems, 8(4) (1991) 331-394.

9. Davis, S. S., Advanced Delivery Systems for Peptides and ProteinsPharmaceutical Considerations. In Delivery Systems for Peptide Drugs, 
Edited by Davis, S., Illum, L., and Tomlinson., E., Plenum Press (1986) pp. 1.

10. Saffran, M., et al., A new approach to the oral administration of insulin and other peptide drugs., Science, 233 (1986) 1081-1084.

11. Goldsmith, L., Biochemistry and Physiology of the skin, Oxford University Press, New York (1983) Chapter. 1.

12. Curatolo, W., The lipoidal permeability barriers of the skin and alimentary tract, Pharm. Res., 4 (1987) 271.

13. Davis, S. S., Advanced Delivery Systems for Peptides and ProteinsPharmaceutical Considerations. In Delivery Systems for Peptide Drugs, Edited by Davis, S., Illum, L., and Tomlinson., E., Plenum Press, (1986) pp. 265-275.

14. Banga, A. K., and Chien, Y. W., Iontophoretic delivery of drugs: fundamentals, developments and biomedical application, J. Contr. Rel, 7 (1988) 1.

15. Chien, Y. W., Lelawongs, P., Siddiqui, O., Sun, Y., and Shi, W. M., Facilitated transdermal delivery of therapeutic peptides and proteins by iontophoretic delivery device, J. Contr. Rel, 13 (1990) 263. 
16. Miller, L., Kolaskie, C.J., Smith, G. A., and Riviere, J., Transdermal iontophoresis of gonadotrophin releasing hormone (LHRH) and two analogues, J. Pharm. Sci., 79 (1990) 490.

17. Srinivasan, V., Su, M. H., Higuchi, W. I., and Behl, C. R., Iontophoresis of polypeptides: effects of ethanol pretreatment of human skin., J. Pharm. Sci., 79 (1990) 588.

18. Burnette, R. R., and Marerro, D., Comparison between the iontophoretic and passive transport of thyrotropin releasing hormones across excised nude mouse skin., J. Pharm. Sci., 75 (1986) 738-743.

19. Kari, B., Control of blood glucose levels in alloxan-diabetic rabbits by iontophoresis of Insulin., Diabetes., 35 (1986) 217-221.

20. Siddiqui, O., et al ., Facilitated transdermal transport of insulin., J. Pharm. Sci., 76 (1987) 341-345.

21. Tyle, P., Iontophoretic devices for drug delivery, Pharm. Res. 3, 318-326, 1986.

22. Lee, V. H. L., Mechanisms and facilitation of corneal drug penetration, J. Contr. ReJ., 11 (1990) 79.

23. Lee, V. H. L., Carson, L. W., Dodda-Kashi, S., and Stratford, R. E., Metabolic permeation barriers to the ocular absorption of topically applied enkephalins in albino rabbits, J. Ocular Pharmacol., 4 (1989) 179. 
24. Yamamoto, ., Luo, A. M., Dodda-Kashi, S., and Lee, V H. L., The ocular route for systemic insulin delivery in the albino rabbit, J. Pharm. Exp. Ther., 249 (1989) 249.

25. Chiou, C. Y., and Chang, M.S., Systemic delvery of enkephalin, Life Sci., 43 (1988) 509.

26. Chiou, G. C., and Chuang, C. Y., and Chang, M.S., Reduction of blood glucose concentrations with insulin eye-drops, Diabetes Care, 11 (1988) 750 .

27. Chiou, G.C., and Chuang, C. Y., Treatment of hypoglycemia with glucagon eyedrops, J. Ocular Pharmacol., 4 (1989) 179.

28. Chiou, G. C. Y., Chuang, C. Y., and Chang, M. S., Reduction of blood glucose concentration with insulin eye drops, Diabetes Care, 11 (1988) 750.

29. Chiou, G. C., and Ching, Y. C., Improvement of systemic absorption of insulin through eyes with absorption enhancers, J. Pharm. Sci., 78 (1989) 815.

30. Lee, W. A., Permeation enhancers for the nasal delivery of protein and peptide therapeutics, Biopharm, (11-12) (1990) 22.

31. Crooks, P., Lung Peptidases and their activities presented at respiratory drug delivery II, Keystone, CO, March 26-30 (1990). 
32. Clark, A. R., Invitro Assessment of spacer devices, Presented at Respiratory Drug Delivery II, Keystone, CO, March 26-30 (1990).

33. Newman, S. P., Clark, A. R., Talasee, N., and Clarke, S. W., Pressurized inhaler deposition in the human lung with and without an "open" space device, using a simple radiolabelling technique, Thorax, 44 (1989) 706.

34. Oberdorster, G., Aveolar clearance of inhaled particles and drugs, Aerosol Age, January (1991) 34 .

35. Merkle, H., Anders, R., Wermerskirchen, A., Rachs, S., and Wolany, G., Buccal routes of peptides and protein drug delivery in Peptide and Protein Drug Delivery, Lee, V. H. L., Ed., Marcel Dekker, New York (1991) Chap.11.

36. Davis, S. S., Advanced Delivery Systems for Peptides and ProteinsPharmaceutical Considerations., In Delivery Systems for Peptide Drugs, Edited by Davis, S., Illum, L., and Tominson. Plenum Press, (1986)pp265275 ,

37. Rytting, H., Rectal route of peptide and protein drug delivery, in Peptide and Protein Delivery, Lee, V H. L., Ed., Marcel Dekker, New York, $579(1991)$

38. Nishihata, T., et al., Enhancement of rectal absorption of insulin in dogs using salcylate in dogs., J. Pharm. Pharmacol., 35 (1983) 148-151. 
39. Morimoto, K., et al., Enhanced rectal absorption of [Asu 1,7]-eel calcitonin in rats using polyacrylic acid aqueous gel base., J. Pharm. Sci., 73 (1984) 1366-1368

40. deLeede, L. G. J., et al.,Enhancement of rectal absorption of insulin using salicylate in dogs., J. Pharmacokin. Biopharm. 10 (1982) 525-537.

41. deLeede, L. G. J., et al., Rectal and intravenous propranol infusion to steady state: Kınetics and $\beta$ receptor blockade., Clin. Pharmacol. Ther. 35 (1984) $148-155$

42. De Boer, A. G., Van Hoogdalem, E. J., Heijligers-Feijen, C. D., Verhoef, J.C., and Breimer, D. D., Rectal Absorption enhancement of peptide drugs, J. Controlled. Release, 13 (1990) 241.

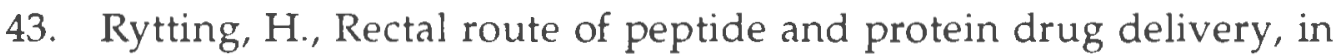
Peptide and Protein Delivery, Lee, V. H. L., Ed., Marcel Dekker, New York, 579 (1989)

44. Davis, S. S., Advanced Delivery Systems for Peptides and ProteinsPharmaceutical Considerations. , In Delivery Systems for Peptide Drugs, Edited by Davis, S., Illum, L., and Tominson. Plenum Press, (1986) pp $45-49$,

45. Davis, S. S., Advanced Delivery Systems for Peptides and ProteinsPharmaceutical Considerations. In Delivery Systems for Peptide Drugs, 
Edited by Davis, S., Illum, L., and Tominson. Plenum Press, (1986) pp7679.

46. Pontiroli, A. E., Secchi, A., and Alberetto, M, Alternative routes of peptide hormone administration, Spec. Topics Endocrinol. Metabn., 7 (1985) 77

47. Harris, A. S., Biopharmaceutical aspects of the intranasal administration of peptides, in Delivery Systems for Peptide Drugs, Davis, S. S., Illum, L., and Tomlinson, E, Eds., Plenum Press, New'York, (1986) pp 191.

48. Su, K.S. E., Nasal route of peptide and protein drug delivery, in Peptide and Protein Drug Delivery, Lee, V. H. L., Ed., Marcel Dekker, NewYork, (1991) Chapter. 13. 


\section{OBJECTIVES}


The objectives of the present research were:

1. To identify the formulation and device variables that are critical in enhancing the low intranasal absorption of the polypeptide, salmon calcitonin.

2. To systematically characterize the effect of formulation and device variables on the droplet size distribution and dynamics of spray profile.

3 To study the primary and interactive effects of varying levels of viscosity and tonicity on the nasal absorption of salmon calcitonin.

4. To study the effect of the novel absorption enhancer, Dimyristoylphosphatidylglycerol (DMPG) on the absorption of salmon calcitonin.

5. To characterize the optimal calcium lowering response of salmon calcitonin as a function of salt concentration, viscosity and concentration of absorption enhancer, dimyristoylphosphatidylglycerol.

6. To demonstrate the use of response surface methodology (RSM) as an aid in determining optimal formulations. 
SECTION II 
MANUSCRIPT I

EVALUATION OF FORMULATION AND DELIVERY DEVICE VARIABLES ON NASAL SPRAY CHARACTERISTICS 


\section{ABSTRACT}

The aim of this study was to evaluate the effect of formulation variables; viscosity, tonicity, concentration of absorption enhancer and nasal delivery devices; mechanical metered nasal spray pumps, pump components and a prototype device, the nasal micron spray pump on the spray characteristics and dose administration of a model nasal product. Formulations were prepared within specified ranges of viscosity ( 1 to $380 \mathrm{cps}$ ), tonicity $(100,300$ and 600 mOsms) and absorption enhancer ( 0 and $0.5 \% \mathrm{w} / \mathrm{w})$. Viscosity was determined using a Brookfield cone and plate viscometer. The spray characteristics of the formulations were analyzed with a Malvern laser sizer and evaluated by characterizing the size distribution of the sprayed droplets using M50 and M90 parameters. For the metered nasal spray pumps, results indicated that among the formulation variables, increasing viscosity or addition of an absorption enhancer increased droplet size and produced a deviation from a Gaussian size distribution of the sprayed droplets. It was not possible to spray any solution greater than $2.12 \mathrm{cps}$ and maintain a Gaussian spray distribution with a metered nasal spray pump. Tonicity did not demonstrate any significant effect on the droplet size distribution. Changes in pump based on two different mechanisms of spray delivery or actuator assembly design based on the orifice diameter or spray angle of spray insert did not produce any significant differences in spray characteristics. However with the use of a prototype device, the nasal micron spray pump, it was possible to spray solutions up to a viscosity of $76 \mathrm{cps}$ as a fine spray.

Key words: Spray characteristics, Malvern laser sizer, Metered nasal spray pump, Formulation variables, Device variables, Nasal micron spray pump 


\section{INTRODUCTION}

* Several types of delivery devices such as nasal pump sprayers, compressed air nebulizers, instillation catheters and dry powder insufflators are used to administer drugs to the nose. There are mechanistic variations in these devices that produce differences in the delivery of a drug in terms of volume and reproducibility. The instillation catheter has high accuracy but only a small volume, less than $50 \mu l$, therefore limited doses can be delivered. An aerosol spray can deliver higher volumes, up to $140 \mu \mathrm{l}$ but the amount of active ingredients delivered is limited by drug solubility and viscosity. Dry powders offer the option of delivering the highest mass of active ingredients because they may not formulated to contain a carrier vehicle. Thus $100 \%$ of mass delivered can be active ingredient. Reproducibility is also an important factor. Administration by instillation catheter and compressed air nebulizer have been shown to provide good reproducibility with respect to the amount of material delivered. On the other hand administration by a nasal spray pump or dry powder insufflator have been found to be considerably more variable particularly with respect to amount of material deposited in the nose $\mathbf{1}^{1}$

t These devices influence the mode in which the drug is administered, ie., whether the drug is delivered as drops, aerosol or spray. The mode of drug administration can affect drug distribution in the nasal cavity, which in turn influences bioavalability of a drug. It has been demonstrated that significant differences in drug distribution were observed when drug was administered by catheter, mechanical metered nasal spray pump and metered dose 
pressurized aerosol. The results indicated that the metered nasal spray pump gave a constant dose and a very good nasal mucosal distribution 2,3 .] *

* Delivery devices as well as the density, shape, hygroscopicity of the particles and the particle size distribution affect the deposition site within the nasal cavity. The deposition site in turn influences the extent and rate of absorption which in turn is dependent on ciliary movement and/or diffusion in the mucous layer and subsequently the biological response in experimental animals and humans] [ ${ }^{*}$ uniform distribution of particles throughout the nasal cavity may be achieved by delivering the particles from a nasal spray using a pressurized propellant. A metered dose delivery system developed for the nasal delivery of drugs could provide a consistent dose delivery and spray pattern which affects the deposition of droplets in the nasal cavity. Metered nasal spray devices have shown the ability to deposit well controlled doses in the nasal cavity which remain there for sufficient period to provide complete absorption $\left.{ }^{4}\right]^{*}$

* Experimental work has demonstrated that the relative bioavailability and biological response can be improved by adminstration of a drug via nasal spray pumps rather than by nasal drops. Nose drops disperse the dose throughout the length of the nasal cavity, from atrium to the nasopharynx. The nasal spray deposits droplets anteriorly in the nasal cavity with little or no dose reaching the turbinates. The drug deposited anteriorly in the nasal cavity remained in the nose longer while drops are cleared more rapidly than the dose administered as a spray 5,6 . $]^{*}$ 
* [n addition to the proper choice of nasal device, it is imperative that studies be performed to select the variables such as concentration and volume of the dose to be sprayed for optimum intranasal delivery. Nasal bioavailability has been found to be a function of the volume and concentration of the nasal spray. It has been demonstrated that a formulation administered by two $50 \mu \mathrm{l}$ sprays gave a biological response superior to that of same drug administered by one $100 \mu \mathrm{l}$ dose 7 . Thus both administration devices and formulation design can affect drug distribution, deposition and the clearance process from the nasal cavity, leading to modifications in the biopharmaceutical aspects and bioavailability of the drug administered.] *

Despite the fact that nasal delivery devices have been available for over a decade there is still very little fundamental information as to how variations in the design of a nasal pump assembly can interact with the formulation variables and affect the dynamics of spray plume, droplet size, spray deposition and distribution in the nasal cavity. This information along with an understanding of nasal formulation parameters could aid in optimized products designed to enhance bioavailability. This paper documents the nasal devices and their interaction with the formulation variables.

In this study two types of nasal spray devices; a metered nasal spray pump and its mechanical components i.e., mechanism of pump, design of actuator and a prototype device, the nasal micron spray pump were studied.

The metered nasal spray pump is a drug delivery device that administers a predetermined volume of formulation into the nasal cavity. It has been successfully utilized commercially in the administration of several locally 
acting drugs, such as corticosteroids (Extracort, Syntaris), beclomethasone dipropionate (Aldecin, Beconase, Becotide, Vancenase), flunisolide (Nasalide), tramazoline (Tobispray), and nasal decongestants (Rhinospray, Otrivin, Afrin, Nostril, Nostrilla, Dristan); and is also used for the systemic delivery of calcitonin (Calcitonina, Calsynar), nafarelin acetate (Synarel), cromolyn acetate (Nasalcrom), insulin, desmopressin acetate, nitroglycerin. A typical nasal spray pump is composed of 10-13 spray components, to include metering chamber (5-7), actuator (2-3) and closure (2) components.

The metered nasal spray pump is available as (i) a ball and spring pump or (ii) a dual spring compression pump. As the names suggest, these pumps use two different mechanisms to aspirate the liquid from container and to release the spray. The ball and spring pump is composed of a cylinder, shut off valve (ball), spring, piston, stem, and a device for connection to the actuator. The dual spring compression or precompression pump is composed of piston, diptube and twin springs; these twin springs help to aspirate the liquid from container and also act as a shut off valve.

The actuator in a mechanical nasal spray pump aids in expelling the liquid mass aspirated by the pump assembly or metering chamber. Actuators are available as a one or two piece assembly and house a spray insert with a specified diameter to expel the liquid as spray. When a pump is actuated, a dose volume aliquot is released from the metering chamber and travels as a liquid mass until it encounters the restriction of the orifice of the spray insert. This restriction may have a series of spiral baffles, which begin the liquid breakup and impart a spinning motion to the liquid resulting in the spray mist. The spray pattern is determined by the number of spiral baffles and is 
used to produce a wide $\left(50-70^{\circ}\right)$ or narrow $\left(20-40^{\circ}\right)$ spray cone. Droplet size is dependent upon force of the liquid mass striking the orifice, plus the design of the baffles, the diameter of the opening as well as the characteristics of the liquid itself.

It has been previously demonstrated that the addition of a viscosity enhancing agent increases contact time in the nose by reducing the rate of mucociliary clearance of the dosage form and may help to enhance the activity by increasing the "window" of absorption for the administered drug. Viscosity also seems to change the pattern of deposition and clearance $\mathbf{8}^{\text {. }}$ However previous studies have investigated viscosity in the range of 1-3.5 cps, which can be considered as low viscosity solutions. The nasal micron spray pump (NMSP), a prototype device originally developed for administration of pulmonary inhalation solutions (figure 1) was used in this study to investigate the feasibility of using the device to deliver solutions of higher viscosity to the nose. The NMSP is a hand actuated propellent free spray device that is capable of producing a fine spray. The physical and technical requirements have been achieved by using an air blast nozzle (figure 2). The air blast nozzle is the heart of this spray device and its geometry is mainly responsible for the ability to generate small droplets especially for viscous solutions. The nozzle consists of a mixing chamber whose volume is partly filled by a polyurethane sponge with open pores. The NMSP also consists of two pumps, a liquid metering pump and an air pump. When the device is actuated by turning the top part in a rotational motion, a liquid volume is metered into the mixing chamber simultaneously. The device is now primed. By pressing the actuation button the air valve opens and air starts to flow through the nozzle and is compressed. This compressed 


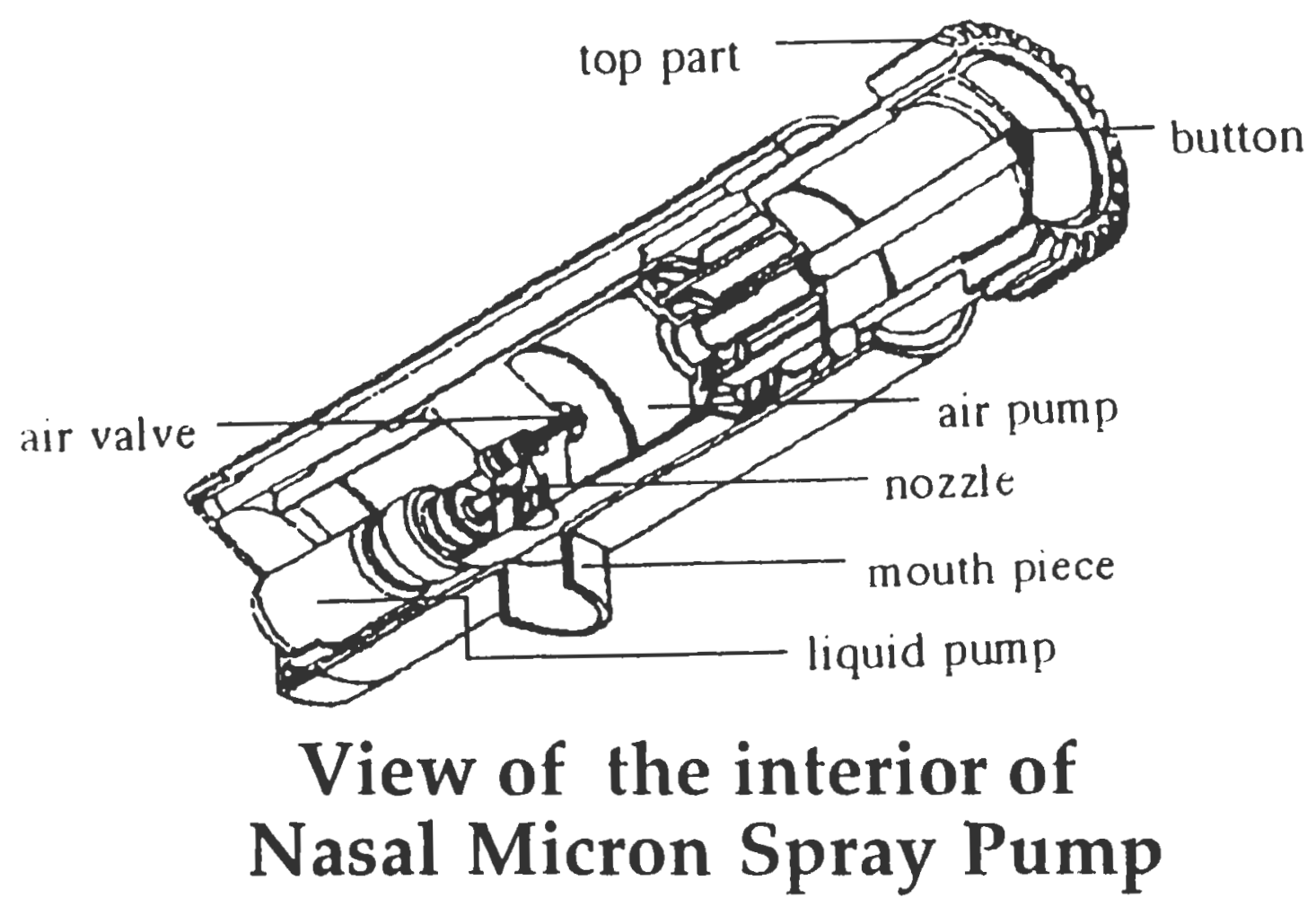

Figure 1 


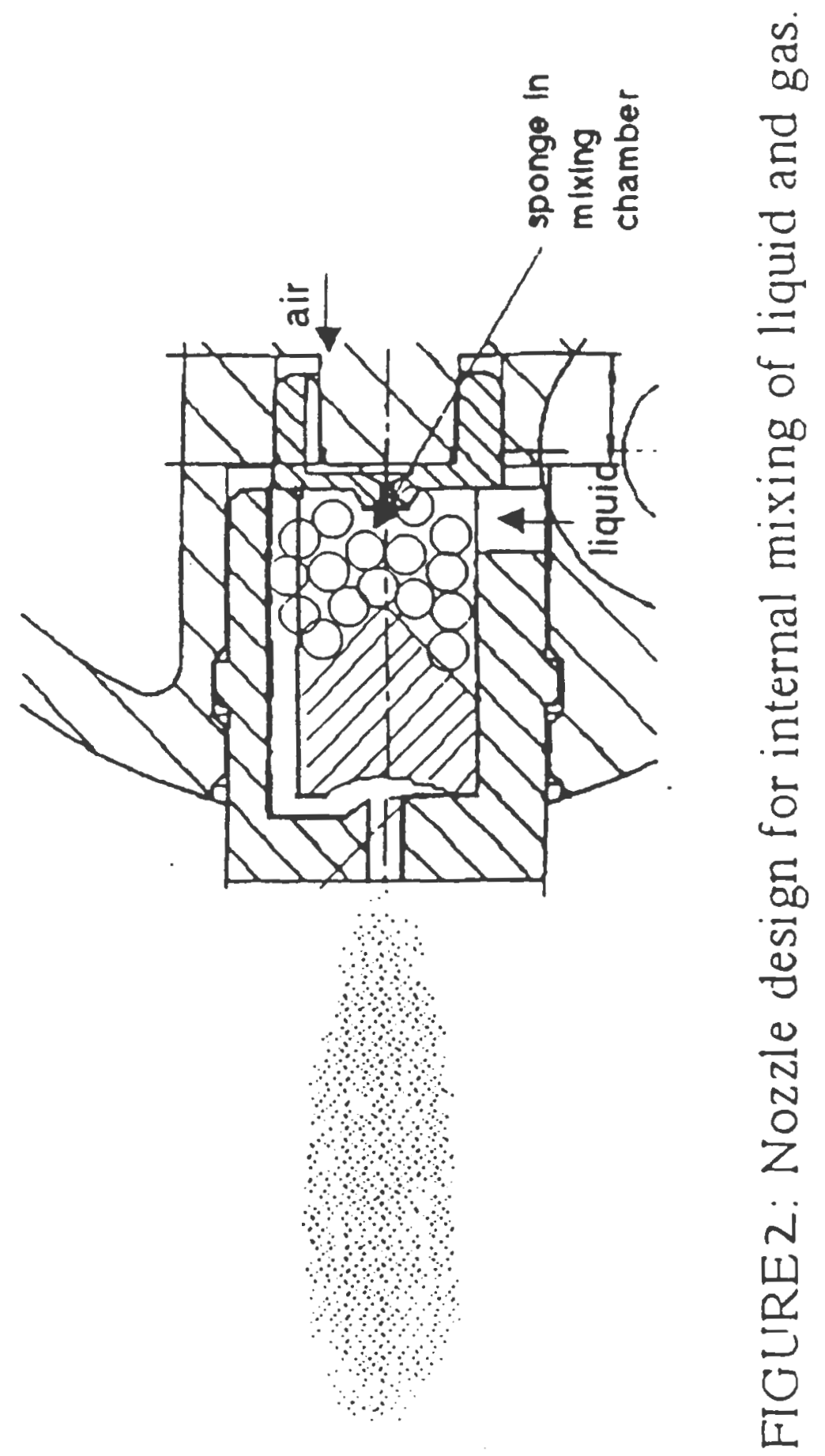


air expands through the nozzle system with increasing velocity. The solution is now accelerated by the expanding ambient air leaving the nozzle and the kinetic energy of the air stream pushes and shears the liquid which was previously dispersed in the sponge and thus disintegrates the liquid into small droplets 9

The geometry of air blast nozzle of the NMSP provides a huge improvement as compared to the metered nasal spray pump which uses a mechanical actuator to spray the liquid mass. The use of this new device for nasal delivery could be invaluable for administering the drugs in high viscosity solutions because it is able to generate a fine mist of spray for distribution into the nasal cavity 9

Nasal devices are capable of generating different spray profiles because of the different types of components which makeup the functional unit. The literature shows no investigation of the influence of nasal administration device variables on spray characteristics. Likewise the spray characteristics may also be affected by the formulation variables.

Since it is strongly postulated that the functional components of a nasal pump assembly can interact with the formulation variables and affect the dynamics of spray profile, spray deposition and distribution in the nasal cavity; it was decided to evaluate the influence of the formulation variables: viscosity, tonicity, concentration of absorption enhancer with the nasal administration device variables: mechanism of pump (ball and spring versus dual spring compression pump), design of actuator (orifice diameter of spray insert, spray angle), on the spray characteristics and droplet size distribution. 


\section{EXPERIMENTAL}

\section{Materials}

Methylcellulose, Methocel A15C Premium (Dow Chemical Co., Midland, MI) was used as a viscosity enhancing agent in the concentration of $0.25 \%-2 \%$ w/w. Sodium Chloride (Fisher Scientific, Fairlawn, NJ) was used to adjust tonicity. Dimyristoylphosphatidylglycerol (Avanti Polar Lipids, Alabaster, AL) was used in the concentration of $0.5 \%$ as absorption enhancer. Chlorbutanol $0.5 \% \mathrm{w} / \mathrm{w}$ (Sigma Chemical Co., St. Louis, MO) was used as a preservative.

\section{Methodology}

Selection of formulation variables

Viscosity

Methylcellulose (Methocel), a natural carbohydrate that contains a repeating structure of anhydroglucose units was chosen as a viscosity enhancing agent. It is odorless and colorless. The premium grade was chosen as it is a GRAS substance and approved by FDA. Formulations containing methylcellulose were prepared in concentrations ranging from $0.25 \%$ to $2 \%$.

\section{Tonicity}

Tonicity was investigated at three levels using sodium chloride as a tonicity adjusting agent. Formulations were prepared at $600 \mathrm{mOsms}$ (hypertonic), 300 mOsm (isotonic) and 100 mOsms (hypotonic).

\footnotetext{
Absorption Enhancer

Dimyristoylphosphatidylglycerol, an acidic phospholipid, a novel permeation enhancer was used at a concentration of $0.5 \% \mathrm{w} / \mathrm{w}$.
} 


\section{Preservative}

Chlorbutanol, a lipophilic preservative, $0.5 \% \mathrm{w} / \mathrm{w}$ was used as a preservative.

\section{Preparation of Formulations}

The formulations were prepared with a concentration of methylcellulose ranging from $0.25 \%$ to $2 \%$ in a sodium acetate-acetic acid buffer at $\mathrm{pH} 4$. Methylcellulose was dispered in hot water $\left(90-95^{\circ} \mathrm{C}\right)$ and stirred until all the particles were hydrated. Cold water was added slowly to the above mixture, the mixture was kept in an ice bath. The above dispersion was agitated for 3-4 hrs, the specified quantity of sodium chloride was added depending upon the osmolarity required for the formulation and then stored in a refrigerator overnight. The dispersion was brought to the $\mathrm{pH} 4$ with buffer after bringing it to the room temperature. All the formulations were filled into $4 \mathrm{ml} \mathrm{clear}$, round, Type I glass serum vials equipped with metered pumps.

\section{Determination of Viscosity}

The viscosity of all the formulations was determined using a Brookfield coneplate viscometer, Model DV II. This cone-plate viscometer is equipped with a detachable "cone" and can be used with cones ranging from 0.8 to $3^{\circ}$ radians. Cone, CP 52D, diameter of $2.4 \mathrm{cms}$ and a cone of $3^{\circ}$ was selected to carry out the viscosity determinations at $25^{\circ} \mathrm{C}$. The viscometer was calibrated using standards ranging from 1 to $500 \mathrm{cps}$. Viscosity was determined at rotational speeds ranging from 0.5 to $100 \mathrm{rpm}$. Shear torque readings were recorded at each rotational speed. 


\section{Selection of delivery systems for intranasal drug administration}

There has not been any investigation of the interaction of the components of a spray pump and the formulation variables on the spray profile and droplet size distribution. The evaluation of the metered nasal spray pumps was performed using the different available components of (i) pump mechanism ie., ball and spring (Pfeiffer); dual spring compression (Valois) (ii) orifice diameter of the actuator ie., $0.1 \mathrm{~mm}, 0.3 \mathrm{~mm}$ and $0.7 \mathrm{~mm}$ and (iii) angle of spray of the actuator ie., $20^{\circ}, 35^{\circ}, 60^{\circ}$.

\section{Dose reproducibity studies}

After priming of the pumps the weight loss per spray actuation was recorded for 10 consecutive strokes and arithmetic mean and standard deviation were calculated. Since these devices would later be used to administer the drug in bioavailability studies and since the dose was to be administerd within a interval of 60 minutes to the experimental animals, the dose accuracy was measured after $1 \mathrm{hr}$ to determine if a second priming stroke was required before the second dose was administered. The procedure was also repeated, after $24 \mathrm{hrs}$.

\section{Screening of Nasal Devices}

An initial qualitative screening was performed with formulations ranging in viscosity ( $1 \mathrm{cps}$ to $380 \mathrm{cps}$ ), tonicity $(100,300$ and $600 \mathrm{mOsm})$ and concentration of the absorption enhancer $(0$ and $0.5 \% \mathrm{w} / \mathrm{w})$ in combination with the various nasal device components such as the type of pump and actuator design etc. The initial evaluation of the spray profile was obtained by spraying against a background of black and white. The spray pattern was categorized as a fine spray, stream or stream with drops. Only the nasal spray devices 
producing a fine spray were later used to determine the droplet size distribution using a Malvern laser sizer.

* Determination of Droplet size using the Malvern laser sizer

The samples were analyzed using a Malvern laser particle sizer (Malvern Digital PC 3000 computer Instruments, Inc., Southborough, MA)., equipped with 1600 analyzing unit, and DIGITAL PCXBV Cobr monitor. Software: Malvern mastersizer NEG Powormate SX/16i computer, version-BO datzequistion-software- a sof tware spray synchronizer (PS51), and infrared trigger sensor (PS57), NEC Multisync 2A monitor, and an Okidata Microline 320 dot matrix printer. An adjustable metal support bracket, to hold samples, was machined by Trans American Tool Co., Inc., Spring City, PA. The Malvern 2600c analyzing unit was equipped with a $300 \mathrm{~mm}$ range lens and configured as shown in figure 3. After performing a background measurement the sample bottle was positioned in the support at a distance of $10 \mathrm{~cm}$ from the actuator to the tip to the laser beam. The centerline of the bottle was $17 \mathrm{~cm}$ from the range lens. A "measure sample" command was executed from the key board prior to the actuation of the sample. Samples were actuated four times for each analysis. The analysis was performed in triplicate. The computer system was configured so that a total of 1000 sweeps (measurements) were executed during each analysis. The computer sweeps the detector at a rate of approximately 125 sweeps per second thereby giving the analyst sufficient time (about eight seconds) to perform four actuations per sample analysis of each sample.

\section{Statistical Analysis}

In order to determine the influence of the experimental variables on the spray characteristics, the measured droplet size distributions were subjected to 


\section{Figure 3 Configuration of Malvern laser sizer}

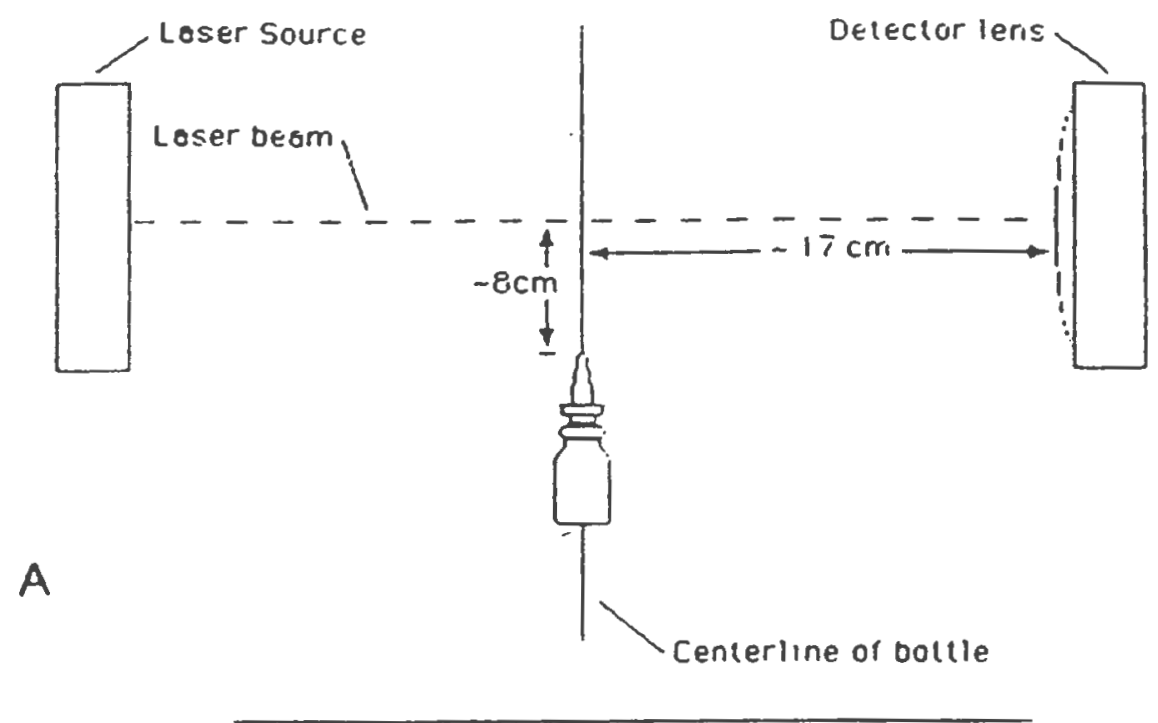

B
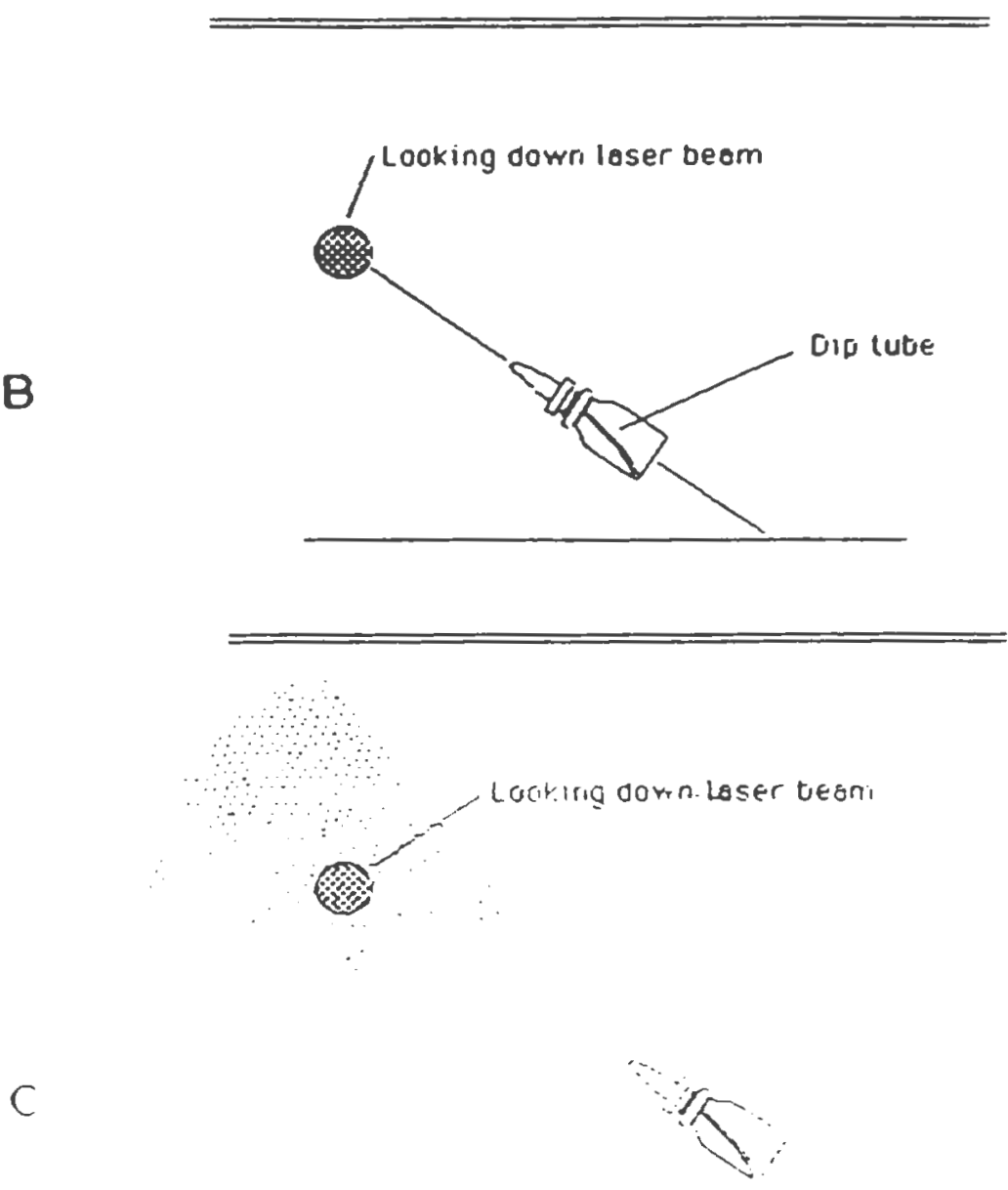
ANOVA. A completely randomized design was used. The analysis was performed using Statistical Analysis Software (SAS) and subjected to an F Test and hypothesis testing at 0.01 and 005 significance level. According to the hypothesis testing it was assumed that there was no difference among the droplet size measured and in cases where $F_{0}$ was greater than $F$ at 0.01 level and 0.05 levels, the hypothesis testing was rejected. Scheffe's multicomparison test were performed to further indicate significant differences among groups

\section{RESULTS AND DISCUSSION}

Viscosity studies

The viscosity of the formulations varying in methylcellulose concentration was determined using a Brookfield cone and plate viscometer. The flow behavior was determined from a plot of shear rate versus shear stress(figure 4). Methylcellulose exhibited a non-Newtonian flow behavior. There was a nonlinear relationship between the shear rate and shear stress for the methylcellulose indicating a deviation from the Newtonian behavior. Thus the viscosity was determined at a fixed rotational speed of $50 \mathrm{rpm}$. The viscosity at $50 \mathrm{rpm}$ was found to be $1 \mathrm{cps}$ for formulations without methylcellulose. The viscosity was calculated to be $2.12 \mathrm{cps}, 11.35 \mathrm{cps}, 76$ and $380 \mathrm{cps}$ for formulations containing $0.25 \% \mathrm{w} / \mathrm{w}, 0.5 \% \mathrm{w} / \mathrm{w}, 1 \% \mathrm{w} / \mathrm{w}$ and $2 \%$ $\mathrm{w} / \mathrm{w}$ of methylcellulose.

\section{Qualitative screening of formulations}

All prepared formulations were qualitatively screened. When the nasal devices with various actuator designs were tested ie., the metered spray pump 
FIGURE 4 NON-NEWTONIAN FLOW EXHIBITED BY METHYLCELLULOSE

A

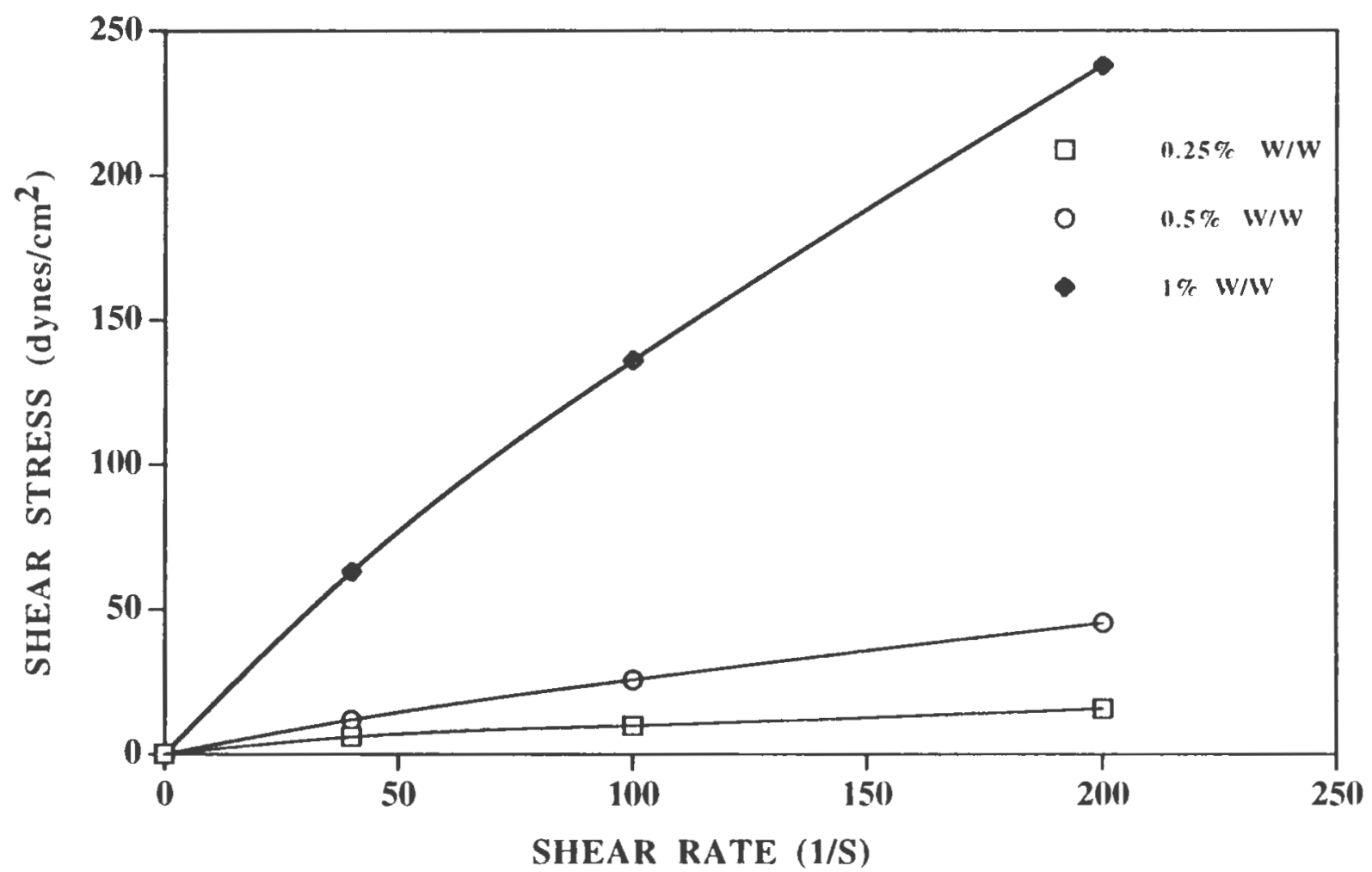


using either a ball and spring mechanism or a dual spring compression pump; the actuator designs with orifice diameters of spray insert of $0.1 \mathrm{~mm}$, $0.3 \mathrm{~mm}$ and $0.7 \mathrm{~mm}$ and spray angle, 200, $35^{\circ}$ and 600; all the test combinations generated a fine spray when the buffer solution with a viscosity of $1 \mathrm{cps}$ or a $u .25 \% \mathrm{w} / \mathrm{w}$ methylcellulose formulation with a viscosity of 2.12 cps was sprayed. All the formulations varying in tonicity, $300 \mathrm{mOsm}, 600$ mOsm and $100 \mathrm{mOsm}$ or concentration of absorption enhancer, $0 \% \mathrm{w} / \mathrm{w}$ and $0.5 \% \mathrm{w} / \mathrm{w}$ produced a fine spray. However when formulations with $0.5 \%$ $\mathrm{w} / \mathrm{w}$ methocel with a viscosity of $11.35 \mathrm{cps}$ were tested with the various pump and actuator designs; all the test combinations generated a mixture of spray with drops.

Formulations, with a viscosity greater than $11.35 \mathrm{cps}$ were investigated using the (NMSP). It was determined that the NMSP was able to deliver all formulations up to viscosity of $76 \mathrm{cps}$ generated by the $1 \% \mathrm{w} / \mathrm{w}$ methylcellulose as a fine spray. However the viscosity generated by $2 \% \mathrm{w} / \mathrm{w}$ methylcelluilose (380 cps) and was released from the NMSP as a gel.

\section{Dose accuracy studies}

A total of 5-6 actuations were required to prime the metered nasal spray pump and ten actuations were required to prime the NMSP. This was determined by measuring the weight loss per spray actuation for a formulation possessing a mean weight of $50 \mathrm{mg}$ for metered nasal spray purp and of $35 \mathrm{mg}$ for the NMSP. The standard deviation was found to be $\pm 2 \%$ from the mean weight of the metered nasal spray pump and $\pm 6 \%$ from the mean weight of the NMSP immediately after priming the pump. However, while the deviation for the metered nasal spray pump was found 
FIGURE 5 DOSE REPRODUCIBILITY STUDIES OF NASAL DEVICES
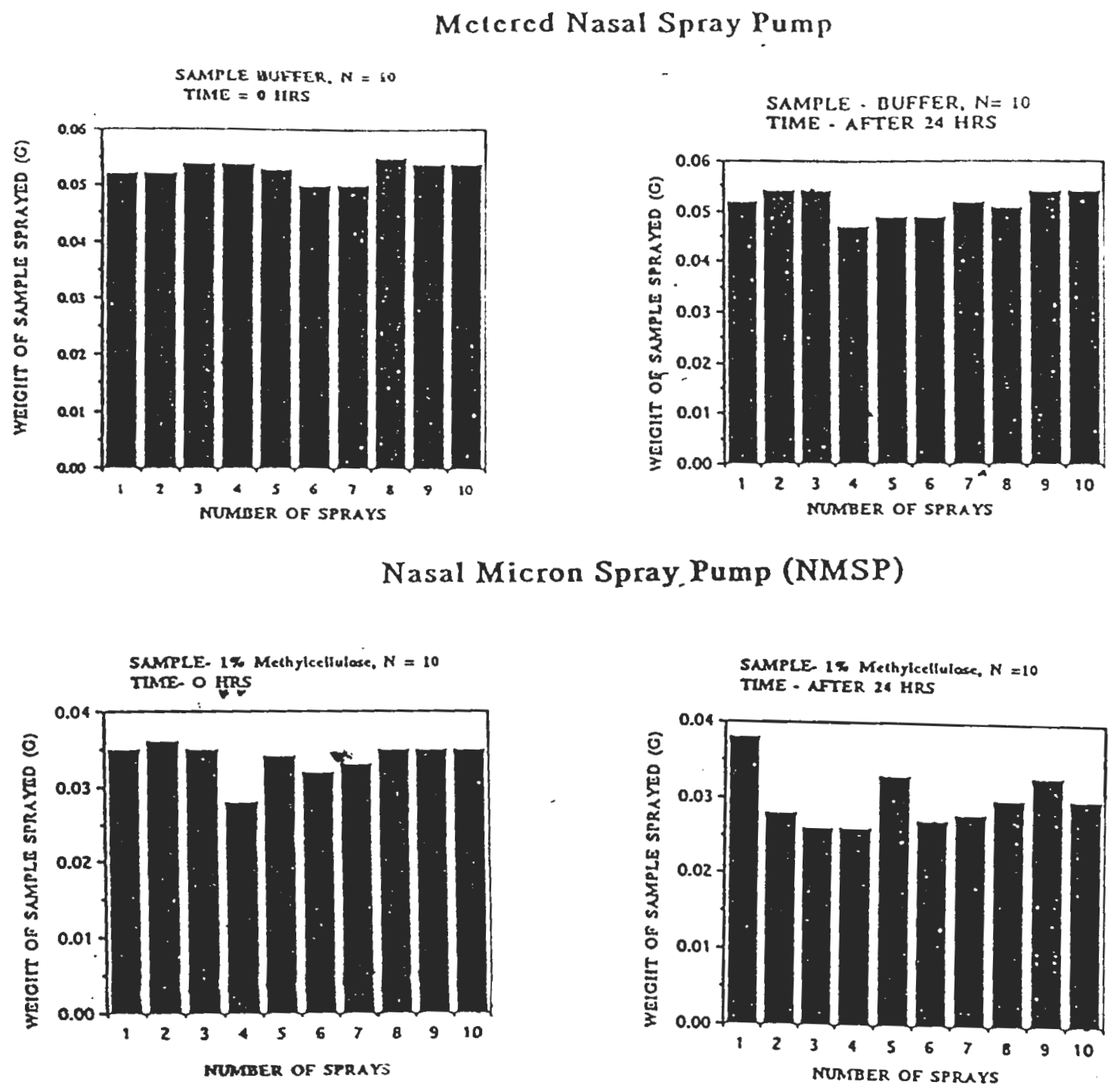
to be $\pm 2 \%$ from the mean weight; the NMSP showed a slight loss of primed value that increased the standard deviation to $\pm 14 \%$ from the mean weight after 24 hrs (figure 5).

\section{Droplet size analysis}

\section{Metered nasal spray pump}

When using a Malvern laser sizer to measure the droplet produced by spray pump, the $\mathrm{M}_{50}$ and $\mathrm{M}_{90}$ seemed to best characterize the size distribution. The parameter M50 represents average droplet size of $50 \%$ of the sprayed droplets and $\mathbf{M}_{90}$ represents an average size of $90 \%$ of the sprayed droplet. The $\mathbf{M}_{50}$ for buffer formulations with a viscosity of $1 \mathrm{cps}$ was $45.23 \pm 1.11 \mu \mathrm{m}$, and $\mathbf{M}_{90}$ was $68.41 \pm 7.94 \mu \mathrm{m}$. The $\mathbf{M}_{50}$ for $0.25 \%$ methylcellulose formulation with an increased viscosity of 2.12 cps was $56.97 \pm 3.45 \mu \mathrm{m}$ and $130.22 \pm 13.59 \mu \mathrm{m}$ for the M90 range. When increasing the methylcellulose to a $0.5 \%$ the viscosity was $11.35 \mathrm{cps}$ and the $\mathbf{M} 50$ increased to $105.86 \pm 7.77 \mu \mathrm{m}$ and the $\mathbf{M} 90$ was $305.04 \pm 18.54 \mu \mathrm{m}$.

The influence of the formulation variable, viscosity, on the spray profile and droplet size analysis (figure 6), demonstrated that the average droplet size increased with higher concentrations of methylcellulose. However with this increase in viscosity the profile of droplet size deviated from a Gaussian distribution. An ANOVA of these formulations varying in viscosity indicated a significant difference at the $\mathbf{M}_{50}$ and at the $\mathbf{M} \mathbf{9 0}$. Scheffe's multiple comparison test and Fisher's Least Significance test indicated that the droplet size distribution obtained from $1 \mathrm{cps}$ and $2.12 \mathrm{cps}$ was significantly different from the distribution produced by solutions with a viscosity of $11.35 \mathrm{cps}$. The 
FIGURE 6 THE INFLUENCE OF VISCOSITY ON THE DROPLET SIZE DISTRIBUTION USING METERED NASAL SPRAY PUMP

\begin{tabular}{|c|c|c|c|c|c|c|}
\hline \multicolumn{8}{|c|}{ VISCOSITY } \\
\hline & \multicolumn{2}{|c|}{1 (cps) } & \multicolumn{2}{c|}{2.12 (cps) } & \multicolumn{2}{c|}{11.35 (cps) } \\
\hline $\mathrm{N}=12$ & M50 & M90 & M50 & M90 & M50 & M90 \\
\hline AVERAGE & 45.23 & 68.41 & 56.97 & 130.22 & 105.9 & 305 \\
\hline S. DEV & 1.11 & 7.94 & 3.45 & 13.593 & 7.77 & 18.54 \\
\hline
\end{tabular}

嵌
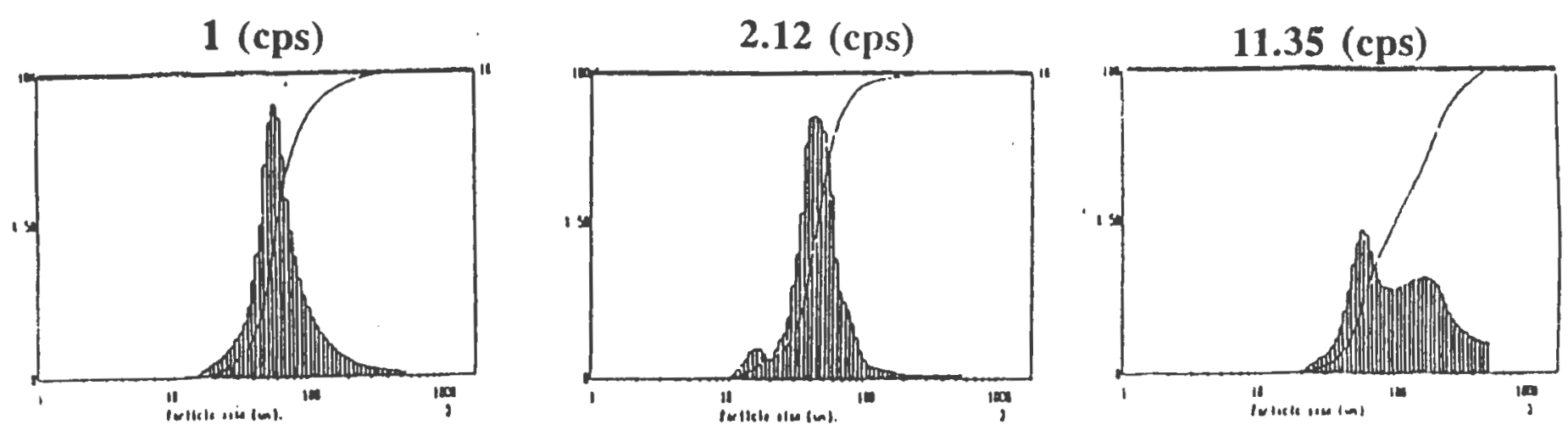
average at the $\mathbf{M}_{90}$ level tends to produce a large standard deviation than that seen for the $\mathbf{M} 5$.

Isotonic formulations with a osmolarity of $300 \mathrm{mOsm}$ generated a M50 of $45.23 \pm 1.15 \mu \mathrm{m}$, and M90 was $68.4 \pm 7.94 \mu \mathrm{m}$. Hypotonic formulations with a osmolarity of $100 \mathrm{mOsm}$ generated a $\mathbf{M}_{50}$ of $45.07 \pm 0.34 \mu \mathrm{m}$ and $\mathbf{M}_{90}$ was 76.32 $\pm 2.49 \mu \mathrm{m}$. Hypertonic formulations with a osmolarity of $600 \mathrm{mOsm}$ generated a $\mathbf{M}_{50}$ of $47.4 \pm 2.25 \mu \mathrm{m}$, and $\mathbf{M}_{90}$ was $130.37 \pm 2.25 \mu \mathrm{m}$. Thus the formulations varying in tonicity (figure 7) did not show any significant difference at M50 but did show a significant difference at M90. Scheffe's multiple comparison test indicated that the droplet size distribution at $\mathbf{M 9 0}$ obtained from the hypertonic formulation was significantly different from the isotonic and hypotonic formulations. The exact reason for this difference is not know'n.

The addition of the absorption enhancer, Dimyristoylphosphatidylglycerol (DMPG) to the formulation also showed an increase in the M50 and M90 (figure 8). The $\mathrm{M}_{50}$ for formulations without DMPG was $45.23 \pm 1.11 \mu \mathrm{m}$, and M90 was $66.79 \pm 6.87 \mu \mathrm{m}$. However the addition of 0.5\% DMPG provided a M50 of $71.16 \pm 3.18 \mu \mathrm{m}$, and a $\mathrm{M} 90$ of $133.07 \pm 0.79 \mu \mathrm{m}$. This increase may be due to the fact that the phospholipid forms a dispersion as compared to the solution seen for the previous formulations. Formulations varying in the concentration of absorption enhancer indicated a significant difference at M50 and at M90 as shown by the Scheffe's multiple comparison test at $\mathrm{p}<0.01$.

Among the device variables, the droplet size distribution and spray profiles for the two different designs of the nasal spray pump are shown in figure 9. The M50 for buffer formulations sprayed with a ball and spring pump was 
FIGURE 7 THE INFLUENCE OF TONICITY ON THE DROPLET SIZE DISTRIBUTION USING METERED NASAL SPRAY PUMP

\begin{tabular}{|c|c|c|c|c|c|c|}
\hline \multicolumn{9}{|c|}{ TONICITY } \\
\hline & \multicolumn{1}{|c|}{ ISOTONIC } & \multicolumn{2}{|c|}{ HYPOTONIC } & \multicolumn{2}{c|}{ HYPERTONIC } \\
\hline $\mathrm{N}=12$ & M50 & M90 & M50 & M90 & M50 & M90 \\
\hline AVERAGE & 45.23 & 68.41 & 45.07 & 76.32 & 47.4 & 130.4 \\
\hline S. DEV & 1.15 & 7.94 & 0.342 & 2.49 & 2.25 & 27.96 \\
\hline
\end{tabular}
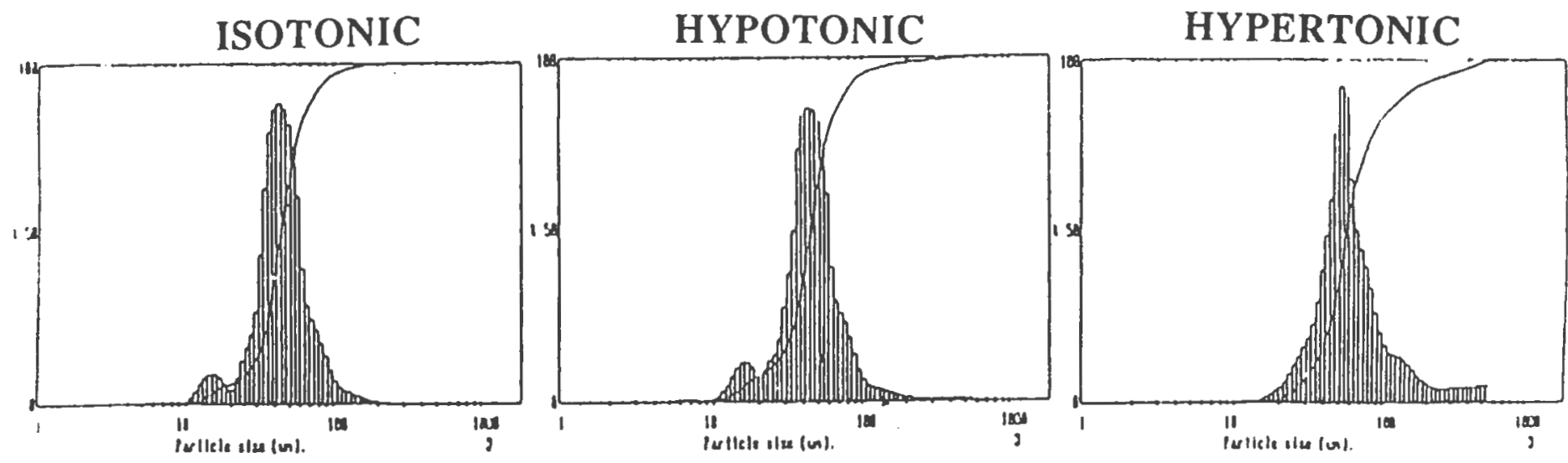
FIGURE 8 THE INFLUENCE OF CONCENTRATION OF ABSORPTION ENHANCER ON THE DROPLET SIZE DISTRIBUTION USING METERED NASAL SPRAY PUMP

\begin{tabular}{|c|c|c|c|c|}
\hline \multicolumn{5}{|c|}{ CONCENTRATION OF ABSORPTION ENHANCER } \\
\hline & \multicolumn{2}{|c|}{$0 \% \mathrm{w} / \mathrm{w}$} & \multicolumn{2}{c|}{$0.5 \% \mathrm{w} / \mathrm{W}$} \\
\hline $\mathrm{N}=12$ & $\mathrm{M} 50$ & $\mathrm{M} 90$ & $\mathrm{M} 50$ & $\mathrm{M} 90$ \\
\hline AVERAGE & 45.23 & 66.79 & 71.16 & 133.07 \\
\hline S. DEV & 1.11 & 6.87 & 3.18 & 0.794 \\
\hline
\end{tabular}
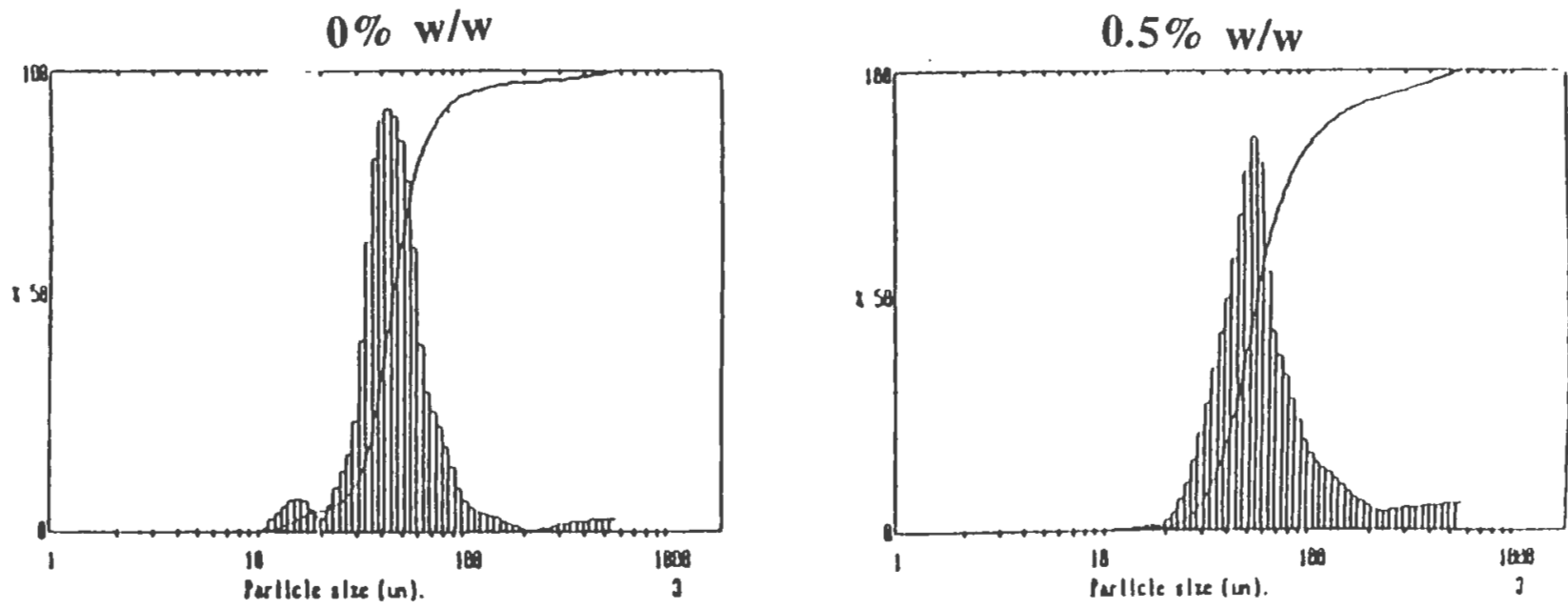
FIGURE 9 THE INFLUENCE OF MECHANISM OF PUMP ON THE DROPLET SIZE DISTRIBUTION FOR METERED NASAL SPRAY PUMP

\begin{tabular}{|c|c|c|c|c|}
\hline \multicolumn{4}{|c|}{} & \multicolumn{2}{|c|}{ MECHANISM OF PUMP } \\
\cline { 2 - 5 } & \multicolumn{2}{|c|}{ Pfeiffer } & \multicolumn{2}{c|}{ Valois } \\
\hline$N=12$ & M50 & M90 Spring & Dual Spring Compression \\
\hline AVERAGE & 44.37 & 76.64 & 47.42 & 106.54 \\
\hline S. DEV & 0.459 & 1.01 & 2.243 & 35.221 \\
\hline
\end{tabular}
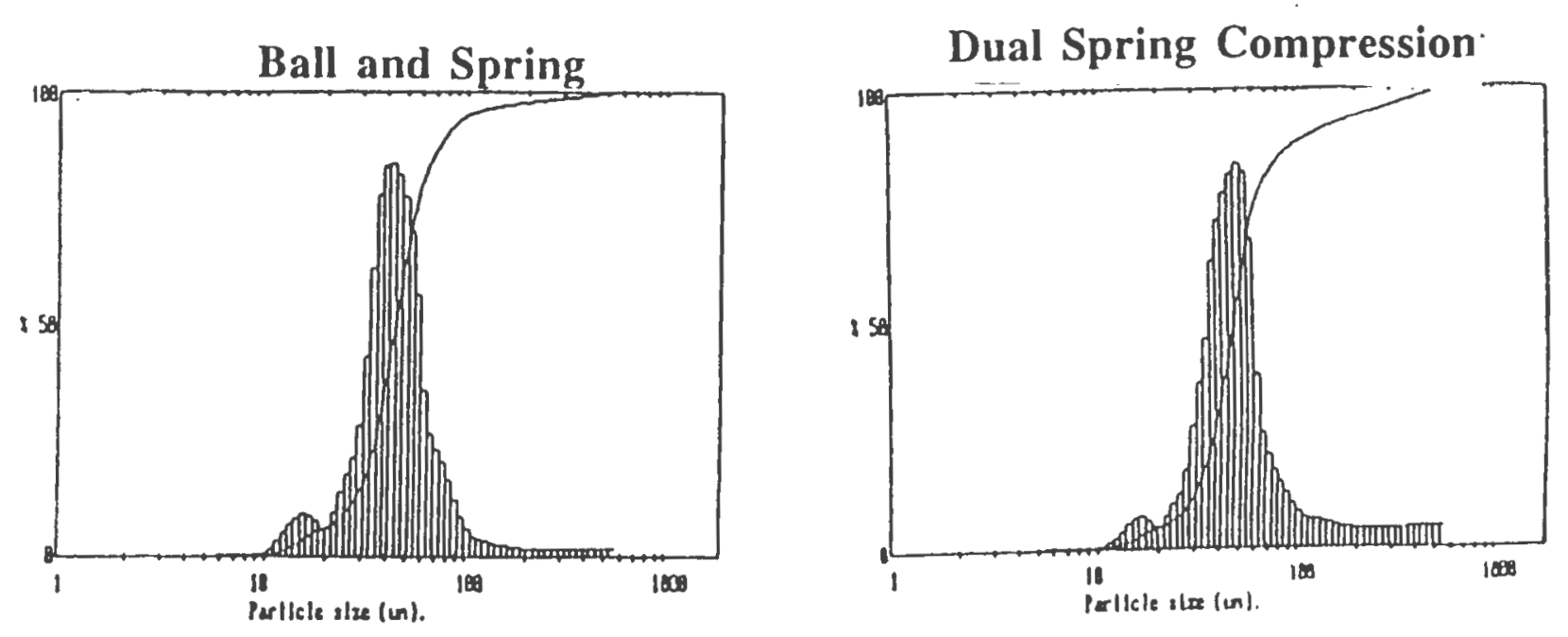
$44.37 \pm 0.459 \mu \mathrm{m}$, and the $\mathbf{M} 90$ was $76.64 \pm 1.01 \mu \mathrm{m}$. The $\mathbf{M} 50$ for buffer formulations sprayed using a dual spring compression pump was $47.42 \pm 2.24$ $\mu \mathrm{m}$, and the M90 was $106.54 \pm 35.22 \mu \mathrm{m}$. The influence of the orifice diameter of the spray insert is shown in figure 10 . The $\mathbf{M}_{50}$ for buffer formulations sprayed using an actuator with $0.1 \mathrm{~mm}$ spray insert was $45.23 \pm 1.15 \mu \mathrm{m}$ and the M90 was $68.41 \pm 7.94 \mu \mathrm{m}$. The $\mathbf{M}_{50}$ for buffer formulations sprayed using a spray insert with a diameter of $0.3 \mathrm{~mm}$ was $45.64 \pm 0.34 \mu \mathrm{m}$, and the M90 was $77.45 \pm 2.81 \mu \mathrm{m}$. The $\mathbf{M}_{50}$ for buffer formulations sprayed with a spray insert with a diameter of $0.7 \mathrm{~mm}$ was $47.40 \pm 2.25 \mu \mathrm{m}$ and the $\mathbf{M 9 0}$ was $123.6 \pm 24.86$ $\mu \mathrm{m}$. Similarly the effect of spray angle is shown in figure 11 . The $\mathbf{M} 50$ for buffer formulations sprayed from an orifice with a spray angle of $20^{\circ}$ was $45.28 \pm 1.05 \mu \mathrm{m}$ and the M90 was $67.51 \pm 7.94 \mu \mathrm{m}$. Using spray angle of $35^{\circ}$ the M 50 for buffer formulations sprayed was $45.07 \pm 0.34 \mu \mathrm{m}$, and the M90 was $76.56 \pm 2.4 \mu \mathrm{m}$. The $\mathbf{M}_{50}$ for buffer formulations sprayed with a spray angle of $60^{\circ}$ was $47.57 \pm 3.4 \mu \mathrm{m}$, and the $\mathbf{M} 90$ was $124.93 \pm 40.34 \mu \mathrm{m}$. Statistical analysis of the results indicated that there was not any significant difference at 0.01 level; between the $\mathbf{M}_{50}$ and $\mathbf{M} 90$ for two different design mechanisms for the pumps, on three different spray angles and the $\mathbf{M}_{50}$ for the threes sizes of spray inserts. However the $\mathbf{M}_{90}$ for the $0.7 \mathrm{~mm}$ orifice insert was found to be significantly different from $0.1 \mathrm{~mm}$ and $0.3 \mathrm{~mm}$.

The actuator and orifice diameter of the spray insert of metered nasal spray pump that were designed to be able to facilitate breakdown of the higher viscosity formulations from a stream to fine spray did not produce any significant differences in the droplet size distributions. This study emphasized the need to explore the effect of increased pressure on the higher viscosity 
FIGURE 11 THE INFLUENCE OF SPRAY ANGLE ON THE DROPLET SIZE DISTRIBUTION USING METERED NASAL SPRAY PUMP

\begin{tabular}{|c|c|c|c|c|c|c|}
\hline \multicolumn{7}{|c|}{ ACTUATOR DESIGN } \\
\hline \multicolumn{7}{|c|}{ SPRAY ANGLE } \\
\hline & \multicolumn{2}{|c|}{20 degrees } & \multicolumn{2}{|c|}{35 degrees } & \multicolumn{2}{|c|}{60 degrees } \\
\hline$N=12$ & M50 & M90 & M50 & M90 & M50 & M90 \\
\hline AVERAGE & 45.28 & 67.51 & 45.07 & 76.56 & 47.57 & 124.9 \\
\hline S. DEV. & 1.05 & 7.94 & 0.342 & 2.4 & 3.4 & 40.34 \\
\hline
\end{tabular}
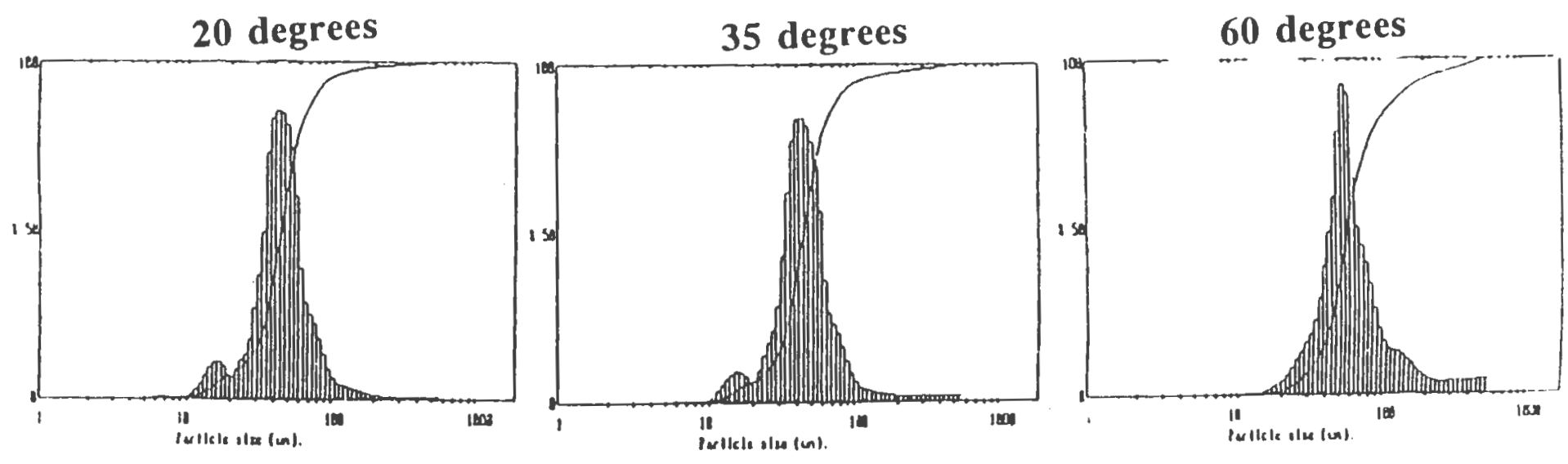
FIGURE 10 ! HE INHLUENCE OF ORIFICE DIAMETER ON THE DROPLET SIZE DISTRIBUTION FOR METERED NASAL SPRAY PUMP

\begin{tabular}{|c|c|c|c|c|c|c|}
\hline \multicolumn{8}{|c|}{ ACTUATOR DESIGN } \\
\hline & $0.1 \mathrm{~mm}$ & \multicolumn{2}{c|}{$0.3 \mathrm{~mm}$} & $0.7 \mathrm{~mm}$ \\
\hline $\mathrm{N}=12$ & $M 50$ & $M 90$ & M50 & M90 & M50 & M90 \\
\hline AVERAGE & 45.23 & 68.41 & 45.64 & 77.453 & 47.4 & 123.6 \\
\hline S. DEV. & 1.15 & 7.94 & 0.342 & 2.81 & 2.25 & 24.86 \\
\hline \multicolumn{3}{|c|}{$0.1 \mathrm{~mm}$} & $0.3 \mathrm{~mm}$ & \multicolumn{3}{c|}{$0.7 \mathrm{~mm}$} \\
\hline
\end{tabular}
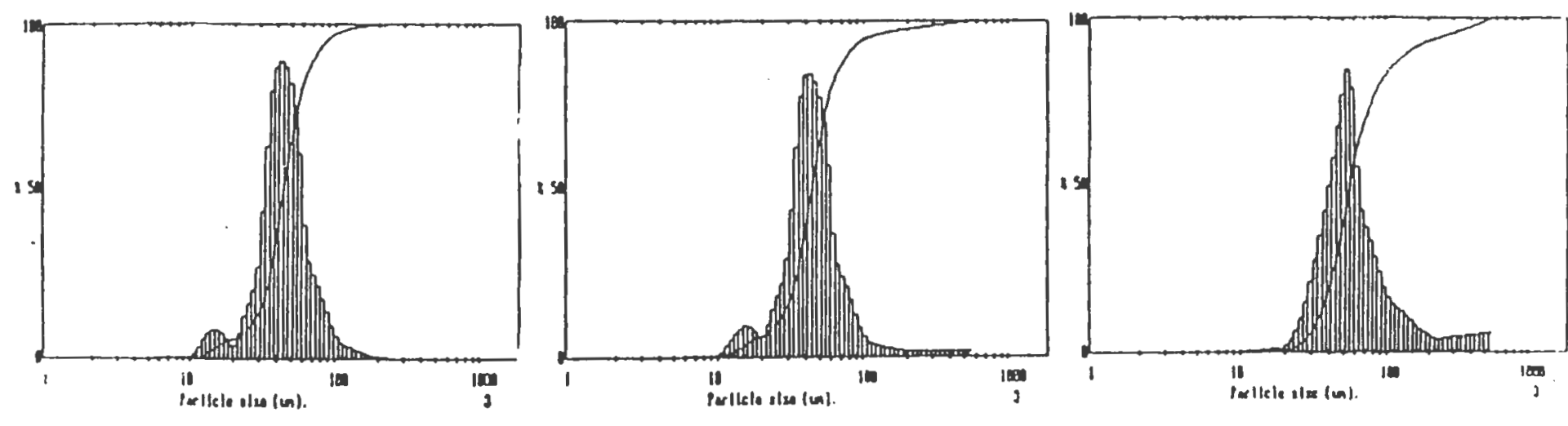
formulations. It was decided to evaluate the prototype nasal micron spray pump.

\section{Nasal micron spray pump}

The nasal micron spray pump (NMSP) is a prototype device designed to reduce the particle size distribution by using the increased pressure generated by the of air blast nozzle. Since viscosity seemed to be the most influential factor in the determination of droplet size, the formulations varying in viscosity were delivered using this new prototype spray pump and droplet size determined. The NMSP was able generate a $\mathbf{M}_{50}$ of $53.27 \pm 3.38 \mu \mathrm{m}$ and a M90 of $223.44 \pm 83.44 \mu \mathrm{m}$ for a $1 \mathrm{cps}$ buffer and also to deliver the $11.35 \mathrm{cps}$ $\left(0.5 \% \mathrm{w} / \mathrm{w}^{\prime}\right)$ and $76 \operatorname{cps}(1 \% \mathrm{w} / \mathrm{w})$ methylcellulose formulations with an average $\mathbf{M}_{50}$ of $54.25 \mu \mathrm{m}$ and $112.45 \mu \mathrm{m}$ respectively (figure 12). These same formulations when delivered with the standard metered spray pump measured $\mathrm{M}_{50}$ of $105.86 \mu \mathrm{m}$ for $0.5 \% \mathrm{w} / \mathrm{w}$ methylcellulose of $11.35 \mathrm{cps}$ and a M90 of $382.38 \pm 45.82 \mu \mathrm{m}$. Thus nasal micron spray pump was able to reduce the average droplet size distribution for high viscosity solutions significantly. However the spray profile for the NMSP showed a bimodal curve which seems to be due to a portion of spray striking the mouthpiece upon release from the air blast nozzle. Interestestingly the NMSP delivered the $76 \mathrm{cps}$ solution formulation as a fine spray, but could not disperse solutions having higher viscosity than $76 \mathrm{cps}$ as a fine spray. Neverthless thos prototype spray device seems to have the potential of provideing more "narrowed " spray distribution for high viscosity formulations. 
FIGURE 12 THE INFLUENCE OF VISCOSITY ON THE DROPLET SIZE DISTRIBUTION USING NASAL MICRON SPRAY PUMP

\begin{tabular}{|c|c|c|c|c|}
\hline \multicolumn{4}{|c|}{ VISCOSITY } \\
\hline & \multicolumn{2}{|c|}{$11.35 \mathrm{cps}$} & \multicolumn{2}{c|}{$76 \mathrm{cps}$} \\
\hline $\mathrm{N}=3$ & $\mathrm{M} 50$ & $\mathrm{M} 90$ & $\mathrm{M} 50$ & $\mathrm{M} 90$ \\
\hline AVERAGE & 54.25 & 257.73 & 112.48 & 382.38 \\
\hline S. DEV & 4 & 110.02 & 27.6 & 45.82 \\
\hline
\end{tabular}
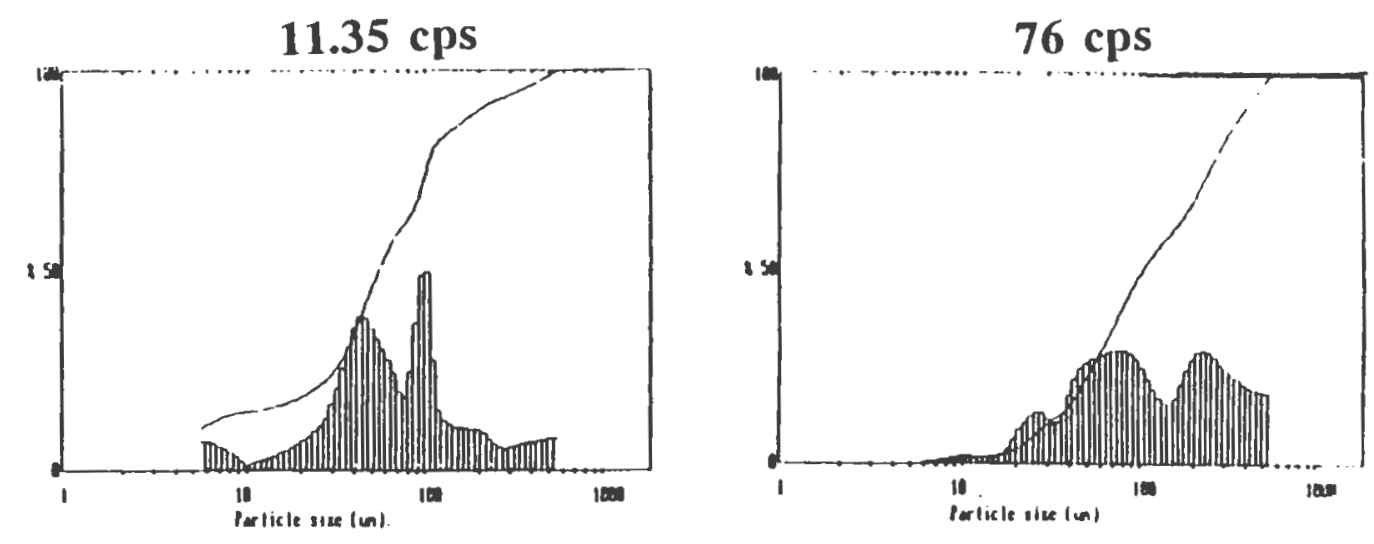
The influence of formulation variables and devices on nasal drug delivery has been focus of many investigations. However there is no published information on how the different components of nasal spray pump can affect the spray characteristics and the droplet size In this study an attempt was made to determine the influence of nasal administration device variables, such as design mechanism of the pumps, actuator, spray insert diameter as well as the various formulation parameters such as viscosity and presence of absorption enhancer on the droplet size parameters $\mathbf{M}_{50}$ and $\mathbf{M}_{90}$. However the influence of these spray profile on bioavailability is not known and is yet to be elucidated.

\section{Acknowledgments}

We would like to thank Rhone Poulenc Rorer, Collegeville, PA, U.S.A for the use of the equipment required for the viscosity and droplet size study and Pfeiffer Gmbh, Germany for the samples of the metered nasal spray pumps and the loan of nasal micron spray pump. 


\section{REFERENCES}

1. Hughes, B.L., Allen, D. L., Dorato, M.A and Wolff, R.K., Effects of delivery devices on nasal deposition and mucociliary clearance in rhesus monkey. J. Aerosol. Sci., 18 (1993) 241-249

2. Mygind, N., and Vesterhauge, S. Aerosol distribution in the nose, Rhinology, 11 (1978) 79.

3. Chien, Y. W., Su, K. S. E. and Chang, S., (Eds), Physicochemical Biopharmaceutical and Toxicophysiological Considerations in Nasal Systemic Drug Delivery. Published by Marcel Dekker, (1989) pp. 53

4. Chien, Y. W., Su, K. S. E. and Chang, S., (Eds), Physicochemical Biopharmaceutical and Toxicophysiological Considerations in Nasal Systemic Drug Delivery. Published by Marcel Dekker, (1989) pp. 64

5. Hardy, J.G., Lee, S. W: S., Wilson, C. G., Intranasal drug delivery by spray and drops., J. Pharm. Pharmacol., 37(1985) 294-297.

6. Aoki, F. Y., Crawley, J.C. W., Distribution and removal of human serum albumin-tecnetium 99m instilled intranasally., Br. J. Clin Pharmacol., 3. (1976) 869-879.

7. Harris, A. S., Ohlin, M., Lethagen, S. and Nilsson, I. M., Effects of concentration and volume on nasal bioavailability and biological response to Desmopressin. J. Pharm. Sci., 77(4) (1988) 337-344. 
8. Harris, A.S., Svensson, E., Wagner, Z.G., Lethagen, S., Nilsson, I. M., Effect of viscosity on Particle Size, Deposition and Clearance of Nasal Delivery Systems Containing Desmporessin., J. Pharm. Sci., 77 (1988) 405408.

9. Jager--Waldau, R., A Two Phase Flow Mechanical Spray Pump: A possible alternative to propellant driven MDI's. Journal of Biopharm. Sci., 3(1/2) (1992) 77-84 
MANUSCRIPT IJ

THE INFLUENCE OF TONICITY AND VISCOSITY ON THE INTRANASAL BIOAVAILABILITY OF SALMON CALCITONIN IN RABBITS. 


\section{ABSTRACT}

As with any drug delivery system, a clear understanding of the physicochernical and formulation factors is necessary for rational design of the dosage form. Formulation factors require careful assessment to identify those which may influence pharmacological or physiological response and thus assure optimum therapeutic activity. On the basis of physicochemical and biopharmaceutical studies of peptide or protein drugs; a nasal formulation administered with an appropriate delivery device may be designed to provide optimal nasal activity. In the present study an attempt was made to investigate the effect of tonicity and viscosity on the intranasal absorption of salmon calcitonin ( $\mathrm{SCT}$ ). Formulations were designed as nasal sprays with a viscosity of 1 or $76 \mathrm{cps}$, using $0 \% \mathrm{w} / \mathrm{w}$ and $1 \% \mathrm{w} / \mathrm{w}$ methylcellulose as the viscosity enhancing agent; and with a tonicity of 100 , 300 or $600 \mathrm{mOsms}$, using sodium chloride as the tonicity adjusting agent to provide hypotonic, isotonic and hypertonic formulations. Chlorbutanol was used as a preservative. The low viscosity formulations were delivered using a metered nasal spray pump and the high viscosity formulations were administered using a prototype device, the nasal micron spray pump, to facilitate a uniform distribution of the spray into the nasal cavity. Serum levels of $\mathrm{sCT}$ were determined in healthy male New Zealand rabbits after intranasal administration of $2000 \mathrm{IU}$ of sCT in $200 \mu \mathrm{l}$. The pharmacodynamic effect of salmon calcitonin of lowering blood calcium level was determined by a visible spectrophotometric technique. A full factorial design was employed with ANOVA and Scheffe's multiple comparison test used to analyze the data. Deviation from isotonicity was found to increase the bioavailability by 45 times. Variation in the viscosity did not influence the bioavailability of 
salmon calcitonin. Response surface methodology and the canonical analysis parameters were applied to determine the optimum formulations.

Key Words: Calcitonin, Intranasal, Tonicity, Viscosity, Methylcellulose, Nasal spray, Osteoporosis, Spray pumps. 


\section{INTRODUCTION}

The recent phenomenal advancement in biotechnology has contrived stimulating opportunities for the use of peptides and proteins as novel therapeutic agents. The emergence of these peptides and proteins has raised questions as to the extent to which existing formulation and drug delivery technologies can be used and the type of new technologies that must be developed to ensure the maximum therapeutic activity. Peptides and proteins have been administered intravenously because of the low oral bioavailability. This is very inconvenient for patients suffering from chronic diseases. Therefore, the administration of peptides and proteins by way of the mucosal routes such as nasal, rectal, buccal, vaginal and ocular mucosae are being investigated $\mathbf{1}$.

The use of the intranasal route for systemic delivery of peptide and protein drugs has several potential advantages including the large surface area of the nasal cavity and the highly vascularized nature of nasal mucosa. Nasal absorption of polypeptides such as oxytocin ${ }^{2}$, synthetic lysine vasopressin ${ }^{3}$, synthetic LH-RH and its analogues 4 , insulin $5-7$, enkephalins analogs 8 , growth hormone releasing factor ${ }^{9-10}$ has been reported. The permeability of the nasal mucosa to peptides seems to decrease with increasing molecular weight. For peptides with a molecular weight of more than 1000D, bioavailabilities are in the range of $1-3 \% \mathbf{1 1 - 1 2}$. The nasal absorption efficiency of peptides and proteins is also influenced by the overall design of the dosage form as well as the devices used for administration. Some of the dosage forms which have been investigated are solutions ${ }^{13-14}$ gels $^{15}$, powders 16 and microspheres 17 . These dosage forms have been used for the administration of 
insulin 18-20, human growth hormone $21-22$, oxytocin 23 , desmopressin 24 and propranolol25. The earliest and the most classical form of nasal formulation is the solution. However solutions have often been shown to provide lower bioavailability because they are more readily cleared from the nasal cavity, particularly when administered as drops. Conversely sprays are confined to the nonciliated regions of the nasal cavity and therefore are retained longer than drops 26 . There is 'ittle information on how the formulation variables of a nasal spray such as buffer concentration, buffer species, ionization of buffer species, ionic strength, viscosity, charge, $\mathrm{pH}$ of vehicle, osmolarity, type and concentration of preservatives could further influence the absorption of peptide and proteins.

Salmon Calcitonin, a polypeptide hormone secreted by the parafollicular C cells of the thyroid gland, lowers serum calcium levels by decreasing bone and renal tubular reabsorption of calcium. Injectable formulations of salmon calcitonin have been used with some success in the management of metabolic bone disorders such as osteoporosis and Paget's disease but this form of administration is inconvenient and has been poorly tolerated by the patients. The development of an intranasal preparation of salmon calcitonin will provide a more convenient means of administering the drug 27 . Intranasal spray preparations containing salmon calcitonin have been shown to be effective in metabolic bone disease ${ }^{28}$. Unfortunately nasal bioavailability is significantly lower than that realized by injection. Salmon calcitonin in a spray form is now registered in some European countries, however a nasal spray of salmon calcitonin has not been approved in United States by FDA as yet. The available data indicate a reasonable absorption, but there is very little detail addressing the effects of formulation parameters, such as $\mathrm{pH}$, ionization 
of buffer salts, osmolarity, viscosity, etc., un the bioavailability 29-30. To optimize drug activity, the factors influencing the drug, formulation components in combination with delivery devices must be identified and modified to realize significant drug activity.

Since the stability of calcitonin dictates such parameters as $\mathrm{pH}$, buffer and preservatives; this study was designed to investigate the effect of the formulation variables, viscosity and tonicity, on the intranasal bioavailability of salmon calcitonin. Previous studies have been carried out with various drugs to evaluate the effects resulting from an increase in viscosity in a formulation. An increase in viscosity is postulated to increase the particle size of a spray formulation which leads to a more localized deposition and slower clearance from nose. However, the effects of increased viscosity on mucociliary clearance, are difficult to interpret. According to some authors, an increase in viscosity results in a decrease in the clearance rate ${ }^{31}$. In other cases a progressive increase in viscosity leads to an initial slowdown of clearance followed by an increase 32 . Increasing viscosity also seems to progressively lower the rate of diffusion of the drug from the deposited droplets resulting in delayed release and absorption without improvement in bioavailability. While the above data was generated using viscosity in the range of 1-11 cps, the present study will investigate the use of a significantly higher viscosity ( $75 \mathrm{cps}$ ) formulation obtained by using $1 \% \mathrm{w} / \mathrm{w}$ methylcellulose. Previous studies have shown that metered nasal spray pumps are limited in their ability to spray higher viscosity solutions as a fine spray. It has been shown that at is not possible to achieve a gaussian droplet size distribution for solutions of viscosity greater than $2.12 \mathrm{cps}^{33}$. However high viscosity formulations can be delivered as a fine spray using a prototype device, the 
nasal micron spray pump, to facilitate the uniform distribution of spray in the nasal cavity. These results will be compared to those obtained using a low viscosity formulation, $1 \mathrm{cps}$, delivered from a commercially available metered dose spray pump. Additionally, the study will compare the droplet size distribution obtained with the two different devices, the effect on Tmax, the time required to obtain maximum concentration in the blood, and the bioavailability of salmon calcitonin.

Isotonic solutions are used to assist cells in maintaining a stable physiological environment. Deviation from isotonic conditions can cause tissue damage, irritation, hemolysis of blood cells and electrolyte imbalance. However very little information has been generated on the effect of varying the degree of tonicity for oral or mucosal drug delivery especially intranasal formulations. Absorption of quinine from the small intestine was found to decrease with increasing hypertonicity 34 . Malone et al, 1960, reported that the oral absorption of phenobarbitone in the rat was higher from hypotonic than from hypertonic solutions ${ }^{35}$. However Ohwaki et al, 198436, demonstrated an increase in the bioavailability of secretin from the nasal cavity with hypertonicity. Based on the information obtained from these few experiments, it is difficult to interpret the effect of tonicity on the absorption in the nasal cavity. The literature does not cite any reference of the effect of tonicity on the bioavailability of salmon calcitonin. This study investigates the effect of tonicity at three levels, isotonicity ( $300 \mathrm{mOsm})$, hypotonicity (100 mOsm) and hypertonicity (600 mOsm). These formulations were obtained by using sodium chloride as tonicity adjusting agent. Since the formulation is meant for a chronic use, mild deviations from isotonic conditions was investigated as severe deviation can effect the integrity of the nasal mucosa. 


\section{EXPERIMENTAL}

\section{Materials}

Salmon calcitonin (sp. activity 5384 I.U./mg) was a gift from Armour Pharmaceuticals, Kankanee, IL). RIA Kits were procured from (Diagnostics Systems laboratories, Webster, TX), Acetic acid and sodium acetate, analytical grade were purchased from (Fisher Scientific, Fair Lawn, NJ). The anesthetics, acepopromazine maleate, ketamine hydrochloride (Aveco Co. Inc., Fort Dodge, IA), DMA Calcium Plus Reagent (DMA, Houston, TX), Methylcellulose, Methocel A15C (Dow Chemical Company, Midland, MI), Chlorbutanol (Sigma Chemical Company, St. Louis, MO), Catheters and Serum separators (Baxter Health Care Corporation, Deerfield, IL), Heparin Sodium injection, USP (Elkins-Sinn Inc., Cherry Hill, NJ) were purchased and used as received. Distilled water was used in all nasal formulations.

A $50 \mu 1$ metered nasal spray pump was chosen to deliver the low viscosity formulations (1 cps). A prototype device, the nasal micron spray pump (NMSP), capable of spraying $35 \mu 1$ per actuation was employed to deliver formulations of higher viscosity (76 cps). Both the pumps were provided by Pfeiffer GMBH, Radolfzell, Germany.

\section{Methods}

\section{Preparations of formulations}

The formulations were prepared with a concentration of methylcellulose ranging from $0 \%$ to $1 \% \mathrm{w} / \mathrm{w}$ in a $0.03 \mathrm{M}$ sodium acetate-acetic acid buffer at $\mathrm{pH}$ 4 and kept in the refrigerator. $\mathrm{A} \mathrm{pH}$ of 4 was selected for the formulation as salmon calcitonin has maximum stability between $\mathrm{pH} 3-5$. The formulation 
was refrigerated as salmon calcitonin has been reported to be most stable when stored at $2-4^{\circ} \mathrm{C}$.

Measurement of the osmotic pressure (tonicity)

The osmotic pressure of the formulations was measured using a A-010 Microdiagnostics Osmometer. Standards were measured ranging from 100 mOsm-2000 mOsm and then formulations were measured in duplicate.

\section{Administration of nasal formulations to the rabbits}

It has been shown 37 that differences in volume, concentration, or dosing technique for an intranasal drug can provide a significant difference in bioavailability. Instılling a drug as a smaller volume in both nostrils as compared to a larger volume in one nostril demonstrated a lower coefficent of variation and slower clearance from the nose.

It has been demonstrated 38 that the addition of a viscosity enhancing agent increases the contact time of the dosage form to the mucosal membrane and may help to enhance the absorption by reducing the clearance of the administered drug. Viscosity also changes the pattern of deposition and clearance ${ }^{38}$. In these studies the viscosity used was in the range of 1-3.5 cps, which can be considered as low viscosity solutions. The NMSP, a prototype device originally developed for inhalation solution was investigated for its ability to deliver higher viscosity solutions as a fine spray. The lower droplet size distribution for the high viscosity solutions is achieved by the NMSP using an air blast nozzle as an actuator. By improving the geometry and therefore the dynamic properties within the spray nozzle, the droplet spectrum has been reduced to smaller diameters leaving the spray nozzle 39 . 
A standard metered manual spray pump was chosen to deliver low viscosity formulations (1 cps). A metered $50 \mu$ nasal spray pump based on a ball and spring mechanism was combined with a flanged actuator using a spray insert with a $35^{\circ}$ spray angle was used. The total volume of $200 \mu$ to contain the dose was instilled by spraying twice into each nostril. The NMSP was employed to deliver formulations of higher viscosity (76 cps). The volume delivered was $35 \mu \mathrm{l}$ per actuation and a $210 \mu \mathrm{l}$ volume to contain the dose was instilled by spraying 3 times into each nostril.

\section{In vivo study}

\section{Animal Model}

The New Zealand white rabbit was selected as an animal model because it provides a well controlled animal model for screening the nasal absorption potential of sprayed drug formulations. The blood volume of the rabbit is sufficiently large to permit frequent blood samples and allow a full characterization of the absorption profile of the drug 40 . Rabbits were obtained from Milbrook farms (Amherst, MA) with a mean weight of about $3 \mathrm{~kg}$. The study protocol was reviewed and approved by the Institutional Animal Care and Use Committee, University of Rhode Island, Kingston, RI

\section{Experimental procedure}

The rabbits were fasted for 36 hours prior to each experiment with free access to water. The rabbits were anesthetized with an i.m. dose of $0.25 \mathrm{mg} / \mathrm{kg}$ of ketamine hydrochloride and $2.5 \mathrm{mg} / \mathrm{kg}$ of acepopromazine maleate. Rabbits were kept lying on their backs on thermal rugs during each experiment. A catheter was placed in the rabbit's median ear artery and a $0.8-1 \mathrm{ml}$ blood sample was collected at $-5,10,20,30,40,50,60,75,90,120,180,240$ and 300 
minutes after administration of the formulation. The samples were allowed to clot for at least 30 minutes at room temperature and then centrifuged at $3000 \mathrm{rpm}$ for 10 minutes and stored at $-20^{\circ} \mathrm{C}$ until assayed.

The control group was used to measure any interference from the trauma of administration of anesthesia on the inherent calcitonin level. The control rabbits were subjected to the same conditions, however calcitonin was not administered. The values obtained were subtracted from the levels obtained after administration of calcitonin formulations.

\section{Study Design}

Calcitonin was administered as spray to the rabbits as per a randomized cross over design. A wash out period of at least one week was allowed between treatments.

\section{Analytical methods}

\section{Serum calcitonin}

All serum samples were assayed with a commercial RIA kit developed at Diagnostics Systems Labortories (Webster, TX). Guinea pig anti-sCT antibodies were used as primary antibodies and have demonstrated less than $2 \% \mathrm{w} / \mathrm{w}$ cross reactivity. The sigmoidal standard curve of $\mathrm{B} / \mathrm{Bo}$ vs [sCT], typical of competitive binding assays was linearized using the log transformation. The best fit line was determined using a non weighted least square regression analysis. The radioimmunoassay quantitation range was $100-5000 \mathrm{pg} / \mathrm{ml}$. The square of the coefficent of determination $\left(\mathrm{r}^{2}\right)$ in this range for the $B /$ Bo versus $\log [\mathrm{sCT}]$ plots was greater than 0.993 for all assays performed in duplicate. 


\section{Serum calcium levels}

Serum calcium levels were determined using a DMA Calcium Plus Procedure(B) utilizing arsenazo III to bind the calcium at an acid $\mathrm{pH}$ and form a bluish purple complex. Serum calcium was quantified spectrophotometrically at $650 \mathrm{~nm}$ and the range of the linearity was determined to be between $5-25 \mathrm{mg} / \mathrm{dl}$. The square of the correlation $\left(\mathrm{r}^{2}\right)$ in this range for the absorbance versus concentration ( $\mathrm{mg} / \mathrm{dl}$ ) was 0.999 for all the assays performed in duplicate during the course of study.

\section{Data Analysis}

The concentration of calcitonin was measured in the serum over a period of 5 hours after administration of salmon calcitonin formulations. Salmon calcitonin activity was determined as a function of lowering of calcium levels. The nasal bioavailability of calcitonin was calculated relative to the serum calcitonin levels over a period of 5 hours after injecting calcitonin intravenously. $C_{\max }$ values are the peak serum calcitonin concentrations observed at time $\mathrm{T}_{\max }$ after adminstration of calcitonin.

$$
\% \text { Absolute Bioavailability }=\frac{\text { AUCin-AUCcontrol }}{\text { AUCiv-AUCcontrol }} \times \frac{\text { Doseiv }}{\text { Dosein }} \times 100
$$

The hypocalcemic effect was measured in terms of maximal decrease (\%max $\left.{ }_{d}\right)$ which was calculated as the highest percentage of reduction in calcium levels as compared to the basal values. The total decrease in serum calcium level (D\%) was calculated using a modified method, by Hirai et al, 198141 .

$$
\mathrm{D} \%=\frac{\text { AUCcontrol-AUCin }}{\text { AUCcontrol }} \times 100
$$


where $A U C_{i n}, A U C_{\text {control }}$ and $A U C_{i v}$ refer to the area under the curve calculated by the linear trapezoidal rule. $A U C_{\text {in }}$ refers to area under the curve calculated after the intranasal administration of calcitonin formulations. $A U C_{i v}$ refers to area under the curve calculated after the intravenous administration of calcitonin formulations. $\mathrm{AUC}_{\text {control }}$ refers to area under the curve calculated without administration of the calcitonin. The time at which this reduction takes place is $T_{\max }$.

The data was analyzed by ANOVA using Statistical Analytical Software (SAS). The formulation effects were compared with the controls using Dunnett's test. Multiple comparison among the treatment effects were determined using Fisher's Least Significant Difference test (LSD) and/or Scheffe's multiple comparison test. Differences among the treatments were assumed to be significant for values of $\mathrm{p}<0.05$.

\section{Determination of optimum formulations}

One of the main objectives of this investigation was to study the effects of tonicity and viscosity on the intranasal bioavailability. Tonicity was investigated at 3 levels of 100, 300 and 600 mOsm and viscosity was studied at two levels of 1 and $76 \mathrm{cps}$. In order to optimize the effects of the independent variables of viscosity and tonicity on the dependent factor, area under the curve, a full factorial statistical design, was used. A factorial design was used to study the primary effects of viscosity and tonicity and the secondary effects or interactions of viscosity and tonicity on the intranasal absorption of $\mathrm{SCT}$

In the simplest of cases, techniques used for optimization involve the determination of maximum or minima but when the relationship for the 
response is given as a function of two or more than two independent variables, the system becomes more complicated. In the present case, Response surface methodology (RSM) was applied to estimate the maximum or minimum response so as to determine the optimum formulations for the nasal delivery of salmon calcitonin. The SAS/RSREG software was used to fit the parameters of the complete quadratic reponse surface obtained from the three levels of tonicity incorporated in the formulations. The fitted surface was analyzed to determine the level of the independent variable providing the optimum response. The predicted optimal value can be found from the estimated surface, which usually shows a minima, maxima or saddle point, if there is no clear maxima or minima. Since the independent variable should be at three or more levels, tonicity was designated an independent variable with area under the curve as a response surface. Viscosity was used as a covariate that was investigated at two levels. 42

\section{RESULTS AND DISCUSSION}

\section{(A) Intravenous administration}

The average serum sCT concentration versus time profile for 5 I.U. of i.v. administered dose is shown in figure 1 . The average $C_{\max }$ was $25 \pm 2.9 \mathrm{ng} / \mathrm{ml}$ at a $T_{\max }$ of $14 \pm 2.4$ minutes and the area under the curve (AUC) was 1102.1 $\pm 19.8 \mathrm{ng} \cdot \mathrm{min} / \mathrm{ml}$ as compared to control group in which average concentration was $2 \mathrm{ng} / \mathrm{ml}$ and the AUC was $401 \pm 75.3 \mathrm{ng} \cdot \mathrm{min} / \mathrm{ml}$. The salmon calcitonin levels obtained in the serum were significantly different from the control level at $p<0.05$. The pharmacokinetic parameters are simmarized in Table I. 
FIGURE 1 CONCENTRATION TIME PROFILE OF SALMON

CALCITONIN AFTER IV ADMINISTRATION (N=5); DOSE 5 IU

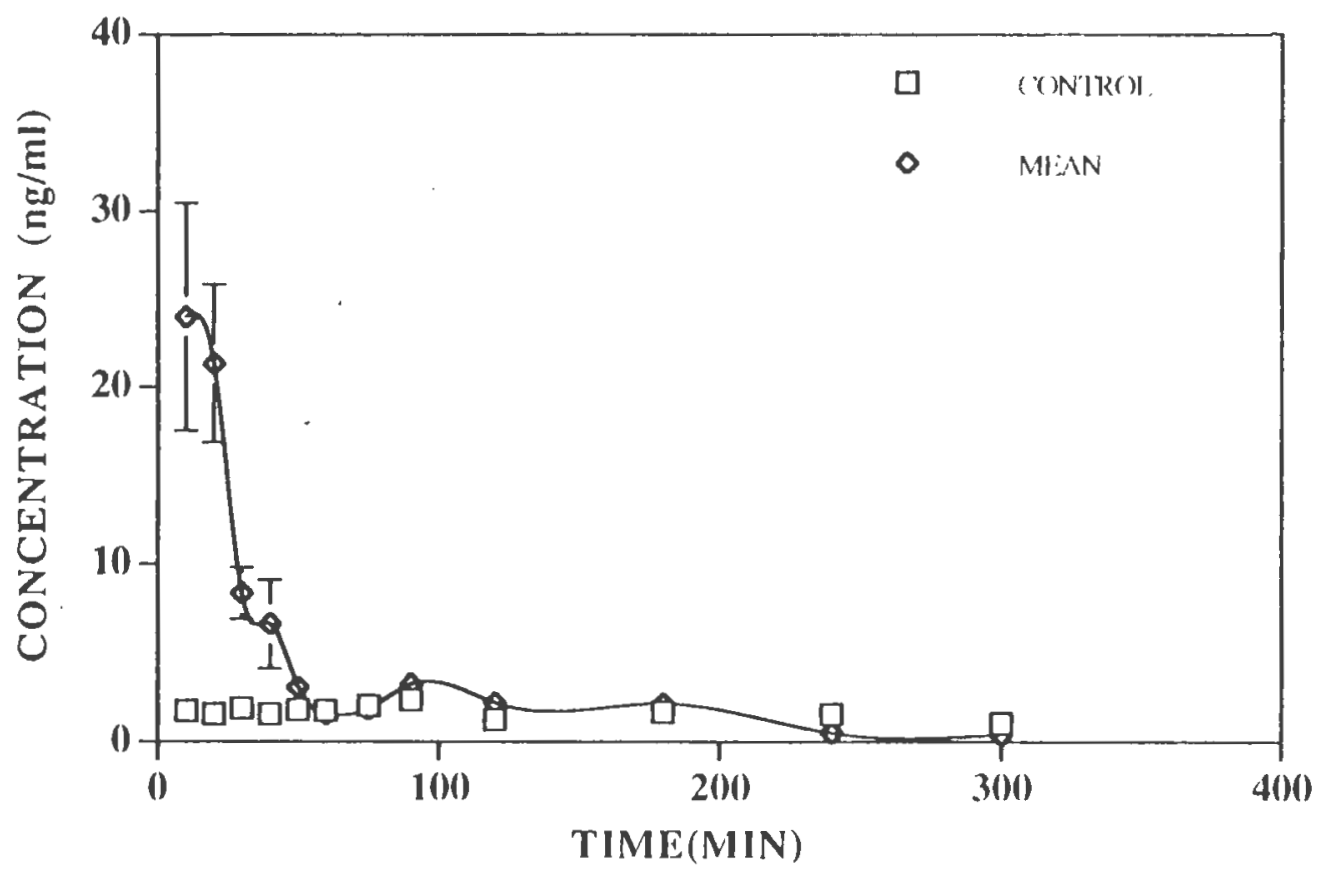


TABLE I PHARMACOKINETIC PARAMETERS AFTER INTRANASAL ADMINISTRATION OF SALMON CALCITQNIN TO NEW ZEALAND RABBITS $(N=5)$

\begin{tabular}{|c|c|c|c|c|}
\hline VARIABLE & Tmax (min) & Cmax(ng/ml) & AUC(ng.min/ml) & \%Bioavailability \\
\hline CONTROL & & & $401 \pm 75.3$ & \\
\hline I.V (5 I.U.) & 14 & $25 \pm 2.9$ & $1102.1 \pm 19.8^{\mathrm{a}}$ & 100 \\
\hline $\begin{array}{c}\text { INTRANASAL } \\
\text { LOW VISCOSITY }\end{array}$ & & & & \\
\hline DOSE 2000 I.U. & & & & \\
\hline ISOTONIC & 40 & $10 \pm 4.2$ & $714.2 \pm 15.7$ & 0.16 \\
\hline HYPERTONIC & 90 & $42 \pm 19.6$ & $3508 \pm 1280^{\mathrm{b}}$ & 0.80 \\
\hline HYPOTONIC & 38 & $26 \pm 7.6$ & $3171 \pm 258^{\mathrm{b}}$ & 0.71 \\
\hline $\begin{array}{c}\text { INTRANASAL } \\
\text { HIGH VISCOSITX }\end{array}$ & & & & \\
\hline DOSE 2000 I.U. & & & & \\
\hline ISOTONIC & 120 & $23 \pm 2.4$ & $3579 \pm 1030^{\mathrm{b}}$ & 0.14 \\
\hline HYPERTONIC & 58 & $12 \pm 9.7$ & $604.6 \pm 97.74$ & 0.62 \\
\hline HYPOTONIC & 90 & $32 \pm 19.6$ & $2183 \pm 258^{\mathrm{b}}$ & \\
\hline
\end{tabular}

a significantly different from control at $p<0.05$

$b$ significantly different at low and high viscosity at $p<0.5$ 
The pharmacodynamic effect of SCT of lowering calcium is shown in figure 2 and summarized in Table II. The total reduction in calcium level is termed as $\mathrm{D} \%$. The hypocalcemic effect is also measured in terms of maximal percent decrease $\left(\% \max _{\mathrm{d}}\right)$. which is the highest percent of reduction in calcium levels as compared to the basal values. The time at which this reduction takes place is $\mathrm{T}_{\max }$. However between $\mathrm{D} \%$ and $\% \max _{\mathrm{d}}$; the $\mathrm{D} \%$ is considered to be a more acceptable measure of hypocalcemic activity as it encompasses the overall reduction in activity rather than reduction at one time point.

It car, be seen that the administration of the $5 \mathrm{IU}$ iv dose resulted in a initial percent maximal decrease $\left(\% \max _{d}\right)$ of $28 \%$ of calcium at 30 minutes $\left(\mathrm{T}_{\max }\right)$. After 30 minutes there was an increase in the calcium level, and then there was a gradual decrease after 75 minutes until 240 minutes. This pattern of concentration change may be explained on the basis that often administration of salmon calcitonin, there is a decrease in the calcium level, once the calcium level reaches a critical value, the parathyroid hormone already present in the body counteracts the effects of calcitonin and raises the calcium level. Thus the total lowering, $\mathrm{D} \%$, was calculated and was found to be $32 \%$ as compared to the control group. The AUC for i.v. administration was $2732 \pm 271.39 \mathrm{mg} \cdot \mathrm{min} / \mathrm{dL}$ as compared to the AUC for the control group of $4045.40 \pm 255.17 \mathrm{mg} . \mathrm{min} / \mathrm{dL}$ and was significantly different at $\mathrm{p}<0.05$. 
TABLE II PHARMACODYNAMIC PARAMETERS AFTER INTRANASAL ADMINISTRATION OF SALMON CALCITONIN TO NEW ZEALAND RABBITS ( $N=5$ ); DOSE 2000 IU

\begin{tabular}{|c|c|c|c|c|}
\hline VARIABLE & Tmax(min) & Maxd. $\%$ ) & $\underline{\text { AUC (mg.min/dL) }}$ & $\underline{\%}$ \\
\hline CONTROL & & & $4045.40 \pm 255.17$ & \\
\hline I.V (5 IU) & 30 & 28 & $2732 \pm 271.39 \mathrm{a}$ & 32 \\
\hline LOW VISCOSITY & & & & \\
\hline ISOTONIC & 240 & 12.96 & $3724.12 \pm 120.99$ & 7.9 \\
\hline HYPERTONIC & 75 & 28.83 & $3267.74 \pm 31.31^{\mathrm{a}, \mathrm{b}}$ & 19 \\
\hline HYYOTONIC & 180 & 28.12 & $3308.0 \pm 42.45^{\mathrm{a}}$ & 18 \\
\hline HIGH VISCOSITY & & & & 19 \\
\hline ISOTONIC & 240 & 28.81 & $3242.83 \pm 21.66$ & 9.0 \\
\hline HYPERTONIC & 90 & 23.52 & $3696.28 \pm 53.24^{\mathrm{a}, \mathrm{b}}$ & 22 \\
\hline HYPOTONIC & 120 & 34.58 & $3154.47 \pm 102.49 \mathrm{a}$ & \\
\hline
\end{tabular}

$a=$ significantly different from control at $p<0.05$

$b=$ significantly different at low and high viscosity $p<0.05$ 
FIGURE 2 THE INFLUENCE OF IV ADMINISTRATION OF SALMON CALCITONIN ON THE CALCIUM I.EVEL $(\mathrm{N}=5)$

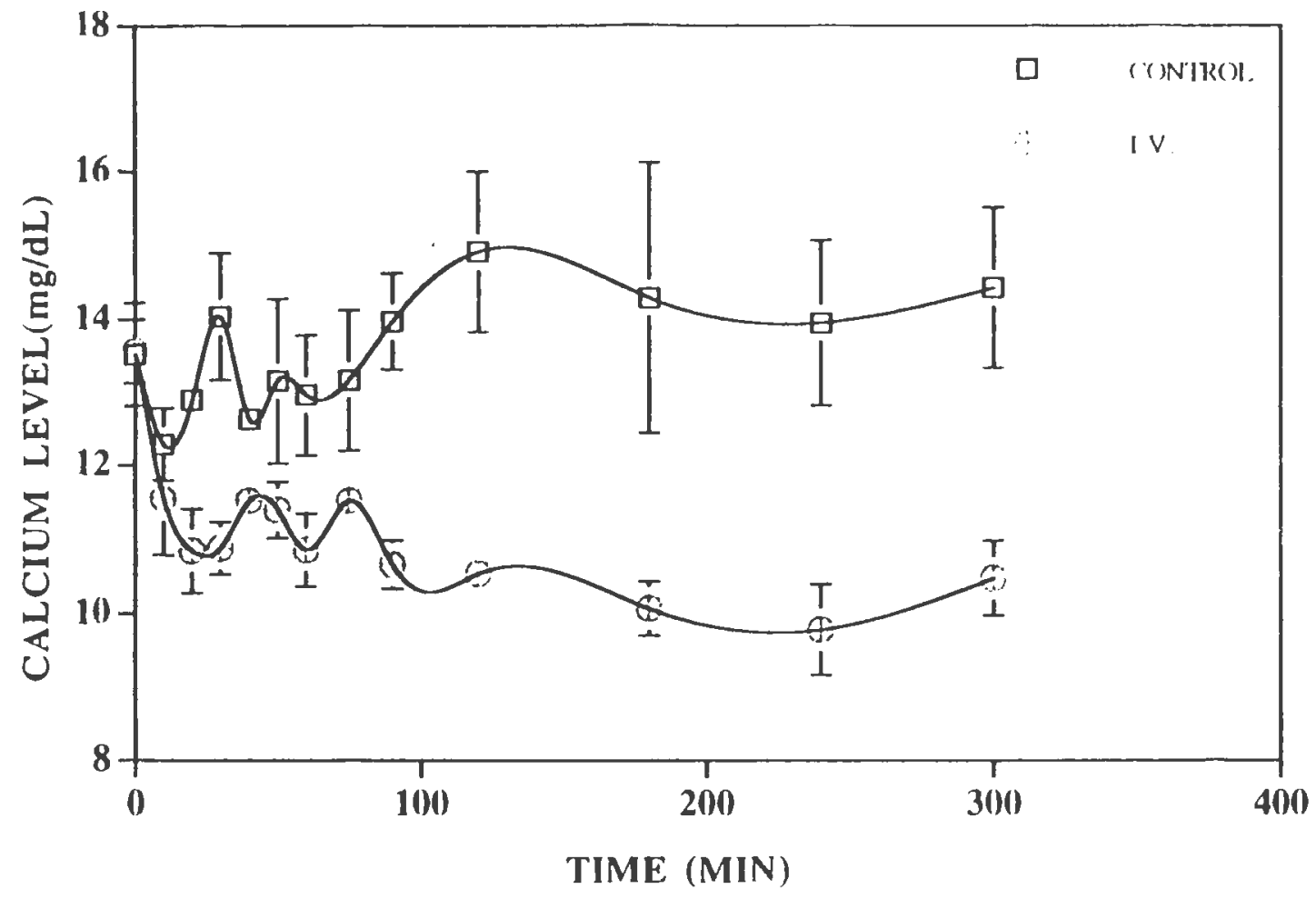




\section{(B) Intranasal administration}

\section{Effect of tonicity with varying viscosity}

\section{Influence of isotonicity}

To determine the effect of toricity on the absorption of salmon calcitonin, the base formulations containing a dose of $2000 \mathrm{IU}$ salmon calcitonin in a isotonic $0.03 \mathrm{M}$ acetate buffer at a pH 4 with a viscosity of $1 \mathrm{cps}$ were administered to the rabbits. The AUC, Cmax, Tmax and bioavailability of all the formulations differing in tonicity are summarized in table I. The AUC of isotonic formulations at a viscosity of $1 \mathrm{cps}$ was $714.2 \pm 15.7 \mathrm{ng} \cdot \mathrm{min} / \mathrm{ml}$ with a bioavailability of 0.16 . The Cmax obtained by the formulations was $10 \pm 4.2$ $\mathrm{ng} / \mathrm{ml}$ at a Tmax of 40 minutes.

In contrast higher viscosity (76 cps) isotonic $(300 \mathrm{mOsm})$ formulations were prepared with $1 \%$ methylcellulose at pH 4 containing 2000 IU salmon calcitonin in $200 \mu \mathrm{l}$ sprayed into the nasal cavity of rabbits elicited a Cmax of $12 \pm 9.7 \mathrm{ng} / \mathrm{ml}$ at a Tmax of $58 \pm 8.3$ minutes as shown in figure 3 . The AUC for the higher viscosity isotonic formulations was $604.6 \pm 97.74 \mathrm{ng} \cdot \mathrm{min} / \mathrm{ml}$ with a bioavailability of 0.14 . There was no significant difference in the low and high viscosity formulations at isotonic conditions.

The bioavailability obtained by the intranasal administration of salmon calcitonin for low and high viscosity isotonic formulations was extremely low and is typical of higher molecular weight polypeptides as shown by previous investigators 11 . 
FIGURE 3 THE INFLUENCE OF VISCOSITY ON THE INTRANASAL ABSORPTION OF SALMON CALCITONIN IN ISOTONIC SOLUTIONS

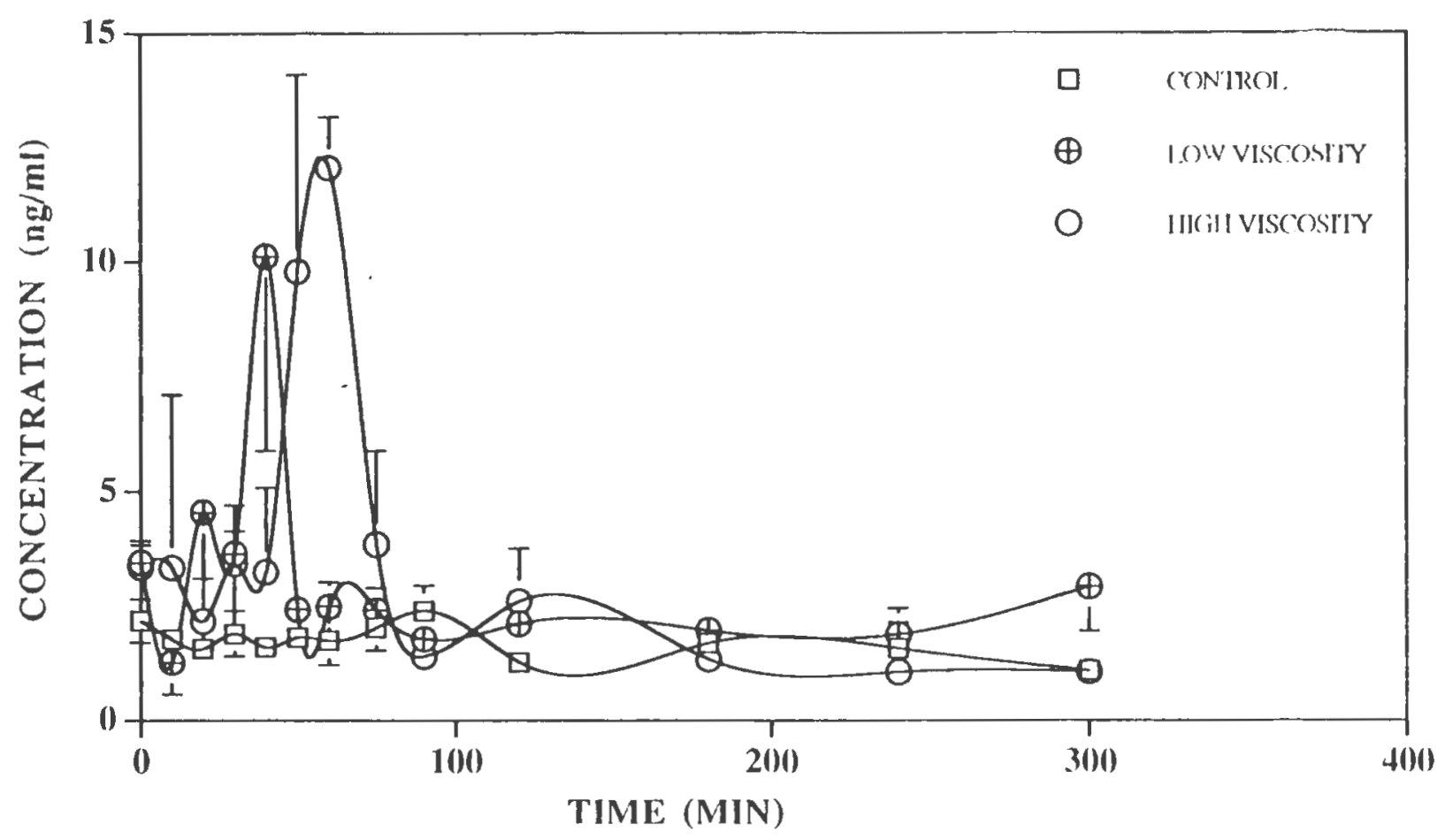




\section{Influence of hypertonicity}

The low viscosity hypertonic $(600 \mathrm{mOsm})$ formulations sprayed intranasally showed a $C_{\max }$ of $42 \pm 19.6 \mathrm{ng} / \mathrm{ml}$ at $T_{\max }$ of $90 \pm 12$ minutes as shown in figure 4 , as compared to a $\mathrm{C}_{\max }$ of $10 \pm 4.2 \mathrm{ng} / \mathrm{ml}$ at a Tmax of 40 minutes for low viscosity isotonic ( 300 mOsm) formulations. Thus deviation from isotonicity elicited a higher concentration of $\mathrm{SCT}$ in the serum at a low viscosity of $1 \mathrm{cps}$. The AUC calculated for low viscosity hypertonic salmon

calcitonin formulations was $3508 \pm 1280 \mathrm{ng} \cdot \mathrm{min} / \mathrm{ml}$ with a bioavailability of 0.80. The bioavailability obtained was about five times higher than that obtained for low viscosity isotonic formulations.

The higher viscosity (76 cps) hypertonic $(600 \mathrm{mOsm})$ formulations prepared with $1 \%$ methylcellulose and sprayed into the nasal cavity of rabbits elicited a $\mathrm{C}_{\max }$ of $32 \pm 19.6 \mathrm{ng} / \mathrm{ml}$ at $\mathrm{T}_{\max }$ at $90 \pm 12$ minutes as shown in figure 4 . The area under the curve was $2183 \pm 258 \mathrm{ng} \cdot \mathrm{min} / \mathrm{ml}$ with a bioavailability of 0.62 . Thus deviation from isotonicity at a higher viscosity also demonstrated an increased level of salmon calcitonin in the serum. The bioavailability obtained by high viscosity hypertonic salmon calcitonin formulations was significantly different from high viscosity isotonic formulations as determined at $\mathrm{p}<0.05$

\section{Influence of hypotonicity}

The low viscosity (1cps) hypotonic $(100 \mathrm{mOsm})$ formulations in an acetate buffer at $\mathrm{pH} 4$ when sprayed into the nasal cavity of rabbits produced a $\mathrm{C}_{\max }$ of $26 \pm 7.6 \mathrm{ng} / \mathrm{ml}$ at $\mathrm{T}_{\max }$ of $38 \pm 9.16$ minutes as shown in figure 5 . The AUC obtained was $3171.33 \pm 258 \mathrm{ng} \cdot \mathrm{min} / \mathrm{ml}$ with a bioavailability of 0.71 . The AUC obtained for low viscosity hypotonic formulations was almost of the same 
FIGURE 4 TIIE INFLUENCE OF VISCOSITY ON TIIL INTRANASAL AIBSORPTION OF SALMON CALCITONIN IN HYPERTONIC SOLUTIONS

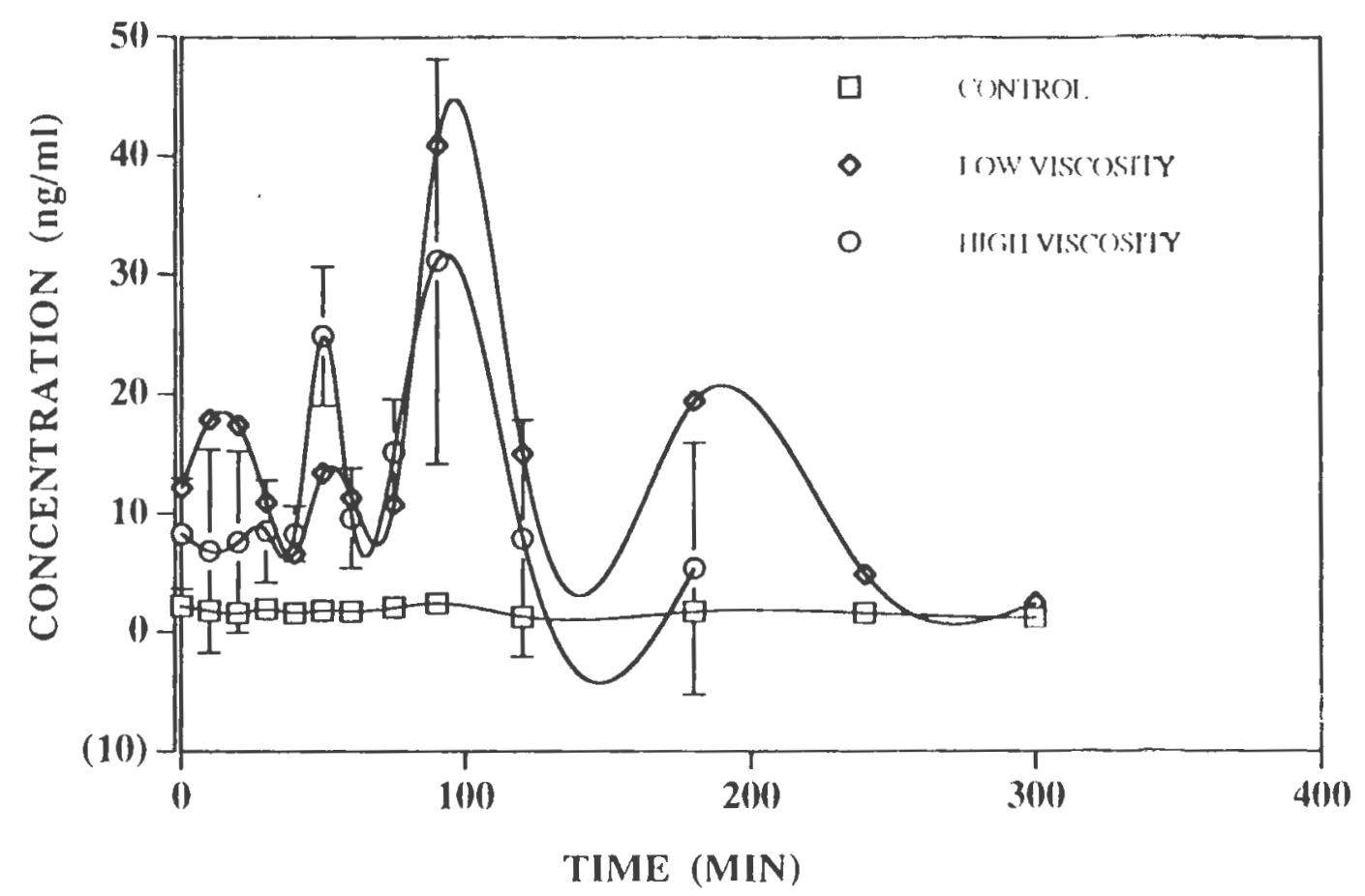


FIGURE 5 TIIE INFLUENCE OF VISCOSITY ON TIIE INTRANASAL ABSORPTION OF SALMON CALCITONIN FOR IIYPOTONIC SOIUTIONS

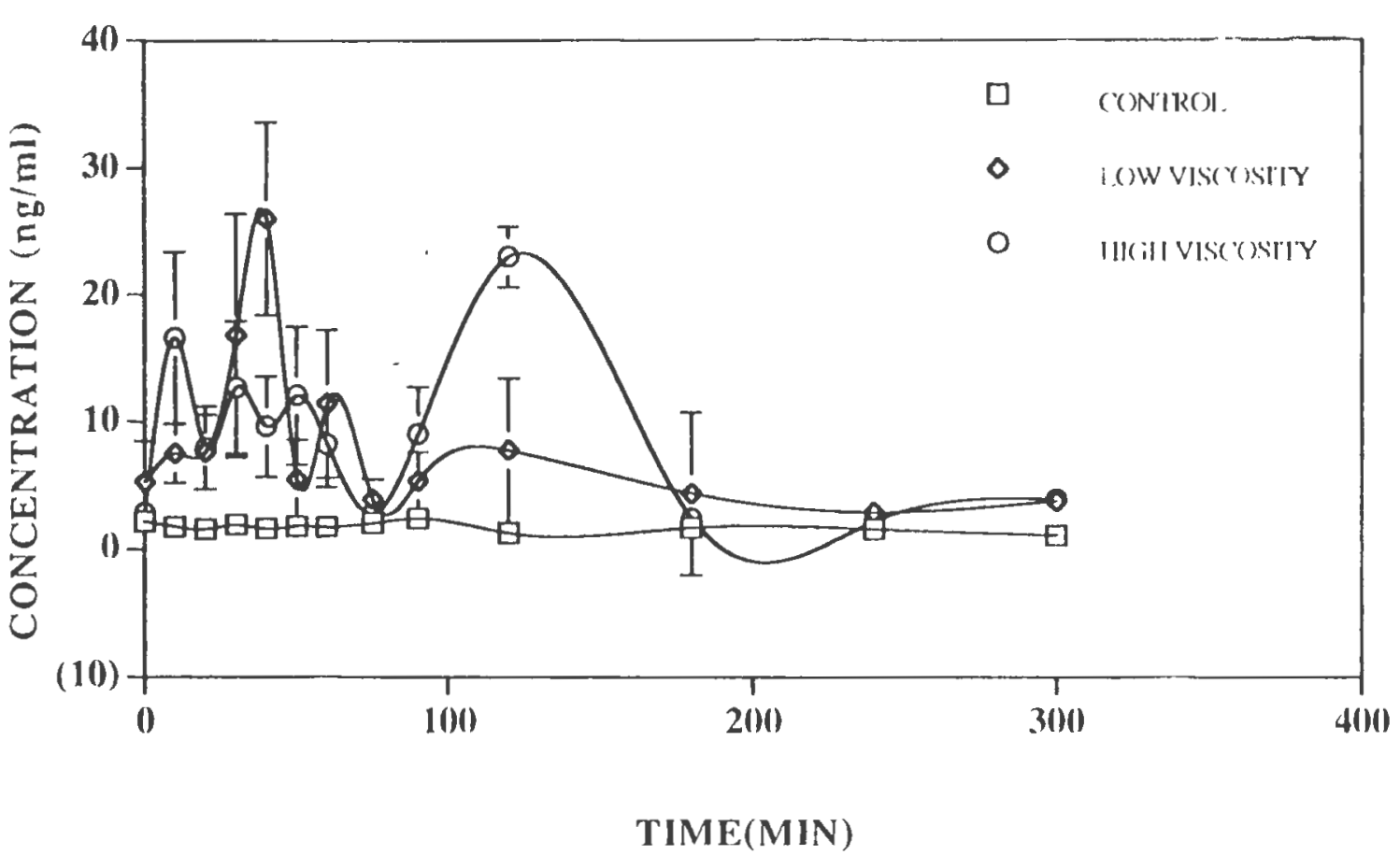


magnitude as low viscosity hypertonic formulations and was significantly different from low viscosity isotonic formulations at $\mathrm{p}<0.05$.

The hugher : iscosity hypotonic $(100 \mathrm{mOsm})$ formulations prepared with $1 \%$ methylcellulose at a $\mathrm{pH}$ of 4 when sprayed into the nasal cavity of rabbits produced a $C_{\max }$ of $2.3 \pm 2.4 \mathrm{ng} / \mathrm{ml}$ at $T \max$ of $120 \pm 18$ minutes respectively. The AUC calculated was $3579 \pm 1030 \mathrm{ng} / \mathrm{ml}$ with a bioavailability of 0.81 . Even at high viscosity, a deviation from isotonicity produced an increase in the bioavailability.

Thus, it can be seen that absorption of hypertonic and hypotonic formulations was significantly different from isotonic formulations at both low and high viscosity and bioavailability of the drug was enhanced in both the hypotonic and hypertonic conditions by approximately $4-5$ fold.

There have been very few experiments performed to study the effect of tonicity, but the information generated from these studies indicates that deviation from the tonicity influences the absorption and this could be explained by the fact that the hypertonic solutions cause shrinkage of the cells and hypotonic solutions cause swelling of the epithelial cells as a result of increased water uptake which could alter the pore size within the cell junctions and the permeability of the cell walls thus leading to enhanced absorption 43 .

\section{Influence of viscosity}

It can be seen from the literature that low and high viscosity (1-11 cps) formulations when administered using a metered nasal spray pump that the 
ability of this pump to produce a fine uniform spray is limited for high viscosity formulations. Therefore, in this study a metered dose spray pump based on a ball and spring mechanism was used to spray low viscosity (1cps) formulations and a nasal micron spray pump (NMSP) designed with a air blast spray nozzle was used to spray higher viscosity $(76 \mathrm{cps})$ formulations. The droplet size distribution generated by both the devices had been previously measured using a Malvern sizer and categorized as $\mathbf{M}_{\mathbf{5 0}}$ which is the droplet size of $50 \%$ of the droplets sprayed 33 .

The average $\mathbf{M}_{50}$ droplet size for formulations with a viscosity of $1 \mathrm{cps}$ was $45 \pm 1.11 \mu \mathrm{m}$ and the droplet size $\mathrm{M}_{50}$ of formulations of viscosity, $76 \mathrm{cps}$ was $112.48 \pm 27.6 \mu \mathrm{m}$ when sprayed using a metered dose spray pump 33 . The M50 generated by the NMSP was $53.27 \pm 3.38 \mu \mathrm{m}$ for the $1 \mathrm{cps}$ and $112.45 \pm 27.6 \mu \mathrm{m}$ for the $76 \mathrm{cps}$ formulations. The M50 generated by two nasal delivery devices for the formulations differing in viscosity by $76 \mathrm{cps}$ was approximately different by 2.5 fold ( $45 \mu \mathrm{m}$ vs $112.45 \mu \mathrm{m}$ ). Thus nasal micron spray pump was very successful in lowering the average droplet size as well as reducing the range of the droplet size distribution. Interestingly, the distribution produced by metered nasal spray pump for 1 cps viscosity was Gaussian and unimodal while that produced by NMSP deviated slightly from Gaussian behavior and was bimodal 33 .

The Tmax produced by the low viscosity isotonic and hypertonic formulations was 40 and 38 minutes respectively as compared to that for the higher viscosity isotonic and hypertonic formulations of 58 and 120 minutes which agrees with literature that postulates that a higher droplet size leads to a more localized deposition and causes a slower clearance from the nose $\mathbf{3 2}^{\mathbf{2}}$. 
However for the hypertonic formulations, the Tmax for both low viscosity and high viscosity formulations was 90 minutes. A possible explanation may be that the Tmax is not only a measure of higher viscosity but also is affected by the other excipients of the formulation, especially the tonicity adjusting agent, sodium chloride which could change the time required to achieve the maximum concentration by altering the physiological and pharmacological response generated by the formulation in the surrounding enviornment.

There was a decrease in the absorption of $\mathrm{SCT}$ from higher viscosity isotonic and hypertonic formulations. Similiar results have been reported by Harris, 198932 who used methylcellulose as a viscosity enhancing agent and demonstrated no improvement in the bioavailability of the drug and actually reported a decrease in absorption possibly due to the delayed diffusion of drug from the formulation because of the higher viscosity. Variation in the viscosity did not show any significant difference in the absorption of $\mathrm{sCT}$.

\section{Pharmacodynamic effects .}

\section{Effect of tonicity with varying viscosity}

\section{Influence of Isotoncity}

The pharmacodynamic effect of $\mathrm{SCT}$ of the lowering of calcium for all the formulations varying in tonicity as a function of viscosity were calculated and are summarized in table II and shown in figures 6-8. The AUC for isotonic formulations at low viscosity was found to be $3724.12 \pm 120.99 \mathrm{mg} \cdot \mathrm{min} / \mathrm{dL}$ as compared to $4045 \pm 255.17 \mathrm{mg}$. min/dL for the control group and $2732 \pm 271.39$ mg.min/dL for i.v administration. Isotonic low viscosity formulations 
FIGURE 6 THE INFLUENCE OF VISCOSITY ON THE CALCIUM LEVEL AFTER INTRANASAL ADMINISTRATION OF ISOTONIC SALMON CALCITONIN SOLUTIONS

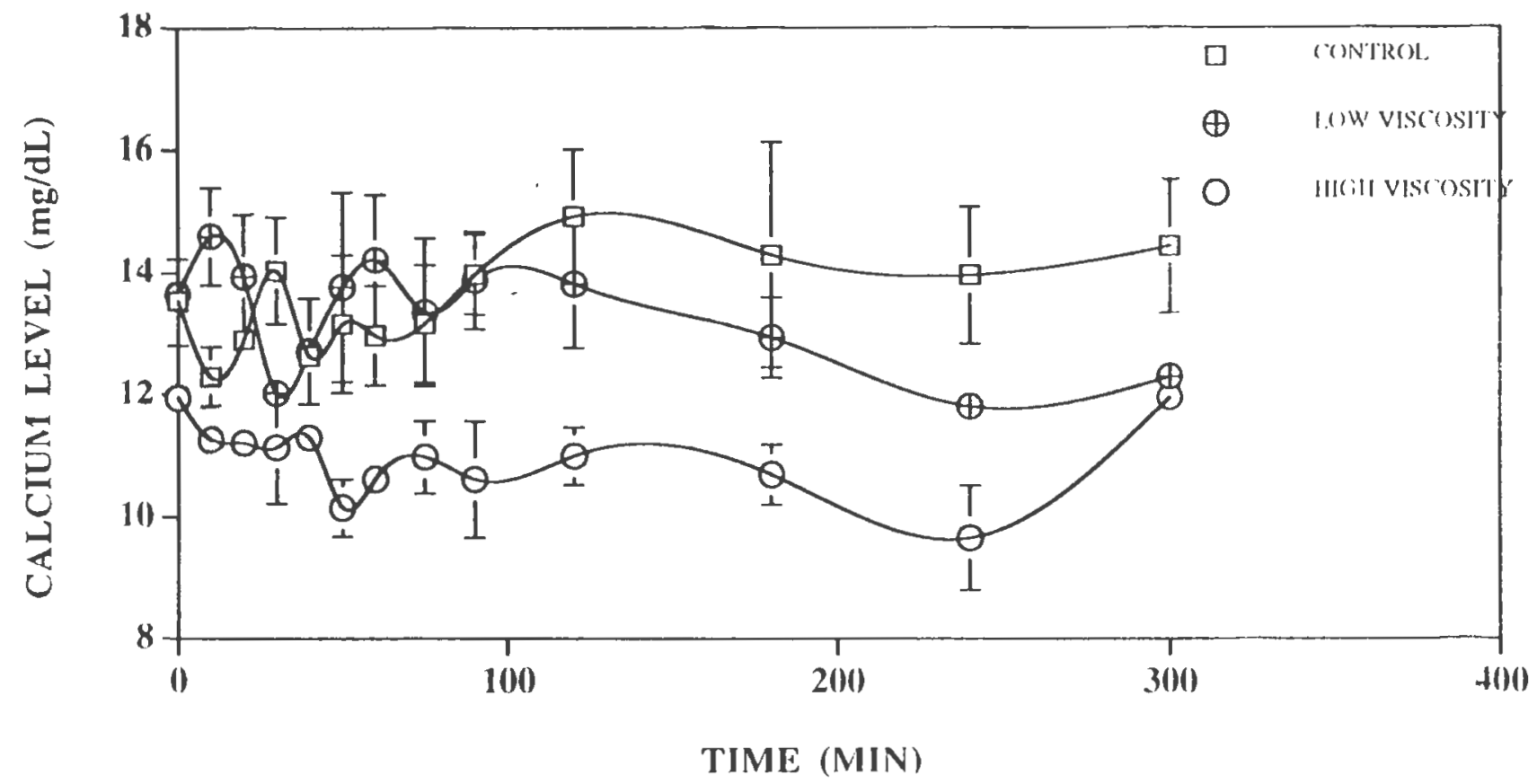


sprayed intranasally were able to produce a reduction in calcium activity (D\%) of $7.9 \%$ and a maximum reduction, $\left(\% \max _{\mathrm{d}}\right)$, of 12.96 at a Tmax of 240 minutes. However the low viscosity isotonir formulations were not able to produce a significant difference as compared to the control group at $\mathrm{p}<0.05$.

The AUC for the high viscosity isotonic formulations was $3242.83 \pm 21.66$ $\mathrm{mg} \cdot \mathrm{min} / \mathrm{dL}$ and produced a total reduction in activity of $19 \%$ and a maximum reduction of 28.81 at a Tmax of 240 minutes. There was an initial maximal decrease at 60 minutes and the level of calcium started rising from 60 minutes until 90 minutes and again there was a gradual decrease until 240 minutes. The maximal percent decrease for the low and high viscosity isotonic formulations was obtained at 240 minutes as seen in figure 6.The high viscosity isotonic formulations generated a significant difference as compared to the control and low viscosity isotonic formulations. This may be due to the slower clearance that is postulated for higher viscosity formulations have longer contact with the mucosal membrane. The calcium lowering effect for high viscosity isotonic formulations was significantly different from low viscosity isotonic formulations and control group.

\section{Influence of hypertonicity}

The AUC for the low viscosity hypertonic formulations was $3267.74 \pm 31.31$ mg.min/dL as compared $4045 \pm 255.17 \mathrm{mg} \cdot \mathrm{min} / \mathrm{dL}$ for the control group. These hypertonic formulations at low viscosity when sprayed intranasally were able to produce a total reduction in calcium activity $(\mathrm{D} \%)$ of $19 \%$ and a maximum reduction, $\% \max _{d}$, of 28.83 at a $\mathrm{T}_{\max }$ of 75 minutes. The total calcium lowering effect of low viscosity hypertonic formulations was almost 2.5 times 
FIGURE 7 THE INFLUENCE OF VISCOSITY ON THE

CALCIUM LEVEL AFTER INTRANASAL ADMINISTRATION

OF SALMON CALCITONIN IIYPERTONIC. SOLU'TIONS

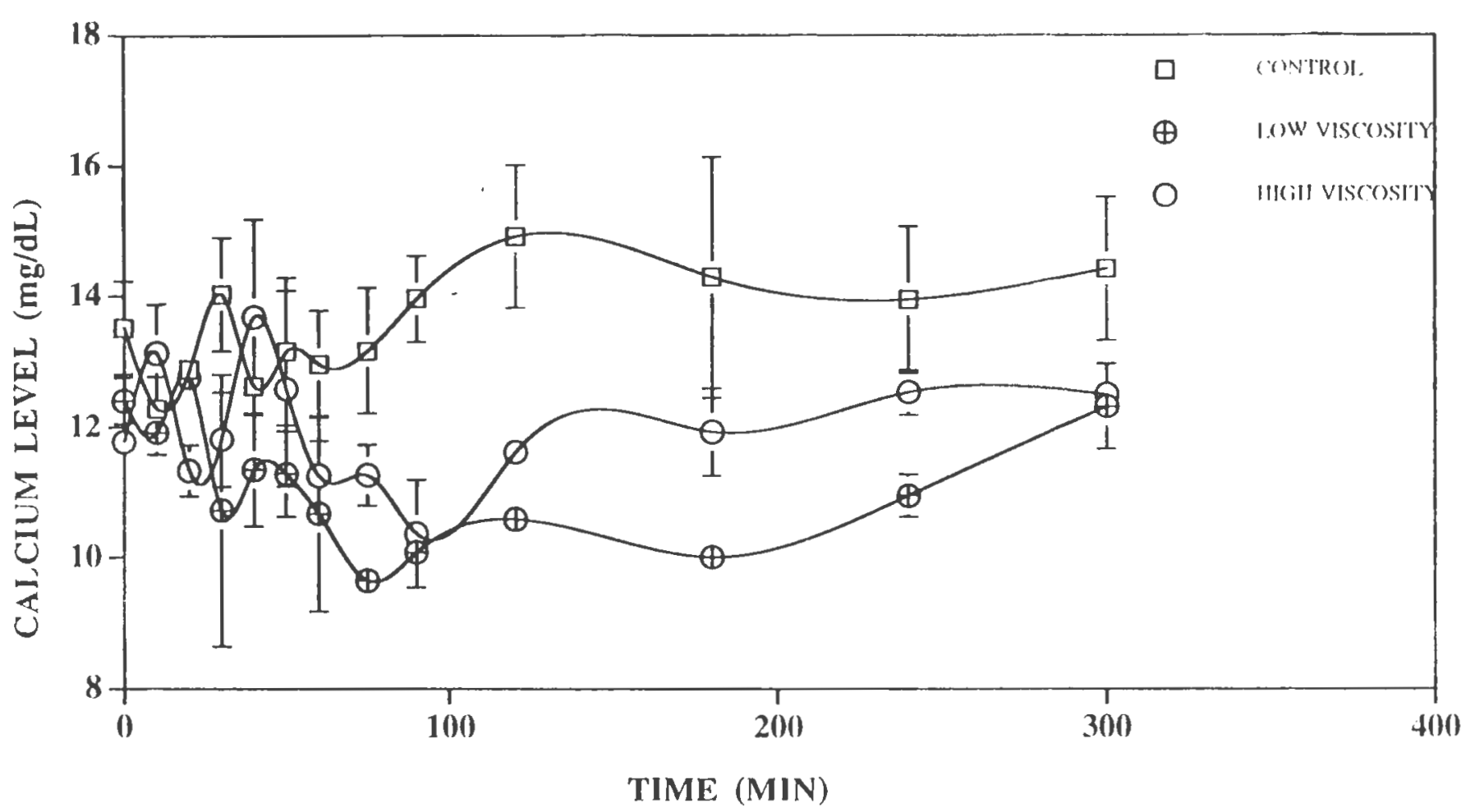


more than low viscosity isotonic formulations and was also significantly different from control group.

The AUC for high viscosity hypertonic formulations was $3696.28 \pm 53.24$ $\mathrm{mg} \cdot \mathrm{min} / \mathrm{dL}$ and when sprayed intranasally were able to produce a total reduction activity of $9 \%$ and a maximum reduction of 23.52 at a Tmax of 90 minutes. The calcium lowering effect for high viscosity formulations was significantly different from low viscosity formulations and was more comparable to the low viscosity isotonic formulations. The difference in the pattern of low and high viscosity hypertonic formulations on the calcium lowering effect is not known.

\section{Influence of hypotonicity}

The AUC for the low viscosity hypotonic formulations was $3308 \pm 42.45$ mg.min/dL and produced a total reduction in calcium activity of $18 \%$ and a maximum reduction of $28.12 \%$ at a Tmax of 180 minutes as seen in figure 8. . The calcium lowering effect produced by low viscosity hypotonic formulations was comparable to that produced by low viscosity hypertonic formulations and was significantly different from controls.

The AUC for high viscosity hypotonic formulations was $3154.47 \pm 102.49$ $\mathrm{mg} \cdot \mathrm{min} / \mathrm{dL}$ produced a total reduction in activity of $22 \%$ and a maximum reduction of 34.58 at a Tmax of 120 minutes. The calcium lowering effect of the high viscosity hypotonic formulations was also similiar to low viscosity hypotonic formulations and significantly different from the low viscosity isotonic and control formulations. 
FIGURE 8 TIIE INFLUENCE OF VISCOSITY ON TIIE CALCIUM LEVEL AFTER INTRANASAL ADMINISTRATION OF SALMON CALCITONIN IIYPOTONIC SOLUTIONS

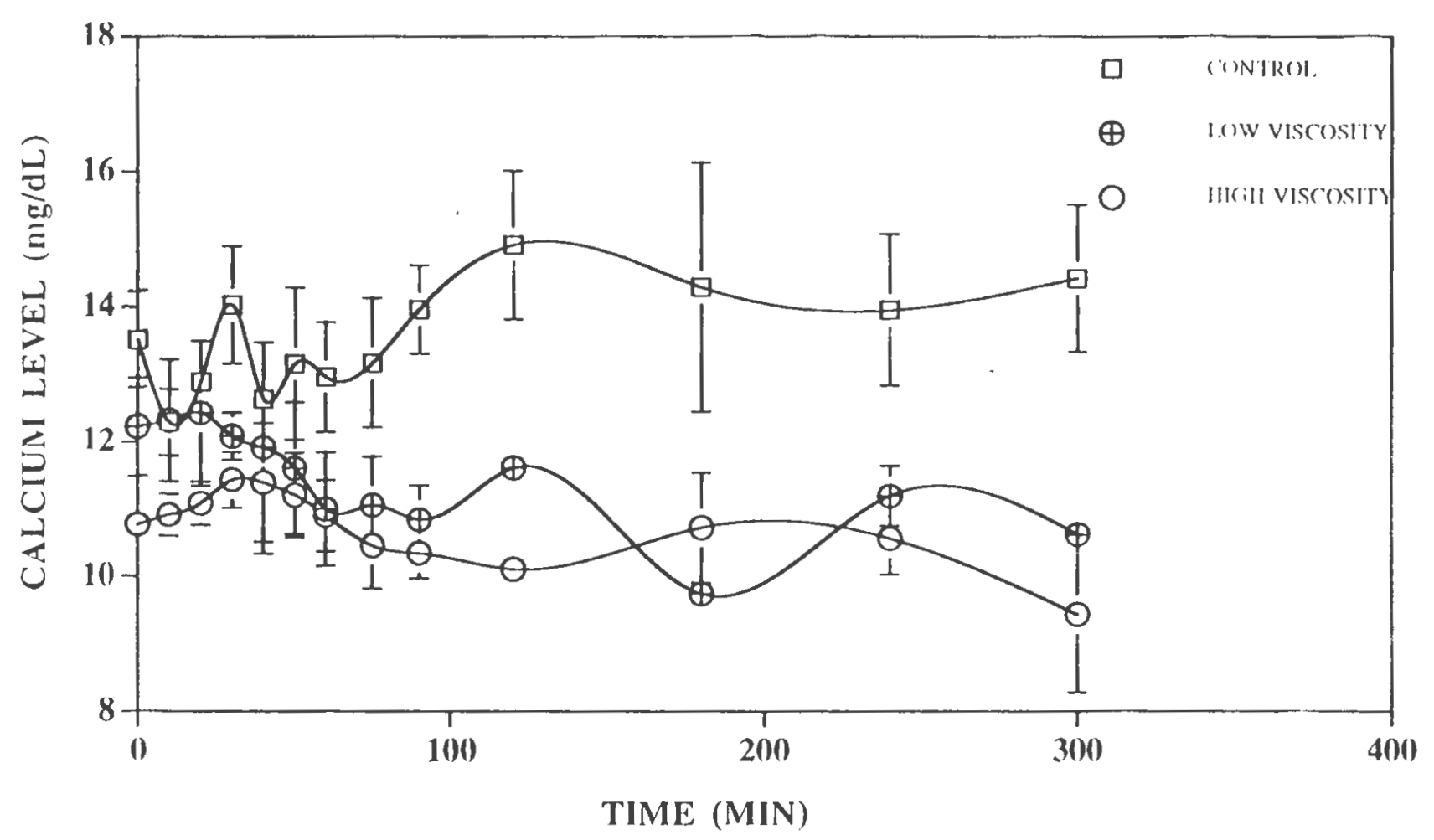


The $\% \max _{\mathrm{d}}$ of $28.83 \%$ produced by low viscosity hypertonic formulations ( 600 mOsm) and $28.12 \%$ produced by low viscosity hypotonic formulations (100 mOsm) was comparable to $\%$ maxd produced by i.v. administration of $28 \%$. However the total reduction in activity ( $D^{\circ}(i)$ for the iv formulations were significantly greater than that seen after nasal administration.

The lowering of calcium for all formulations ranged from 7.9 to $22 \%$ of the basal value in intranasal formulations as compared to $32 \%$ for the iv solutions. The \% maxd intranasal delivery ranged from 12 to $34.5 \%$ as compared to $28 \%$ in iv administration. The similarity of the extent of the hypocalcemic effect observed after administration of different intranasal formulations of SCT may be attributed to the acute homeostatic mechanism between calcitonin and the parathyroid hormone. The parathyroid hormone counteracts the effects of calcitonin once a critical level of hypocalcemia is attained. Thus the extent of the hypocalcemic effect is controlled by the hormonal balance. The acute control of blood calcium is accomplished by the feedback action of calcitonin and the parathyroid hormone. This complex regulation of blood calcium concentration makes it difficult to evaluate the efficacy of sCT delivery systems by observation of the hypocalcemic effect 44 .

Although the measure of pharmacodynamic effects is useful clinically especially in the event of low bioavailability, the results obtained from the various biochemical markers for salmon calcitonin such as lowering in salcium, bone turnover and decrease in the urinary hydroxyproline are difficult to interpret as these parameters are also under hormonal regulation and may or may not differ for healthy subjects and diseased subjects. 
It has been demonstrated that the hypocalcemic effect of intranasal salmon calcitonin is governed by the underlying rate of bone turnover and therefore the effect is minimal in healthy volunteers. That is healthy subjects do not show a significant change in bone turnover while a more pronounced action is observed in subjects with active osteoporosis or Paget's disease 45 .

On the other hand, quantitatively similiar reductions in urinary hydroxyproline excretion were demonstrated, indicating similiar levels of inhibition of osteoclastic bone resorption following intranasal administration of 200 to $400 \mathrm{IU}$ salmon calcitonin in healthy volunteers aged less than 30 years and elderly patients with osteoporosis or Paget's disease $\mathbf{4 6 .}$

Since the hypocalcemic effects of calcitonin are governed by the underlying rate of bone turnover, the pharmacokinetic parameters which relate to the presence of salmon calcitonin in the serum should be a more reliable indicator of the nasal bioavailability of salmon calcition

\section{Optimization of formulations}

Six formulations resulting from using 3 levels of tonicity and 2 levels of viscosity were administered to rabbits. The area under the curve was calculated and analyzed by ANOVA. The results generated from the experimental data suggested that hypertonic and hypotonic formulations were significantly different from isotonic formulations at both low and high viscosity. The results were confirmed using Scheffe's multiple comparison test. Regression was carried out to define the relationship between area under the curve and the independent factors of tonicity and viscosity; and the optimum region was determined by the response surface analysis. 
A saddle point curve (figure 9) was obtained which suggests that there is no maximum or minimum tonicity but that a deviation from the mid point (isotonicity) would favor an increase in the area under the curve and ultimately bioavailability. Viscosity, used as a covariate and plotted along with tonicity and area under the curve demonstrated that there was no influence of viscosity on the area under the curve and subsequently bioavailability. This lack of increasing viscosity effect is shown in figure 9 which indicates a AUC of $8000-10000 \mathrm{ng} \cdot \mathrm{min} / \mathrm{ml}$ for hypotonic formulations through out the viscosity range from 1 to $80 \mathrm{cps}$. There is a decrease in the AUC from 8000 to $2000 \mathrm{ng} \cdot \mathrm{min} / \mathrm{ml}$ as the tonicity increases to $300 \mathrm{mOsm}$. Again the surface shows a increase as the tonicity increases from $300 \mathrm{mOsm}$ to $600 \mathrm{mOsm}$ there is a consistent increase in AUC from 2000-6000 $\mathrm{ng} . \mathrm{min} / \mathrm{ml}$.

In conclusion it is feasible to enhance the absorption of $\mathrm{sCT}$ across the nasal mucosa using proper formulation variables. In spite of low plasma levels and bioavailability, there are clinical data which support the efficacy of intranasal formulations in conditions such as Paget's disease and osteoporosis. Clinical trials have consistently reported an excellent tolerability and acceptability of intranasal formulations $\mathbf{1 1}$.

However further investigations are required for the evaluation of the toxicological effects of tonicity on the integrity of nasal mucosa, the chronic use of these formulations when administered intranasally may have the potential of damaging either the mucociliary system or the underlying epithelium. 
FIGURE 9 THREE DIMENSIONAL SURFACE PLOT OF TONICITY AND VISCOSITY VERSUS AREA UNDER THE CURVE

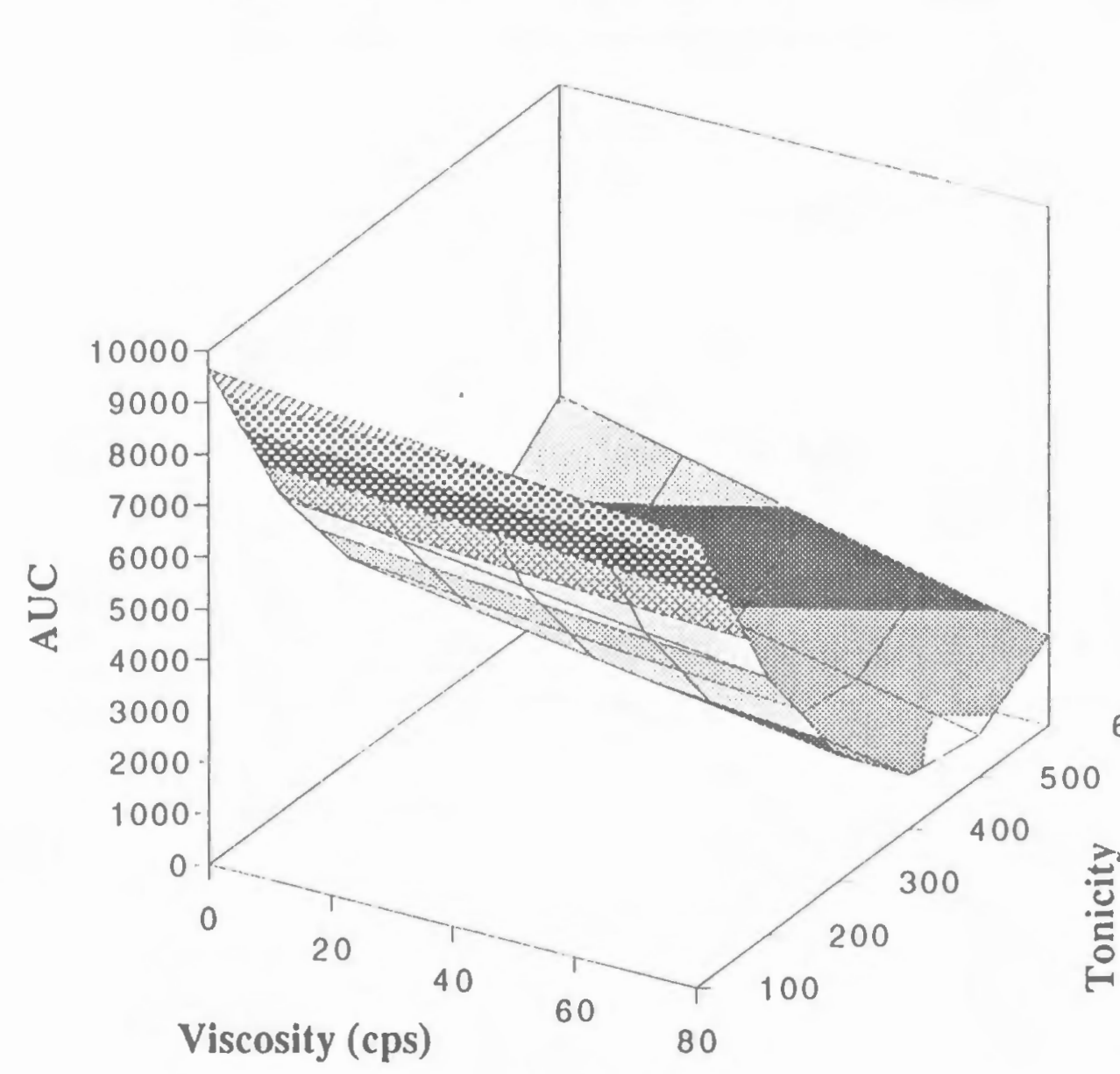

AREA UNDER CURVE A UC (ng.min/ml) 约 9000-10000 郗 8000-9000

$7000-8000$ 6000-7000

[ $5000-6000$

17000-5000

1.1 $3000-4000$

2000-3000

1000-2000

[.] $0-1000$

Viscosity (cps) 
In summary, the development and use of salmon calcitonin nasal spray holds a lot of promise for the future treatment and management of metabolic bone disorders. 


\section{REFERENCES}

1. Lee, V. H. L., Peptide and Protein Drug Delivery Systems., Pharm. Res., 1 (3) (1988) 24-31.

2. Muller, K., Osler, M., Induction of labor, a comparison of intravenous, intranasal and transbuccal oxytocin, Acta Obstet. Gynecol. Scand., 46 (1967) 59-67.

3. Moses, A. M., Synthetic lysine vasopressin nasal spray in the treatment of diabetes insipidus, Lancet, 1 (1964) 422.

4. London, D. L., Butt, W. R., Lynch, S. S., Marshall, J. C., Robinson, W. R., and Stephanson, J. M., Hormonal response to intranasal luteinizing hormone releasing hormone, J. Clin. Endocrinol. Metab., 37 (1973) 829831.

5. Nagai, T., Nishimoto, Y., Nambu, N., Suzuki, Y. and Sekine, K., Powder dosage forms of Insulin for nasal administration. Jour. Cont. Rel, 1(1984) 15-22.

6. Illum, L., Farraj, N. F., Critchley, H., Johansen, B. R., and Davis, S. S., Enhanced nasal absorption of insulin in rats using lysophosphatidylcholine., Int. J. Pharm, 57 (1989) 49-54. 
7. Longnecker, J. P., Moses, A. C., Flier, J. S., Silver, R. D., Carey, M. C., Dubov, E. J., Effects of sodium taurodihydrofusidate on nasal absorption of insulin in sheep., J. Pharm. Sci., 76(5) (1987) 351- 355.

8. Su, K. S. E., Campanale, K. M., Mendelsohn, L. G., Kerchner, G. A., and Gries, C. L. Nasal delivery of polypeptides. I Nasal absorption of enkephalins in rats, J. Pharm. 74 (1985) 394-398.

9. Pontiroli, A. E., Perfetti, M.G., Fattor, B., Pozza, G., Effect of intranasal growth hormone releasing hormone and corticotrophic- releasing hormone administration improved bioavailabilty by means of sodiumglycoholate. J. Clin. Endocrinol. Meta., 68 (1989b) 821-824.

10. Evans, W. S., Borges, J. L. C., Kaiser, D. L., Vance, M. L., Seller, R. P., Macleod, R. M., Vale, W., Rivier, J. and Thorner, M. O., Intranasal administration of human pancreatic tumor GH-releasing factor-40 stimulates GH release in normal men, J. Clin. Endocrinol. Metab., 57 (1983) 1081-1084

11. Lee, W.A., Ennis, R.D., Longnecker, J.P., and Bengtsson, P., The bioavailability of intranasal salmon calcitonin in healthy volunteers with and without a permeation enhancer. Pharm. Res., 11(5) 1994.

12. Balin, B. J., Broadwell, R. D., Salcman, M., and El- Kakkiny, M. Avenues for entry of peripherally administered protein to the central nervous system in mouse, rat and squirrel monkey, J. Comp. Neurol. 251 (1986) 260. 
13. Hussain, A. A., Kimura, R., and Huang, C. H., Nasal absorption of testosterone in rats, J. Pharm. Sci., 73 (1984) 1300.

14. Hussain, A. A., Hirai, $S$ and Bawarshi, R., Nasal absorption of natural contraceptives steroids in rats- Progesterone absorption, J. Pharm. Sci., 70 (1981) 466.

15. Juhasz, J., Lenaerts, V., and Ong, H., Poloxamer gels for peptide deliveryin vitro studies, J. Controlled Release, 13 (1990) 322.

16. Keenan, J., and Chamberlain, M. A. Nasal mucosal absorption of tetracosactrin as indicated by rise in plasma flurogenic corticosteroids, $\mathrm{Br}$. Med. J., 4 (1969) 407.

17. Illum, L., Microspheres as a potential controlled release nasal drug delivery systems in Delivery systems for peptide drugs, Davis, S. S., Illum, L., and Tomlinson, E., Plenum Press, New York, (1980) pp. 205210.

18. Su, K. S. E., Howey, D. C., Campanale, K. M., and Oeswein, J. Q., Intranasal admininstration of human sodium insulin in rats, dogs and humans: Absorption and possible mechanisms, Diabetes, 35 (1986) A 64.

19. Salzman, R., Manson, J. E., Griffing, G. T., Kimmerle, R., Ruderman, N., et al., Intranasal aerosolizedd insulin, mixed meal studies and long term use in type I diabetes, New England Journal of Medicine, 312 (1985) 10781084 . 
20. Su, K. D. E.., Oeswein, J. Q., and Campanale, K. M., Intranasal administration of human zinc insulin in rats:Absorption and possible mechanisms, A. PhA Acad. Pharm. Sci., 15 (1985) 89.

21. Vance, M. L., Evans, W. S., Kaiser, D. L., Burke, R. L., Rivier, J. et al., The effect of intravenous subcutaneous, and intranasal GH-RH analog on growth hormone secretiion in normal men: dose response relationship. Clin. Pharmacol. Ther., 40 (1986) 627-633.

22. Evans, W. S., Borges, J. L. C., Kaiser, D. L., Vance, M. L., Seller, R. P., Macleod, R. M., Vale, W., Rivier, J., and Thorner, M. O., Intranasal administration of human pancreatic tumor GH release in normal men, J. Clin. Endocrinol. Metab., 57 (1983) 1081.

23. Hendricks, C., and Gabel, R. A. Use of intranasal oxytocin in obstetrics I. Laboratory evaluation, Am. J. Obstet. Gynecol., 79 (1960) 780.

24. Grossman, A., Fabbri, A., Goldberg, P. L. and Nesser, G. M., Two new modes of desmopressin administration, Br. Med. J., 280 (1980) 1215.

25. Hussain, A. A., Hirai, S., Kashihara, T., Batenhorst, R., et al., Nasal Absorption of propranolol in humans. J. Pharm. Sci., 69 (1989) 1240.

26. Hardy, J. G., Lee, S. W., Wilson, C. G., Intranasal drug delivery by spray and drops., J. Pharm. Pharmacol., 37 (1985) 294-297. 
27. Clissod, S. P., Fitton, A., Chrisp, Paul., Intranasal salmon calcitonin- A review of its pharmacological properties and potential utilities in metabolic bone disorders associated with aging, Drugs and Aging, 1 (5) (1991) 405-423.

28. Kurose, H., Seino, Y., Shima, M., Tanaka, H., Ishiiida, M., et al, Intranasal absorption of salmon calcitonin, Calcified Tissue Intl., 41 (1987) 249-251.

29. Hanson, M., Gazdick, G., Cahill, J., Augustine, M., Intranasal delivery of the peptide, salmon calcitonin, In Davis et al, (Eds.,) Delivery systems for peptide drugs., Plenum Press, New York, (1986) pp. 232-242,

30. Chien, Y. W., Su., K. S. E., Chang, S., (Eds.,) Nasal Systemic Drug Delivery, Physicochemical, Biopharmaceutical and Toxicophysiological Considerations., Marcel Dekker, Inc., NY., (1989) pp 49.

31. Harris, A.S., Svensson; E., Lethagen, S., and Nilsson, Effect of viscosity on Particle Size, Deposition and Clearance of Nasal Delivery Systems Containing Desmopressin., J.Pharm. Sci., 77(5) (1988) 405-408.

32. Pennington, A.K., Ratcliffe, J. H., Wilson, C.G., and Hardy, J. G., The Influence of solution viscosity on nasal spray deposition and clearance., Int. J. Pharm., 43 (1988) 221-224.

33. Dua, R, Zia, H., Needham, T., Evaluation of formulation and device variables on nasal spray characteristics, Manuscript in Preparation. 
34. Saikiya, Y., Miyauchi., Y., Tsuemura, Y. Influence of osmotic Pressure and Viscosity on intestinal Drug Absorption. II Quinine Concentration profile in plasma after oral administration of variousQuinine solutions to Rats. Chem., Pharm., Bull. 29 (1981) 1470-1472

35. Morvola, M., Reinikaine, A., Heliovaara, M., Huikari, A. J., The effects of some sweetening agents and osmotic pressure on the intestinal absorption of sulfafurazole in the rat. Journ. Pharm. Pharmacol. 31 (1979) 615.

36. Ohwaki, T., Ando, H., Watanabe, S., and Miyake, Y., Effects of dose, pH, and osmolarity on nasal absorption of secretin in Rats. J. Pharm. Sci. 74 (1985) 550-552.

37. Harris, A.S., Ohlin, M., Svensson, E., Lethagen, S. and Nilsson, I. M., Effects of concentration and volume on nasal bioavailability and biological response to Desmopressin, J. Pharm. Sci., 77( 4) (1988) 337-339.

38. Harris, A.S., Ohlin, M., Svensson, E., Lethagen, S. and Nilsson, I. M., Effect of viscosity on the pharmacokinetics and biological response to intranasal desmopressin., J. Pharm. Sci., 77(5) (1988) 405-408.

39. Jager-Waldau, R., A Two Phase Flow Mechanical spray pump: A possible alternative to propellant driven MDI's. Journal of Biopharm. Sci. 3(1/2) (1992) 77-84. 
40. Gizurason, S., Animal models for intranasal drug delivery studies., Acta Pharm Nord., 2(2) (1990) 106-122.

41. Hirai, S., Yashiki, T., Mima, H., Effect of surfactants on the nasal absorption on insulin on rats., J. Pharm., 9 (1981) 165-172.

42. SAS/STAT User's guide, Vol 2., GLM-VAR COMP, Version 6, 4th Edition, SAS Institute Inc., Cary, NC 27512, pp. 1457-1478.

43. Pujara, C. P., Shao, Z., Duncan, M. R., and Mitra, A. K., Effects of formulation variables on nasal epithelial cell integrity: Biochemical evaluations. Int. J. Pharm. 114 (1995) 197-203.`

44. Mohamadi, M., Becker, K. L., and Bivins, L. E.., Paradoxical Effects of Salmon Calcitonin on serum calcium: Studies on intact and Thyroparathroidectomized men and dogs, Acta Endocrinologica., 79 (1975) 700-708.

45. Milhaud, G., Tsieng-Ming, Nesralla, H., Moukhtar, M.S., Perault-Staub, A. M., Studies on the mode of action and the therapeutic use of thyrocalcitonin in Taylor, S. F., (Eds.) Calcitonin, Heinemann, London(1967) p. 347.

46. Christiansen, C., Christiensen, M.S. Larsen, N.E., Transbol, I. B., Pathophysiological mechanisms of estrogen effect on bone metabolism. Dose-response relationships in early postmenopausal women. Journ. Clin. Endocrinol. Metab., 55(1982) 1124-1130. 


\section{MANUSCRIPT III \\ THE INFLUENCE OF DIMYRISTOYLPHOSPHATIDYLGLYCEROL ON THE NASAL ABSORPTION OF SALMON CALCITONIN}




\section{ABSTRACT}

The objective of this investigation was to study the effect of the phospholipid, dimyristoylphosphatidylglycerol (DMPG) on the intranasal absorption of polypeptide, salmon calcitonin ( $\mathrm{SCT}$ ). DMPG was included as an absorption enhancer for salmon calcitonin in a $0.03 \mathrm{M}$ acetate buffer at $\mathrm{pH} 4$ in a nasal spray formulation. The absorption of SCT was also studied as a function of $\mathrm{NaCl}$ salt concentration from $0.045-0.3 \mathrm{M}$. Serum calcitonin was determined using a double antibody RIA. The presence of the phospholipid demonstrated a significant difference in the intranasal bioavailability of salmon calcitonin. The results showed DMPG enhanced nasal absorption of SCT by approximately two fold at a salt concentration of $0.045 \mathrm{M}$. However higher salt concentration in the formulations demonstrated a decrease in the absorption enhancing effect of DMPG. The effect of DMPG on the calcium lowering effect of $\mathrm{SCT}$ was also studied. The serum calcium was quantified using arsenazo III complex spectrophotometrically at $650 \mathrm{~nm}$. There was no significant difference in the hypocalcemic activity of $\mathrm{sCT}$ in the presence of DMPG. In addition it was found that increasing viscosity of nasal formulations containing DMPG could not further increase the bioavailability of SCT.

Key Words: Calcitonin, Dimyristoylphosphatidylglycerol, Absorption enhancer, Bioavailability, Viscosity, Salt concentration, Nasal micron spray pump. 


\section{INTRODUCTION}

The mammalian body possesses several mechanisms to restrict the entry of macromolecules including polypeptides and proteins. These include the presence of various epithelia that are poorly absorptive, the presence of significant levels of enzymatic activity at various locations between the point of entry into the systemic circulation and the target site of a peptide or protein, the availability of multiple enzymes to degrade peptides and proteins at a given location, and varying levels of immunoglobulins to neutralize peptides and proteins both before and after they are absorbed. The inevitable outcome is that the bioavailability of peptides and proteins is likely to be much less than that for a small molecule.

To improve and optimize absorption of peptide and proteins, certain approaches and strategies have been used and these include, the use of penetration enhancers to alter membrane permeability, coadministration of inhibitors to restrain the activity of proteolytic enzymes primarily at the absorption site, and the use of analogs that are metabolically stable and which in turn may be more bioavailable.

Among the strategies mentioned, the formulation of macromolecules with enhancer seems to be a realistic and viable alternative and has been a subject of many investigations. Penetration enhancers are compounds, generally of low molecular weight, that facilitate the absorption of solutes across biological membranes. With few exceptions and regardless of the nonparenteral route of administration, penetration enhancers are required for the absorption of peptides and proteins in pharmacologically active quantities. 
Most of the penetration enhancers chosen for mucosal delivery have belonged to one of the four major classes. They are: chelators such as EDTA, citric acid, salicylates, $\mathrm{N}$-acyl derivatives of collagen, and enamine( $\mathrm{N}$-amino acyl derivatives of $B$-diketones); surfactants such as sodium lauryl sulfate, polyoxyethylene-9-lauryl ether, polyoxyethylene-20-cetyl ether; bile salts such as sodium deoxycholate, sodium glycocholate, and sodium taurocholate; and fatty acids such as oleic acid and monolein1.

Numerous absorption enhancers have been described for the use in the nasal route and their efficacy is very evident, although variable, depending on the peptide considered. Some of these absorption promoters include anionic and cationic surfactants ${ }^{2}$, bile salt-fatty acid mixed micelles ${ }^{3}$, fusidic acid derivatives $\mathbf{4 - 6}$, medium chain fatty acid salts 7 , fatty acid derivatives of carnitines $^{8}$, enamine derivatives of amino acids $9-10$, glycerine esters 11 , salicylates $\mathbf{1 2 - 1 3}$ and carboxylic acids $\mathbf{1 4}$.

Different mechanisms of action have been proposed such as alteration in the mucus rheology, reduction in the nasal ciliary beat frequency, enhancement of transcellular transport by affecting membrane lipids and proteins, enhancement of paracellular transport, suppression of proteolytic activity or enhancement of the thermodynamic activity of peptides and proteins. Penetration enhancers improve peptide and protein absorption by one or more of the several mechanisms. Bile salts have been shown to reduce the viscosity of the mucus layer adhering to all mucosal surfaces, thereby facilitating peptide and protein diffusion towards the membrane surface $\mathbf{1 5}$. Chelators 16-19 and to certain extent, polyoxyethylated nonionic surfactants 20 interfere with the ability of calcium ions to maintain the dimension of the 
intercellular space, thereby permitting the paracellular transport of peptides and proteins which otherwise will be excluded from this pathway. Interestingly, most of the penetration enhancers are capable of increasing membrane fluidity either by creating disorder in the phospholipid domain in the membrane, as is the case of salicylates, oleic acid and monolein $21-23$, or by facilitating the leaching of proteins from the membrane, as in the case for surfactants and EDTA.

The efficiency of penetration enhancers depends on several factors, including the nature of peptides, the physicochemical properties of the delivery system as related to peptide and protein release, lipophilicity of the enhancer, the intrinsic ability of the enhancer to perturb membrane permeability, the site of application of enhancer and the animal species used.

Nature of peptide: The intrinsic ability of peptides to cross biological membranes is anticipated to be a complex function of their physicochemical properties. The bioavailability of peptide following nasal administration varies with their primary structure, although the precise relationship between absorption and physicochemical properties is as yet unknown. The coadministration of peptides with $1 \%$ sodium glycocholate elicited an increase in the absorption of a poorly absorbable peptide, namely leuprolide, However it had no effect on the absorption of metkephamid, which is relatively well absorbed peptide. Interestingly even in the presence of adjuvants, the bioavailability of leuprolide and insulin was far from complete $24-26$

Delivery systems: The selection of a delivery system for a peptide and its 
penetration enhancer must take into account the vast difference in physicochemical properties that may exist between these two substances due to the difference in their release rates from the system. For a penetration enhancer to be effective, it must be released either simultaneously with the peptide or shortly before the peptide itself is released. This requirement is supported by the findings of Nishhata et $\mathrm{al}^{27}$ in that the bioavailability of insulin following rectal adminstration in the rat was reduced from $30.2 \%$ to $12.8 \%$ when the release of DL-phenylalanyl ethylacetoacetate, the adjuvant, from the suppository was delayed from 17.5 to 30 minutes prior to the administration of insulin.

Nature of enhancer: A penetration enhancer must be able to penetrate the membrane and at the same time, achieve a high enough comcentration to perturb membrane structure 28 . Hirai et al 29 determined that somewhat lipophilic ester and ether type nonionic surfactants with HLB values of 10-14 appeared to optimize the nasal absorption of insulin in the rat when compared with extremely hydrophilic or lipophilic derivatives. The coadministration of monolein and bile salts has been found to bring about a synergistic effect in enhancing the oral absorption of heparin in the rat persumably due to the facilitation of the membrane penetration of the bile salt by monolein 30 . Inspite of its attractiveness in optimizing the efficiency of adjuvants, the approach of using co-adjuvants that operate by different mechanisms has not been fully explored.

Potency of enhancer: In a series of phenylalanylenamine type enhancers, which act by chealting $\mathrm{Ca}^{2+}$, the extent of hypoglycemia in rabbits following rectal administration of insulin was most pronounced for the most potent 
chelators in that series 31 .

Site of administration: Because the permeability characteristics of each mucosal site vary, the extent of absorption of a peptide differs depending on the site of administration 32 . Polyoxyethylene-9-lauryl ether and sodium glycocholate were far more effective in promoting the nasal absorption of leuprolide rather than vaginal absorption $\mathbf{1 8}$. This was not a surprising finding in light of the fact that the nasal epithelium is comprised of columar cells whereas the vaginal epithelium is comprised of stratified squamous cells 33 .

Animal model: The animal model that reliably mimics peptides and protein absorption in humans, both in the presence and absence of penetration enhancers, has yet to be established. Preliminary evidence suggests that, at least in the case of the nasal absorption of insulin, the extent of enhancement may be a function of the animal model chosen $34-35$.

Since absorption enhancers promote peptide and protein absorption by perturbing membrane integrity, it is inevitable that a varying extent of damage would occur to these mucosal tissues which are in intimate contact with an enhancer. To date only few studies have been undertaken to determine the nature of the potentially exaggerated effects or toxicities caused by the various types of penetration enhancers $36-38$. Overall non-surfactant type enhancers when used on an acute basis appear to cause less severe and more readily reversible morphological changes than their surfactants counterparts. Aside from morphological changes, there is virtually no information on the biochemical changes that may occur locally or the 
systemic toxicity which may result from the absorption of the penetration enhancers themselves and from the absorption of toxins at the mucosal surfaces that otherwise would be excluded from the systemic circulation. Membrane damaging effects have been demonstrated by protein release ${ }^{39}$, ciliostasis 40 , and histological examinations 41 . Such toxicity may eventually preclude use of these agents in clinical trials.

Another emerging class of absorption enhancers is phospholipids. They occurs in cell membranes and can be classifed as acidic or zwitter ions.

Lysophospholipids are surface active zwitter ion compounds generated naturally in biological membranes by action of phospholipases. They are active in low concentrations and are converted within the membrane to normal cell components 42 . L- $\alpha$-Lysophosphatidylcholine (LPC) has been shown to increase the permeability of rat ileum to macromolecules 43 and has more recently been investigated as an enhancer for the intranasal absorption of insulin in rats 44 and of human growth hormone in rats, rabbits and sheep 45-46 although its histopathological effects on the nasal tissue have not been reported. The mechanisms of absorption promotion for LPC is poorly understood but it possesses "membrane activity" and has shown absorption enhancing properties 45 . Dimyristoylphosphatidylglycerol (DMPG) is an acidic phospholipid which has been shown to interact with certain polypeptides like glucagon, insulin, calcitonin, parathyroid, secretin, and growth hormone to form an amphipathic helix ${ }^{47}$. Circular Dichroism spectroscopy studies show that $\mathrm{sCT}$ forms an amphipathic helix and adopts a conformation of higher helical content in the presence of phospholipid DMPG48. This hydrophilic lipoprotein complex (DMPG-sCT) has been associated with an increase in the hypocalcemic activity49-50. However there have been no literature citation of 
describing the use of DMPG as an nasal absorption enhancer for calcitionin.

Calcitonin is a 32 amino acid amidated peptide used for over two decades to treat certain degenerative bone diseases and the hypercalcemia associated with malignancy. Before 1989, calcitonin was administered exclusively by the parenteral route. The bioavailability of an intravenous dose is absolute. However the chronic nature of the ailment and the high cost and discomfort associated with parenteral administration decreases patient compliance. The feasibility of the administration of calcitonin via the nasal route has been documented and the results have been encouraging 51 .

Nasal spray formulations of salmon calcitonin currently are on the market in Europe and Japan and have been extremely well received. Similiar approvals are pending in the United States. These products have provided a much needed alternative for patients, however extremely low bioavailability of less than $3 \%$ of the free drug when administered nasally necessitates the use of absorption enhancers 52 .

The objective of this investigation was to study (i) the effect of DMPG on the intranasal absorption of $\mathrm{SCT}$ in the presence of various $\mathrm{NaCl}$ salt concentrations in a range of 0.045-0.3 M (ii) the effect of DMPG on the calcium lowering effect of $\mathrm{sCT}$ (iii) whether the addition of a viscosity enhancer to these formulations would further increase the intranasal bioavailability of SCT. 


\section{EXPERIMENTAL}

\section{Materials}

Salmon calcitonin (sp. activity $5384 \mathrm{IU} / \mathrm{mg}$ ) was obtained from Armour Pharmaceuticals, Kankanee, IL. Dimyristoylphosphatidylglycerol (DMPG) was purchased from Avanti Lipids, Alabaster, AL. RIA Kits were procured from Diagnostics Systems laboratories, Webster, TX. Acetic acid and Sodium acetate, analytical grade were purchased from Fisher Scientific, Fair lawn, NJ. Anesthetics acepopromazine maleate, ketamine hydrochloride were purchased from Aveco Co. Inc., Fort Dodge, IA. DMA Calcium Plus Reagent ${ }^{\circledR}$, DMA, Houston, TX, Methylcellulose, Methocel A15C, Dow Chemical Company, Midland MI. Chlorbutanol, Sigma Chemical Company, St. Louis MO, Catheters and Serum separators, Baxter Health Care Corporation, Deerfield, IL, Heparin Sodium injection, USP, Elkins-Sinn Inc., Cherry Hill, NJ were purchased and used as recieved. Distilled water was used for all nasal formulations.

A metered nasal spray pump was used to spray $50 \mu l$ at one time. Nasal micron spray pump was employed to deliver formulations of higher viscosity (76 cps), methylcellulose $1 \% \mathrm{w} / \mathrm{w}$. The volume delivered was $35 \mu \mathrm{l}$ at one time. Both the pumps were provided by Pfeiffer GMBH, Radolfzell, Germany.

\section{Methods}

Preparation of formulations containing DMPG and SCT at low viscosity (1 cps)

DMPG was added as a solid to a $0.03 \mathrm{M}$ acetate buffer $(\mathrm{pH} 4)$ and the mixture was stirred. Calcitonin was added and it was allowed to interact at room temperature for 5-6 hrs. The ratio of DMPG to salmon calcitonin was $50: 1$, this 
particular ratio provided a dose of SCT of $2000 \mathrm{IU}$ and 1\% w/w of DMPG. The affinity of $\mathrm{SCT}$ for DMPG has been shown to be independent of temperature within experimental error, between 25 and $38^{\circ} \mathrm{C}$ and the reaction is very spontaneous.

\section{Preparation of formulation containing DMPG and SCT at high viscosity} (76 cps)

It has also been demonstrated 53 that the addition of a viscosity enhancing agent increases the contact time of the dosage form with the mucosal membrane and may help to enhance absorption by reducing the mucociliary clearance of the administered drug.

To prepare formulations containing DMPG and $\mathrm{SCT}$ at a higher viscosity of 76 cps, methylcellulose was used as a viscosity enhancing agent at a concentration of $1 \% \mathrm{w} / \mathrm{w}$. The formulations were prepared using a hot-cold technique. The methylcellulose was dispersed in hot water and then ice cold water was added and stirred for 4-5 hrs for methylcellulose to swell and hydrate and reach the specified viscosity. The $\mathrm{pH}$ was adjusted to 4 . DMPG and calcitonin were added. The mixture was allowed to interact at room temperature for 5-6 hrs.

\section{Administration of nasal formulations to the rabbits}

It has been shown ${ }^{54}$ that by adjusting the volume and the concentration of intranasal drug, a significant difference in bioavailability can be obtained. The bioavailability of desmopressin from $2 \times 50 \mu$ dose was $20 \%$ greater than after administration of a $1 \times 100 \mu \mathrm{l}$ dose. Instilling the drug as a smaller volume in both nostrils as compared to larger volume in one nostril demonstrated 
slower clearance from the nose.

$$
\text { s.p.s. }
$$

However the metered nasal sprays are limited their ability to spray only low viscosity solutions ( $<5 \mathrm{cps}$ ) as fine spray. The nasal micron spray pump, a prototype device, designed to deliver solutions of higher viscosity as a fine spray was investigated for its use in nasal drug delivery $55: \mathrm{r}$.

A metered nasal spray pump based on the mectanism of ball and spring with a flanged actuator using a spray insert of $35^{\circ}$ spray-angle was used to spray 50 $\mu \mathrm{l}$ of low vicosity solutions (1 cps) at one tinte) and the total volume of the dose instilled was $200 \mu \mathrm{l}$ by spraying 2 times into each nostril. The nasal micron spray pump was employed to deliver formulations of higher viscosity (76 cps). The volume delivered was $35 \mu \mathrm{l}$ at one time, arfd a total of $210 \mu \mathrm{l}$ dose was instilled by spraying 3 times into each nostril. $\mathrm{chh}$.

\section{In vivo study}

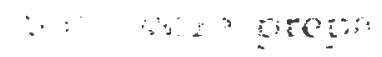

\section{Animal Model}

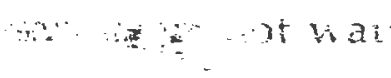

nom thes

New Zealand white rabbits were obtained from Mt\$btook farms (Amherst, MA) with a mean weight of about $3 \mathrm{~kg}$. The stidy pifotócol was reviewed and approved by the Institutional Animal Care and Use Committee at the University of Rhode Island, Kingston, RI

\section{Experimental procedure}

The rabbits were fasted for 36 hours prior to each experiment with free access to water. The rabbits were anesthetized with an i.m. dose of $0.25 \mathrm{mg} / \mathrm{kg}$ of ketamine hydrochloride and $2.5 \mathrm{mg} / \mathrm{kg}$ of acepoprohrazine maleate. Rabbits were kept lying on their backs on thermal rugs during each experiment. A 
catheter was placed in the rabbit's median ear artery and a $0.8-1 \mathrm{ml}$ of blood samples was collected at $-5,10,20,30,40,50,60,75,90,120,180,240$ and 300 minutes after administration of the formulations. The samples were allowed to clot for at least 30 minutes at room temperature and then centrifuged at $3000 \mathrm{rpm}$ for 10 minutes and stored at $-20^{\circ} \mathrm{C}$ until assayed.

For control formulations, rabbits were anesthetized and blood was withdrawn at the same intervals as mentioned above and serum analyzed. This was called control group as no calcitonin was administered and was used to measure any interference from the trauma on administration of anesthesia on the inherent calcitonin level. The values obtained were subtracted from the levels obtained after administration of calcitonin formulations.

\section{Study Design}

The various formulations of calcitonin were administered as spray to the rabbits as per a randomized cross-over design. A wash out period of at least one week was allowed between treatments.

\section{Analytical methods}

\section{Serum calcitonin}

All serum samples were assayed with a commercial RIA kit developed by Diagnostics Systems Labortories (Webster, TX). Guinea pig anti-sCT antibodies were used as primary antibodies and have demonstrated less than $2 \% \mathrm{w} / \mathrm{w}$ cross reactivity. The sigmoidal standard curve of $\mathrm{B} / \mathrm{Bo}$ versus [sCT], typical of competitive binding assays was linearized using a log transformation of SCT. The best fit line was determined using a non weighted least square regression analysis. The radioimmunoassay quantitation range was $100-5000 \mathrm{pg} / \mathrm{ml}$. The 
coefficent of determination $\left(\mathrm{r}^{2}\right)$ in this range for the $\mathrm{B} / \mathrm{Bo}$ versus $\log$ [sCT] plots was greater than 0.993 for all assays performed in duplicate.

\section{Serum calcium levels}

Serum calcium levels were determined using a DMA Calcium Plus Procedure ${ }^{\circledR}$ utilizing arsenazo III to bind the calcium at an acid $\mathrm{pH}$ and form a bluish purple complex. Color intensity was measured spectrophotometrically at $650 \mathrm{~nm}$. The range of the linearity was determined to be between $5-25 \mathrm{mg} / \mathrm{dl}$. The coefficient of determination $\left(\mathrm{r}^{2}\right)$ in this range for the absorbance versus concentration $(\mathrm{mg} / \mathrm{dL}$ ) was 0.999 for all the assays performed in duplicate during the course of study.

\section{Data Analysis}

The nasal bioavailability of calcitonin was calculated relative to the serum calcitonin levels after injecting calcitonin intravenously. $\mathrm{C}_{\max }$ values are the peak serum calcitonin concentrations observed at time $T_{\max }$ after adminstration of calcitonin.

$$
\% \text { Absolute Bioavailability }=\frac{\text { AUCin-AUCcontrol }}{\text { AUCiv-AUCcontrol }} \times \frac{\text { Doseiv }}{\text { Dosein }} \times 100
$$

where $A U C_{i n}, A U C_{i v}$ and $A U C_{\text {control }}$ refer to the area under the curve calculated by the linear trapezoidal rule. $A U C_{i n}$ refers to area under the curve calculated after the intranasal administration of calcitonin formulations. $A U C_{j v}$ refers to area under the curve calculated after the intravenous administration of calcitonin formulations. $A \mathrm{UC}_{\mathrm{control}}$ refers to area under the curve calculated without administration of calcitonin. 
The hypocalcemic effect was measured in terms of percent maximal decrease $\left(\% \max _{d}\right)$; which is defined as the highest percentage of reduction in calcium levels as compared to the basal values. The total decrease in serum calcium level (D\%) was calculated by a modified method, from Hirai et al, 1981.

$$
\mathrm{D} \%=\frac{\text { AUCcontrol-AUCin }}{\text { AUCcontrol }} \times 100
$$

where $A U C_{i n}, A U C_{\text {control }}$ and $A U C_{i v}$ refer to the area under the curve calculated by the linear trapezoidal rule after the intranasal administration of calcitonin formulations. The time at which this reduction takes place is $T_{\max }$. Statistical analysis was performed using ANOVA by Statistical Analytical Software (SAS). Formulation effects were compared with the controls using Dunnett's test. Multiple comparison among the treatment effects were determined using Scheffe's multiple comparison test. Differences among the treatment were assumed to be significant for values of $p<0.05$.

\section{Selection of best formulations}

The primary aim of this investigation was to study the effect of DMPG on the intranasal bioavailability of $\mathrm{SCT}$. The influence of DMPG was investigated at the three levels of salt concentration of $0.045 \mathrm{M}, 0.15 \mathrm{M}$ and $0.3 \mathrm{M}$. In order to optimize the effect of these salt concentrations and the concentration of DMPG on area under the curve, response surface analysis was applied. The SAS/RSREG was used to fit the parameters of the complete quadratic reponse surface obtained at the three levels of salt concentration incorporated in the formulations and analyze the fitted surface to determine the level of the salt concentration needed for the optimum formulations. The predicted optimal value can be found from the estimated surface, which usually shows a

minima, maxima or saddle point, Since the independent variable should be 
at three or more levels, salt concentration was designated as independent variable with area under the curve as a response surface and the concentration of DMPG was used as a covariate investigated at two levels. 56

\section{RESULTS AND DISCUSSION}

Currently, two classes of nasally delivered therapeutic compounds are on the market. The first and largest class encompasses low molecular weight drugs designed to treat local inflammation of the nasal mucosa and sinuses. This class includes topical steroids, cromolyn sodium, and most over the counter nasal products. These compounds are generally hydrophobic in their unionized form, and readily partition into the mucosal membrane. The second class includes those drugs intended for systemic delivery after intranasal administration. Despite the attractiveness of the nasal cavity for systemic administration, the second class includes only a few compounds: vasopressin, oxytocin, LH-RH analogs, calcitonin, and vitamin B-12. Except for vitamin B12 , the compounds are all peptides and show very low bioavailability. Although the bioavailability of these peptides is low, therapeutic activity may often be sufficient because of the high biological potency of these compounds.

This study was designed to evaluate the phospholipid, DMPG, as an absorption enhancer and to determine its ability to enhance the bioavailability of salmon calcitonin. Phospholipids may be directly involved in the binding of many drugs and hormones to specific cell-surface receptors sites $\mathbf{4 - 4 8}$. There is evidence that binding to lipid is required for the activity of peptides including enkephalin $\mathbf{5 7}$ and thyrotropin58. Calcitonin is a membrane active peptide and its interaction with the lipid may be related to 
its biological activity. Circular Dichroism spectroscopy studies show that salmon calcitonin ( $\mathrm{sCT}$ ) forms an amphipathic helix and adopts a conformation of higher helical content in the presence of the phospholipid, Dimyristoylphosphatidylglycerol (DMPG). This hydrophilic lipoprotein complex has been associated with an increase in the hypocalcemic activity $48-50$.

\section{Pharmacokinetic studies}

Since salts are often used in nasal formulations to adjust ionic strength, tonicity etc, it was decided to investigate the effect of salt concentration on the absorption of SCT with or/without DMPG. Table I summarizes the Tmax, Cmax, AUC and Bioavailability for the formulations investigated. In order to determine the absolute bioavailability of intranasal SCT formulations, the AUC for the control formulation and i.v solution was also determined and was calculated to be $401 \pm 75.3$ and $1102.1 \pm 19.8 \mathrm{ng} . \mathrm{min} / \mathrm{ml}$.

\section{Low viscosity formulations}

\section{Effect of $0.045 \mathrm{M} \mathrm{NaCl}$}

The influence of DMPG on the absorption of $\mathrm{SCT}$ in a formulation containing $0.045 \mathrm{M} \mathrm{NaCl}$ at a viscosity of $1 \mathrm{cps}$ is shown in figure 1 . The $\mathrm{Cmax}$ obtained for the formulation containing only $\mathrm{sCT}$ was $26 \pm 7.6 \mathrm{ng} / \mathrm{ml}$ at 38 minutes whereas the Cmax elicited by the formulation containing only DMPG and SCT increased to $82 \pm 30 \mathrm{ng} / \mathrm{ml}$ at 90 minutes. The AUC elicited by SCT formulation at $0.045 \mathrm{M} \mathrm{NaCl}$ was $3171 \pm 258 \mathrm{ng} \cdot \mathrm{min} / \mathrm{ml}$ and an absolute bioavailability of 0.71 whereas the AUC elicited by formulation incorporating DMPG and SCT at $0.045 \mathrm{M} \mathrm{NaCl}$ was $6017 \pm 706 \mathrm{ng} \cdot \mathrm{min} / \mathrm{ml}$ with an absolute bioavailability of 1.4 . The presence of DMPG and $\mathrm{SCT}$ in the formulation demonstrated a two fold 
Figure 1 THE INFLUENCE OF A SALT CONCENTRATION OF 0.045 M AND DMPG ON THE INTRANASAL ABSORPTION OF SALMON CALCITONIN

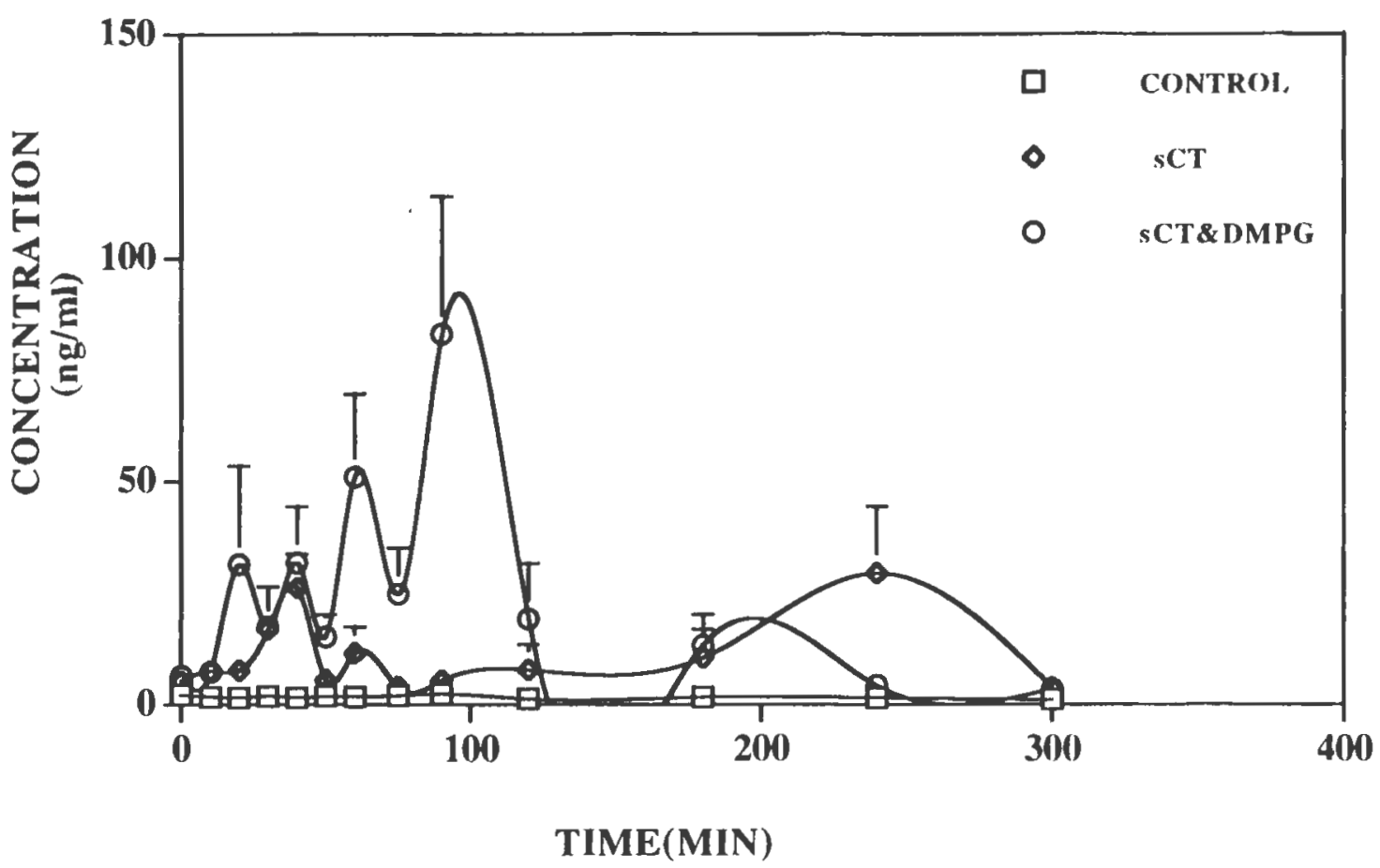


TABLE I PHARMACOKINETIC PARAMETERS OF LOW VISCOSITY SALMON CALCITONIN FORMULATIONS AFTER INTRANASAL ADMINISTRATION IN NEW

ZEALAND RABBITS $(\mathrm{N}=5)$

\begin{tabular}{|l|l|l|l|l|}
\hline VARIABLE & Tmax (min), & Cmax(ng/ml) & AUC(ng.min/ml) & \%Bioavailability \\
\hline CONTROL & & & $401 \pm 75.3$ & \\
\hline I.V (5 I.U.) & 14 & $25 \pm 2.9$ & $1102.1 \pm 19.8^{\mathrm{a}}$ & 100 \\
\hline $\begin{array}{l}\text { INTRANASAL } \\
\text { SCT }\end{array}$ & & & & \\
DOSE 2000 I.U. & & & & \\
\hline 0.045 M & & & & \\
\hline 0.15 M & 38 & $26 \pm 7.6$ & $3171 \pm 258^{\mathrm{b}}$ & 0.71 \\
\hline 0.3 M & 40 & $10 \pm 4.2$ & $714.2 \pm 15.7^{\mathrm{c}}$ & 0.16 \\
\hline INTRANASAL & 90 & $42 \pm 19.6$ & $3508 \pm 1280$ & 0.80 \\
\hline $\begin{array}{l}\text { DMPG-8CT } \\
\text { DOSE 2000 I.U. }\end{array}$ & & & & \\
\hline 0.045 M & & & & \\
\hline 0.15 M & 90 & $82 \pm 30$ & $6017 \pm 706^{\mathrm{b}}$ & 1.4 \\
\hline 0.3 M & 10 & $22 \pm 30$ & $1521 \pm 275^{\mathrm{C}}$ & 0.34 \\
\hline
\end{tabular}

a significantly different from control at $p<0.05$

b significantly different in AUC for DMPG formulations at $0.045 \mathrm{M} \mathrm{NaCl}$ at $p<0.05$

$c$ significantly different in AUC for DMPG formulations at $0.15 \mathrm{M} \mathrm{NaCl}$ at $p<0.05$ 
increase in the absorption of $\mathrm{sCT}$ as compared to formulation containing only $\mathrm{sCT}$ at a $\mathrm{NaCl}$ concentration of $0.045 \mathrm{M}$ and a viscosity of $1 \mathrm{cps}$.

\section{Effect of $0.15 \mathrm{M} \mathrm{NaCl}$}

The influence of DMPG on the absorption of $\mathrm{SCT}$ from formulations prepared with $0.15 \mathrm{M} \mathrm{NaCl}$ at a viscosity of $1 \mathrm{cps}$ is shown in figure 2 . The Cmax was found to be $10 \pm 4.2 \mathrm{ng} / \mathrm{ml}$ at 40 minutes for the formulations containing only sCT whereas the Cmax increased to $22 \mathrm{ng} / \mathrm{ml}$ at 10 minutes for the formulations incorporating DMPG and sCT. The AUC elicited was $714.2 \mathrm{ng} \cdot \mathrm{min} / \mathrm{ml}$ and an absolute bioavailability of 0.16 for the $\mathrm{sCT}$ formulation as compared to an AUC of $1521 \mathrm{ng} \cdot \mathrm{min} / \mathrm{ml}$ and an absolute bioavailability of 0.34 for the formulations containing DMPG and SCT. These results demonstrated that even at a $\mathrm{NaCl}$ salt concentration of $0.15 \mathrm{M}$ and a viscosity of $1 \mathrm{cps}$, the bioavailability elicited by the presence of DMPG in SCT formulations increased two fold compared to SCT formulations without DMPG. However the bioavailability elicited by sCT with a $0.045 \mathrm{M} \mathrm{NaCl}$ salt concentration and a viscosity of $1 \mathrm{cps}$ was higher as compared to formulations containing $\mathrm{sCT}$ at a $0.15 \mathrm{M} \mathrm{NaCl}$ salt concentration and a viscosity of $1 \mathrm{cps}$ (1.4\% versus $0.34 \%)$.

\section{Effect of $0.3 \mathrm{M} \mathrm{NaCl}$}

The influence of increasing the $\mathrm{NaCl}$ salt concentration to $0.3 \mathrm{M}$ with a viscosity of $1 \mathrm{cps}$ in the absence or presence of DMPG on the bioavailability of SCT is shown in figure 3. The Cmax was $42 \pm 19.6 \mathrm{ng} / \mathrm{ml}$ at 90 minutes for the sCT formulations. The $\mathrm{Cmax}$ was reduced to $28 \pm 7.5 \mathrm{ng} / \mathrm{ml}$ at 63 minutes in the presence of DMPG in the $\mathrm{SCT}$ formulations. The AUC for the $\mathrm{SCT}$ administration was $3508 \pm 1280 \mathrm{ng} . \mathrm{min} / \mathrm{ml}$ with an absolute bioavailability of 
Figure 2 THE INFLUENCE OF A SALT CONCENTRATION OF 0.15 M AND DMPG ON THE INTRANASAL ABSORPTION OF SALMON CALCITONIN

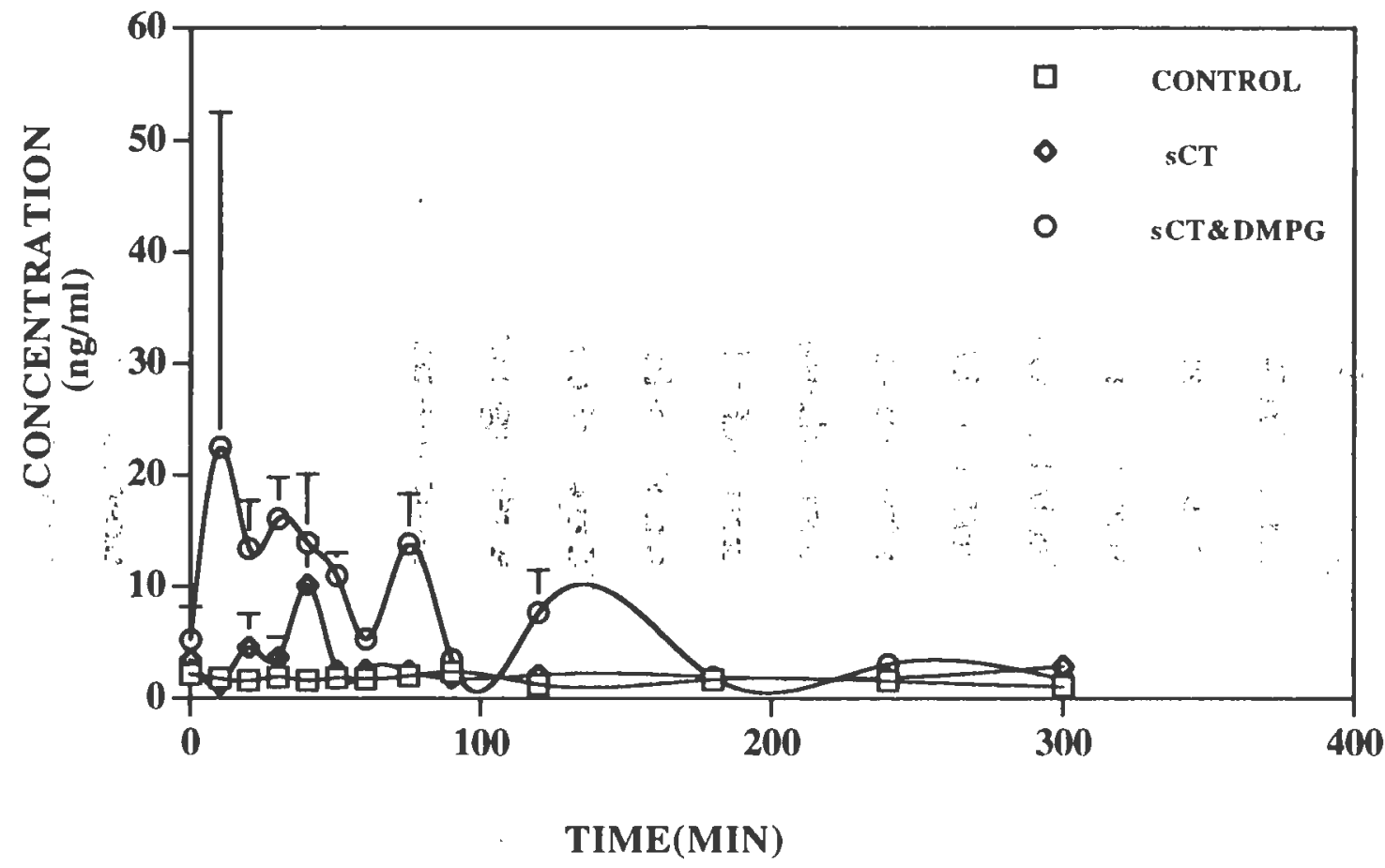


Figure 3 THE INFLUENCE OF A SALT CONCENTRATION OF 0.3 M AND DMPG ON THE INTRANASAL ABSORPTION OF SALMON CALCITONIN

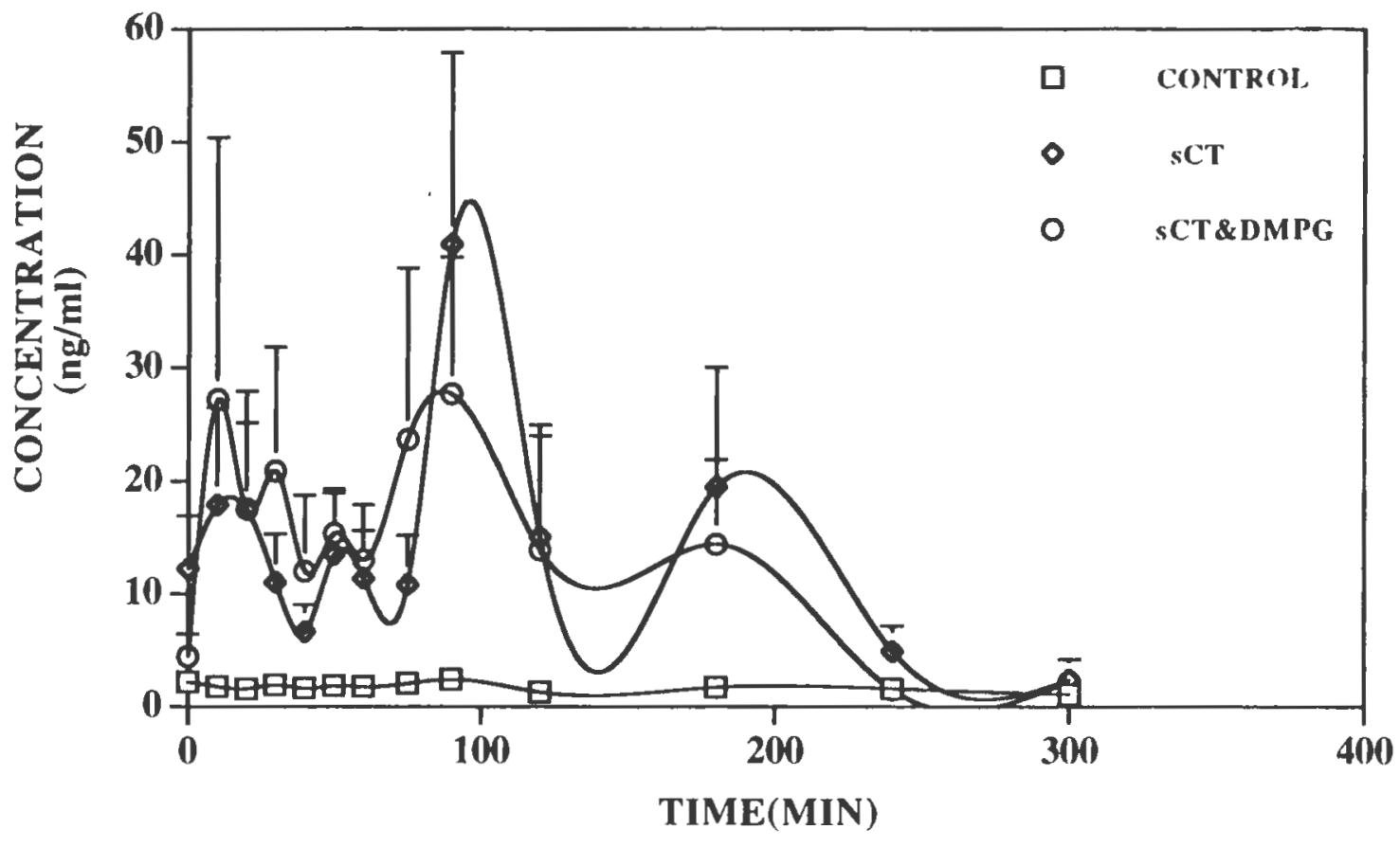


0.80 as compared to an AUC of $3692 \pm 1369 \mathrm{ng} \cdot \mathrm{min} / \mathrm{ml}$ and an absolute bioavailability of 0.84 in the presence of DMPG in SCT formulations. Therefore in the presence of higher salt concentration of $0.3 \mathrm{M} \mathrm{NaCl}$, the absorption of $\mathrm{sCT}$ was not affected by the presence of DMPG, in fact it was approximately the same magnitude as seen without addition of DMPG. This indicated that DMPG did not have any absorption enhancing effect on sCT absorption at $0.3 \mathrm{M}$. Therefore maximum bioavailability elicited by DMPG and the SCT formulations was obtained at the lowest concentration of $\mathrm{NaCl}$.

\section{Pharmacodynamic effects}

It has been suggested that the presence of DMPG in an sCT formulation enhances the helical activity of $\mathrm{SCT}$ and may be related to the increase in the hypocalcemic activity 48-50. Thus the parameters of hypocalcemic activity were determined for formulations containing only $\mathrm{sCT}$ and those containing DMPG along with sCT. The results are summarized in Table II as Tmax (min), $\% \max _{\mathrm{d}}$ (percent maximal decrease), AUC (mg.min/dL) and D\% (total hypocalcemic activity).

\section{Low viscosity formulations}

\section{Effect of $0.045 \mathrm{M} \mathrm{NaCl}$}

The influence of DMPG on the calcium level after intranasal administration of $\mathrm{sCT}$ in the presence of $0.045 \mathrm{M} \mathrm{NaCl}$ at a viscosity of $1 \mathrm{cps}$ is shown in figure 4 . The maximal decrease, $\% \max _{\mathrm{d}}$ was $28.12 \%$ at 180 minutes for $\mathrm{sCT}$ formulations as compared to $\% \max _{\mathrm{d}}$ of $34.58 \%$ at 120 minutes for formulations incorporating DMPG and sCT. The AUC was $3308 \pm 42.45$ $\mathrm{mg} \cdot \mathrm{min} / \mathrm{dL}$ and a total lowering of calcium, D\% of $18 \%$ for $\mathrm{sCT}$ formulations as compared to a AUC of $3209.55 \pm 21.66 \mathrm{mg} \cdot \mathrm{min} / \mathrm{dL}$ with $\mathrm{D} \%$ of $19 \%$ in the 
TABLE II PHARMACODYNAMIC PARAMETERS OF LOW VISCOSITY SALMON CALCITONIN FORMULATIONS AFTER INTRANASAL ADMINISTRATION INTO NEW ZEALAND RABBITS $(\mathrm{N}=5) ;$ DOSE $=2000 \mathrm{I}$. U.

\begin{tabular}{|c|c|c|c|c|}
\hline VARIABLE & Tmax(min) & $\underline{\text { Maxd (\%) }}$ & AUC(mg.min/dL) & \% D \\
\hline CONTROL & & & $4045.40 \pm 255.17$ & \\
\hline I.V (5 I.U.) & 30 & 28 & $2732 \pm 271.39 \mathrm{a}$ & 32 \\
\hline$\underline{\mathrm{sCT}}$ & & & & \\
\hline $0.045 \mathrm{M}$ & 180 & 28.12 & $3308.0 \pm 42.45$ & 18 \\
\hline $0.15 \mathrm{M}$ & 240 & 12.96 & $3724.12 \pm 120.99 \mathrm{~b}$ & 7.9 \\
\hline $0.3 \mathrm{M}$ & 180 & 28.83 & $3267.74 \pm 31.31$ & 19 \\
\hline DMPG-SCT & & & & 19 \\
\hline $0.045 \mathrm{M}$ & 120 & 34.58 & $3209.55 \pm 21.66$ & 20 \\
\hline $0.15 \mathrm{M}$ & 50 & 38.89 & $2884.70 \pm 53.24 \mathrm{~b}$ & 20 \\
\hline $0.3 \mathrm{M}$ & 90 & 38.49 & $3208 \pm 102.49$ & \\
\hline
\end{tabular}

$a=$ significantly different from control at $p>0.05$

$b=$ significantly different in calcium levels at $p>0.05$ 
FIGURE 4 THE INFLUENCE OF A SALT CONCENTRATION

OF 0.045 M AND DMPG ON THE CALCIUM LEVEL AFTER

INTRANASAL ADMINISTRATION OF SALMON CALCITONIN

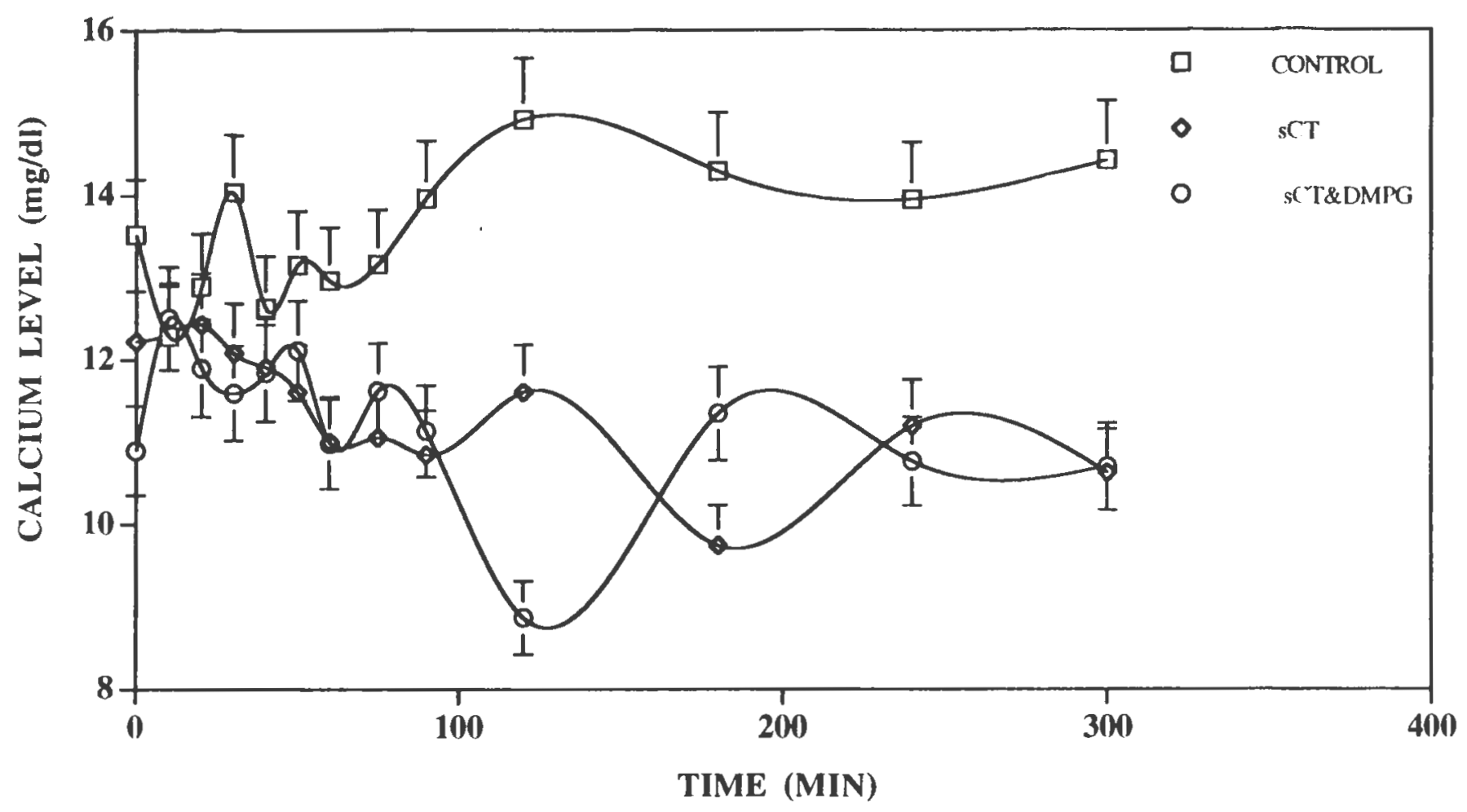


SCT formulations incorporating DMPG. Thus for formulations containing $0.045 \mathrm{M} \mathrm{NaCl}$ salt and a viscosity of $1 \mathrm{cps}$, the maximal decrease in calcium elicited by the presence of DMPG and SCT was higher (34.15\% versus $28.12 \%$ ), but $\mathrm{D} \%$, which is the overall measure of the hypocalcemic activity of SCT was similiar ( $18 \%$ versus $19 \%$ ) to $\mathrm{SCT}$ formulations. Thus there was no significant difference in the total hypocalcemic activity elicited by formulations with or without the enhancer at $p<0.5$.

\section{Effect of $0.15 \mathrm{M} \mathrm{NaCl}$}

The influence of DMPG on the calcium level after intranasal administration of $\mathrm{sCT}$ in the presence of $0.15 \mathrm{M} \mathrm{NaCl}$ at a viscosity of $1 \mathrm{cps}$ is shown in figure 5. The $\% \max _{\mathrm{d}}$ was $12.96 \%$ at 240 minutes and $38.89 \%$ at 50 minutes in the absence and presence of DMPG in the $\mathrm{sCT}$ formulations respectively. The AUC was $3724.12+120.99 \mathrm{mg} \cdot \mathrm{min} / \mathrm{dL}$ with a total lowering of calcium, D\% of $7.9 \%$ for sCT formulations as compared to the AUC of $2884.70 \pm 53.24$ mg.min/dL with a D\% of $20 \%$ in the presence of DMPG in sCT formulations. The comparison of AUC and a D\% for these two formulations demonstrated that there was a significant difference on the total lowering of calcium level in the presence of DMPG in SCT formulations at a salt concentration of $0.15 \mathrm{M}$ and a viscosity of $1 \mathrm{cps}$ as compared to sCT formulations (20\% vs $7.9 \%$ ) at $\mathrm{p}<0.05$.

\section{Effect of $0.3 \mathrm{M} \mathrm{NaCl}$}

The influence of DMPG on the calcium level after intranasal administration of formulations containing $\mathrm{sCT}$ in the presence of $0.3 \mathrm{M} \mathrm{NaCl}$ at a viscosity of $1 \mathrm{cps}$ is shown in figure 6. The maximal decrease was $28.83 \%$ at 180 minutes for formulations containing only $\mathrm{sCT}$ as compared to $38.49 \%$ at 90 minutes for 
FIGURE 5 THE INFLUENCE OF A SALT CONCENTRATION

OF 0.15 M AND DMPG ON THE CALCIUM LEVEL AFTER

INTRANASAL ADMINISTRATION OF SALMON CALCITONIN

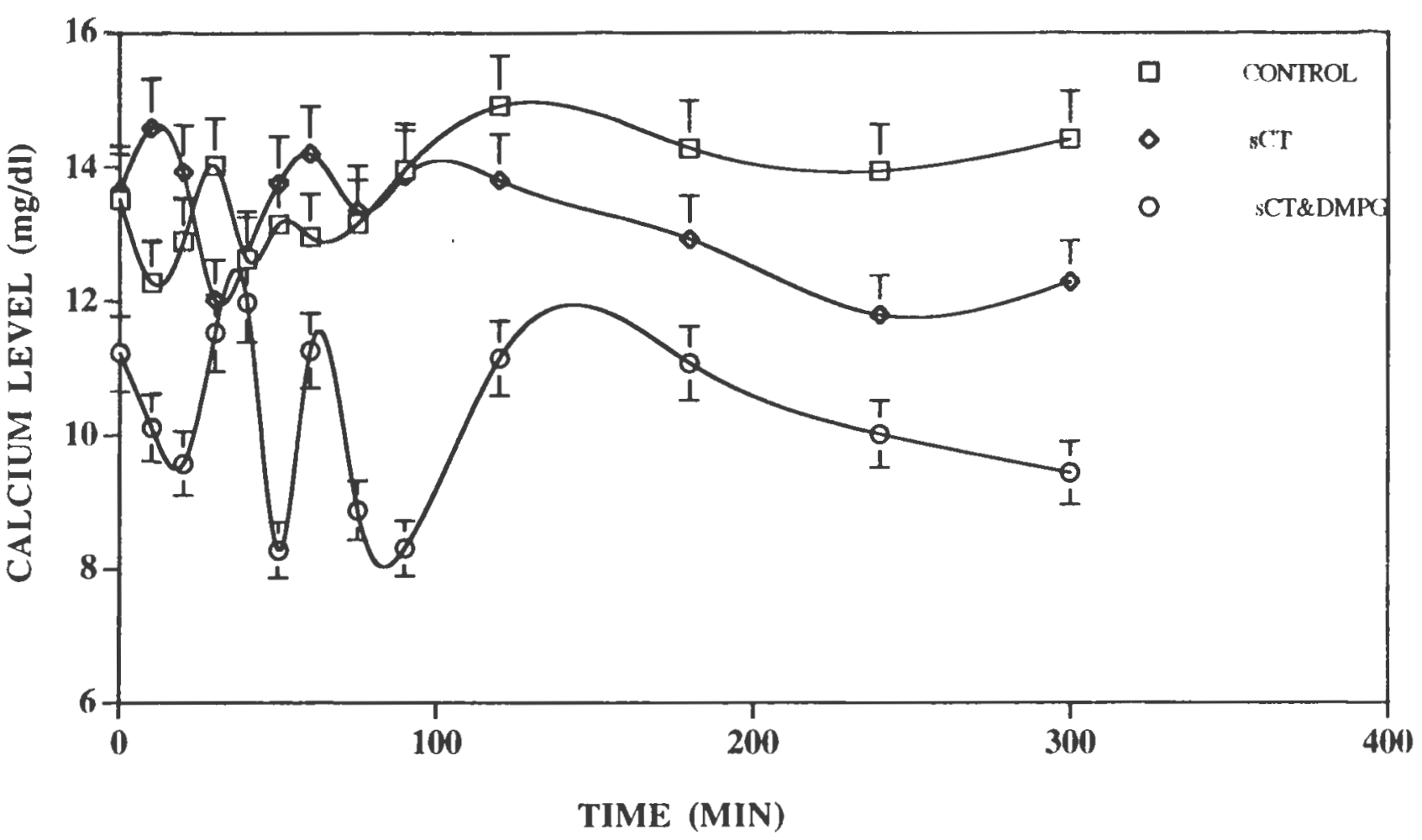


FIGURE 6 THE INFLUENCE OF A SALT CONCENTRATION

OF 0.3 M AND DMPG ON THE CALCIUM LEVEL AFTER

INTRANASAL ADMINISTRATION OF SALMON CALCITONIN

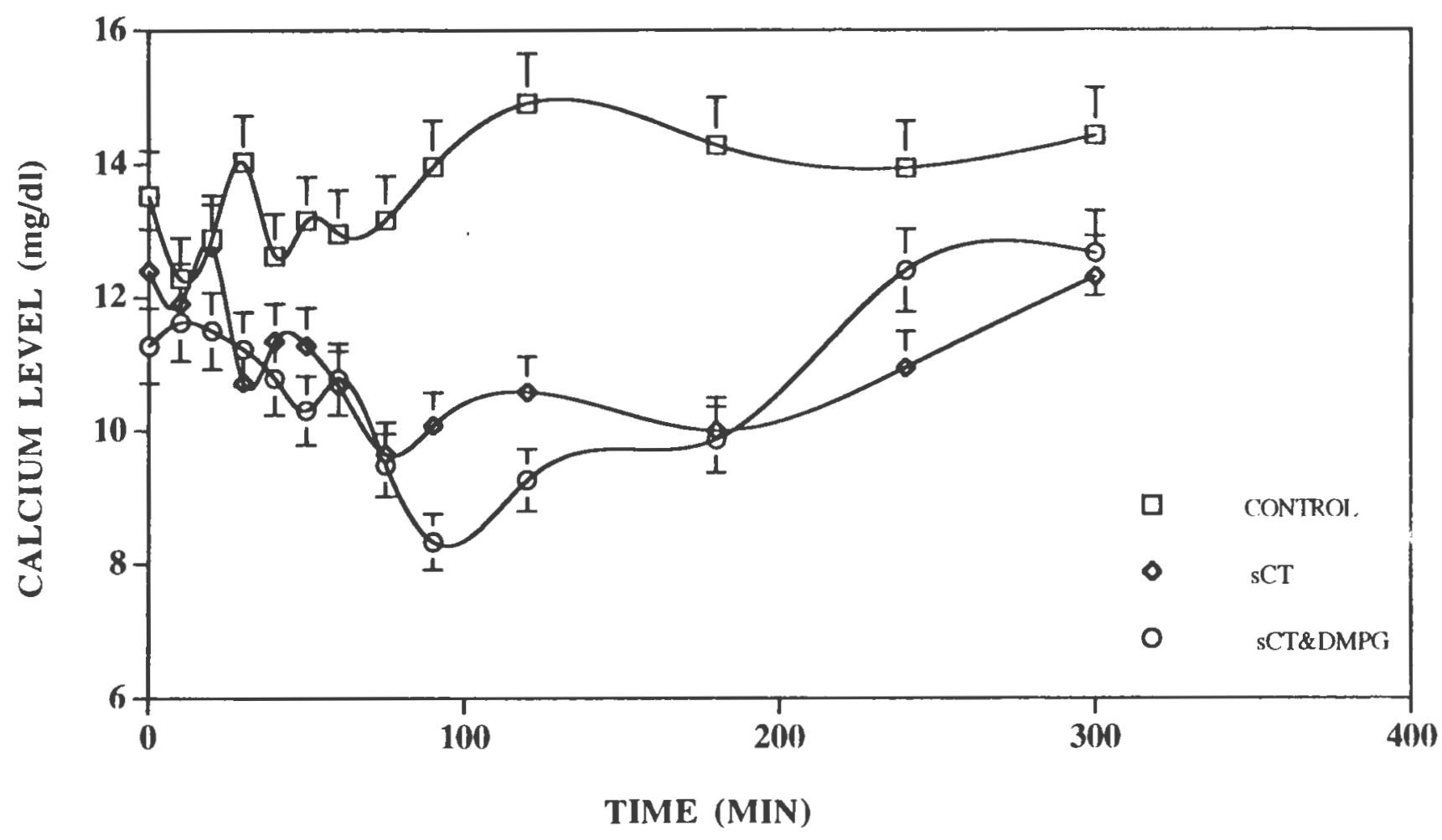


formulations incorporating DMPG and sCT. The AUC was $3267.74 \pm 31.31$ mg.min/dL and a total lowering of calcium, D\% of $19 \%$ for $\mathrm{sCT}$ formulations as compared to AUC of $3208 \pm 102.49 \mathrm{mg} \cdot \mathrm{min} / \mathrm{dL}$ with a $\mathrm{D} \%$ of $20 \%$ for formulations containing DMPG and $\mathrm{SCT}$. This indicated that the total lowering in calcium was comparable, in the absence and presence of DMPG at a salt concentration of $0.3 \mathrm{M}(19 \%$ versus $20 \%)$. Therefore the calcium lowering effects of SCT were demonstrated to be not affected by presence of DMPG when the salt concentration was $0.3 \mathrm{M}$.

The hypocalcemic activity was comparable for formulations containing only sCT and for formulations incorporating DMPG with $\mathrm{sCT}$ at a $\mathrm{NaCl}$ salt concentration of $0.045 \mathrm{M}$ and $0.3 \mathrm{M}$ at the low viscosity of $1 \mathrm{cps}$. However at a $\mathrm{NaCl}$ salt concentration of $0.15 \mathrm{M}$ with a viscosity of $1 \mathrm{cps}$, the formulations containing DMPG with SCT showed a significant difference in the calcium lowering effect of salmon calcitonin. However in all the three salt concentrations the total lowering of calcium ranged from $7.9 \%$ to $20 \%$. The Tmax calculated as a pharmacodynamic parameter for the maximum lowering of calcium ranged from 50 to 240 minutes indicating the pharmacodynamic acitivity of salmon calcitonin in lowering of calcium is sustained and does not correlate with the presence of calcitonin in the serum.

\section{Influence of viscosity}

It was hypothesized that higher viscosity formulations may act in synergism with the absorption enhancing effect of DMPG at a $\mathrm{NaCl}$ salt concentration of 0.045-0.3 M. The pharmacokinetic parameters obtained after administering the absorption enhancer, DMPG in SCT formulations at the higher viscosity of $76 \mathrm{cps}$ were compared to the low viscosity formulations of $1 \mathrm{cps}$, with and 
without the DMPG. The study was designed to evaluate the use of high viscosity ( $75 \mathrm{cps}$ ) formulations obtained by using $1 \% \mathrm{w} / \mathrm{w}$ methylcellulose delivered as a fine spray with a prototype device, the nasal micron spray pump, to facilitate the uniform distribution of spray in the nasal cavity 55 .

It has been demonstrated 53 that the addition of methylcellulose produced a more sustained and slower absorption as indicated by the difference in time to reach maximum plasma concentrations. However the AUC data indicated a similiar bioavailability for the two formulations. It is thought that the addition of a viscosity enhancing agent such as methylcellulose increases the contact time of the dosage form to the mucosal membrane and may help in enhancing the absorption by reducing the mucociliary clearance of the administered formulation and also changing the pattern of deposition and clearance 59 An increase in viscosity increases the particle size in a spray formulation. It also leads to a more localized deposition on the anterior part of the nose and thus facilitates slower clearance 60 .

On the other hand, with regard to mucociliary clearance, results are difficult to interpret. According to some authors, an increase in viscosity results in a decrease in the clearance rate 61 . Viscosity also influences the rate of diffusion of the active ingredient resulting in delayed release without any improvements in bioavailability 62 .

The influence of viscosity on formulations containing DMPG as compared to formulations without DMPG at a $\mathrm{NaCl}$ concentration of $0.045-0.3 \mathrm{M}$ are shown in figure 7-9. The pharmacokinetic parameters of these formulations are summarized in Table III. 
TABLE III PHARMACOKINETIC PARAMETERS OF HIGH VISCOSITY SALMON CALCITONIN FORMULATIONS AFTER INTRANASAL ADMINISTRATION IN NEW ZEALAND RABBITS $(\mathbf{N}=5)$

\begin{tabular}{|c|c|c|c|c|}
\hline YARIABLE & $T \max (\min )$ & Cmax(ng/ml) & $\mathrm{AUC}$ (ng.min/ml) & $\%$ Bioavailability \\
\hline CONTROL & & & $401 \pm 75.3$ & \\
\hline I.V (5 I.U.) & 14 & $25 \pm 2.9$ & $1102.1 \pm 19.8^{\mathbf{a}}$ & 100 \\
\hline $\begin{array}{c}\text { INTRANASAL } \\
\text { SCT } \\
\text { DOSE } 2000 \text { I.U }\end{array}$ & . & & & \\
\hline $0.045 \mathrm{M}$ & 120 & $23 \pm 2.4$ & $357 y \pm 103$ & 0.71 \\
\hline $0.15 \mathrm{M}$ & 58 & $12 \pm 9.7$ & $604.64 \pm 97.74 b$ & 0.14 \\
\hline $0.3 \mathrm{M}$ & 90 & $32 \pm 19.6$ & $3589 \pm 25^{c}$ & 0.72 \\
\hline $\begin{array}{l}\text { INTRANASAL } \\
\text { DMPG-SCI } \\
\text { DOSE } 20001 . U\end{array}$ & & & & \\
\hline $0.045 \mathrm{M}$ & 90 & $54 \pm 24$ & $4203 \pm 384.1$ & 0.96 \\
\hline $0.15 \mathrm{M}$ & 10 & $13 \pm 7$ & $1244 \pm 275^{b}$ & 0.28 \\
\hline $0.3 \mathrm{M}$ & 63 & $8 \pm 7.5$ & $2134 \pm 1369^{c}$ & 0.56 \\
\hline
\end{tabular}

a significantly different from control at $\mathrm{p}<0.05$

b significantly different in AUC for DMPG formulations at $0.15 \mathrm{M} \mathrm{NaCl}$ at $p<0.05$

c significantly different in AUC for DMPG formulations at $0.3 \mathrm{M} \mathrm{NaCl}$ at $p<0.05$ 


\section{High Viscosity formulation}

\section{Effect of $0.045 \mathrm{M} \mathrm{NaCl}$}

The influence of DMPG on the absorption of $\mathrm{SCT}$ in formulations containing $0.045 \mathrm{M} \mathrm{NaCl}$ at a viscosity of $76 \mathrm{cps}$ is shown in figure 7. The Cmax was 23 $\mathrm{ng} / \mathrm{ml}$ at 120 minutes for the $\mathrm{SCT}$ formulations as compared to the Cmax of $54 \pm 24 \mathrm{ng} / \mathrm{ml}$ at 55 minutes elicited by the presence of DMPG in $\mathrm{sCT}$ formulations. The AUC was $3579 \pm 103.0 \mathrm{ng} \cdot \mathrm{min} / \mathrm{ml}$ in the absence of DMPG and $4203 \pm 706 \mathrm{ng} \cdot \mathrm{min} / \mathrm{ml}$ in the presence of DMPG with an absolute bioavailability of 0.81 and 0.96 respectively. The presence of DMPG at a high viscosity of $76 \mathrm{cps}$ did not make a significant difference in the bioavailability of $\mathrm{sCT}$ at a $\mathrm{NaCl}$ concentration of $0.045 \mathrm{M}$ (0.96 vs 0.81$)$. However DMPG at a low viscosity of 1 cps elicited a two fold increase in the bioavailability (1.4 vs 0.71 ). This can be explained by the fact that increased viscosity reduces the diffusion of the drug from the formulation to the site of absorption. Thus the tmax is increased to 60 and 120 minutes for the two high viscosity formulations as compared to the 38 minutes for the low viscosity formulations without much improvement in bioavailabity.

\section{Effect of $0.15 \mathrm{M} \mathrm{NaCl}$}

The effect of the formulation containing DMPG and $\mathrm{SCT}$ at a $\mathrm{NaCl}$ concentration of $0.15 \mathrm{M}$ at $76 \mathrm{cps}$ is shown in figure 8. The Cmax obtained for formulations containing only $\mathrm{sCT}$ was $12 \pm 9.7 \mathrm{ng} / \mathrm{ml}$ at 58 minutes as compared to the Cmax for formulations containing DMPG and SCT of $13 \pm 7$ $\mathrm{ng} / \mathrm{ml}$ at 90 minutes. The AUC was $604.64 \mathrm{ng} \cdot \mathrm{min} / \mathrm{ml}$ and an absolute bioavailability of 0.14 for $\mathrm{sCT}$ formulation whereas an AUC of $1244.914 \pm 275.65$ ng.min $/ \mathrm{ml}$ and a bioavailability of 0.28 was obtained for the formulations containing DMPG and sCT. At $\mathrm{NaCl}$ salt concentration of $0.15 \mathrm{M}$, there was a 
Figure 7 THE INFLUENCE OF A SALT CONCENTRATION OF $0.045 \mathrm{M}$ AND DMPG ON THE INTRANASAL ABSORPTION OF SALMON CALCITONIN AT HIGH VISCOSITY

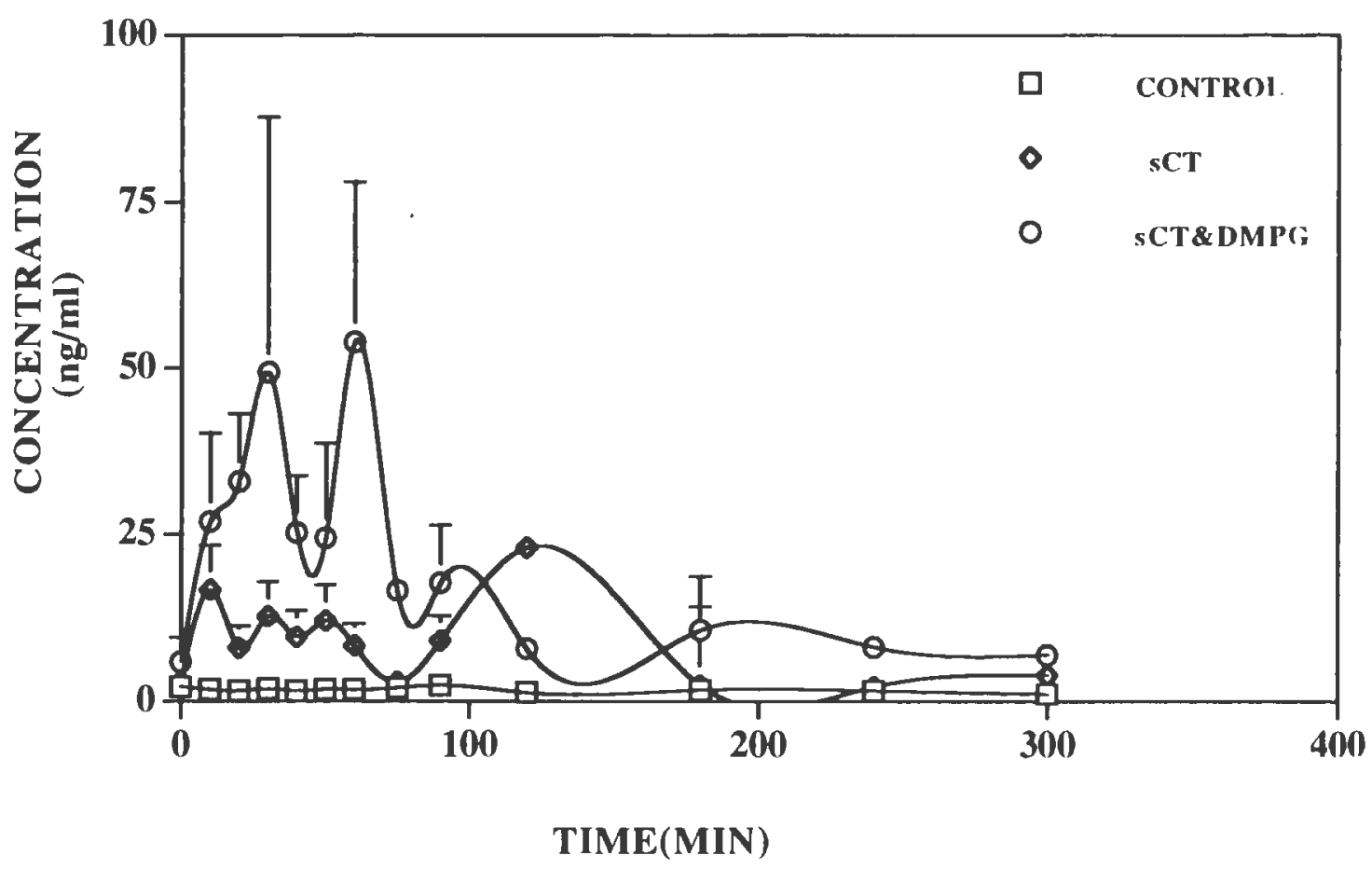


Figure 8 THE INFLUENCE OF A SALT CONCENTRATION OF 0.15 M AND DMPG ON THE INTRANASAL ABSORPTION OF SALMON CALCITONIN AT HIGH VISCOSITY

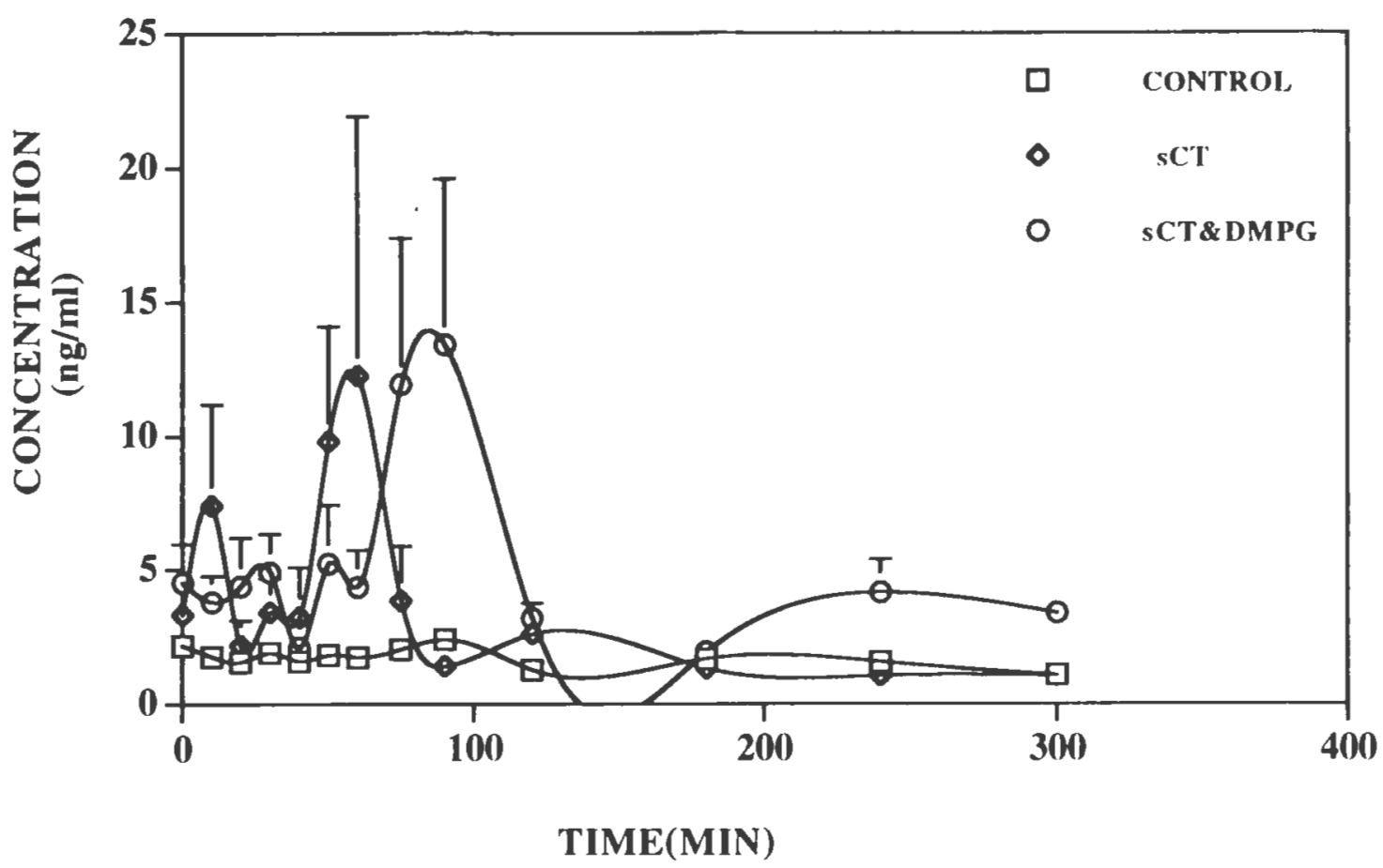


two fold increase ( $0.28 \mathrm{vs} 0.14)$ in the bioavailability of $\mathrm{sCT}$ in the presence of DMPG at a high viscosity of $76 \mathrm{cps}$. These results were very similiar to those obtained at low viscosity formulations of $1 \mathrm{cps}$ at a salt concentration of 0.15 M.

\section{Effect of $0.3 \mathrm{M} \mathrm{NaCl}$}

The effect of the formulation containing DMPG and sCT at a $\mathrm{NaCl}$ concentration of $0.3 \mathrm{M}$ and $76 \mathrm{cps}$ is shown in figure 9. The Cmax was $32 \pm 19.6$ $\mathrm{ng} / \mathrm{ml}$ at 90 minutes for the salmon calcitonin formulations. The Cmax was $8 \pm 7.5 \mathrm{ng} / \mathrm{ml}$ at 63 minutes for DMPG and SCT formulations. The absolute bioavailability of 0.72 was obtained for $\mathrm{sCT}$ formulations in the presence of 0.3 $\mathrm{M}$ salt as compared to a bioavailability of 0.56 for formulations containing DMPG and $\mathrm{SCT}$ in the presence of $0.3 \mathrm{M}$ as shown inTable III. This demonstrated that in the presence of higher salt concentration of $0.3 \mathrm{M} \mathrm{NaCl}$ the DMPG did not elicit an absorption enhancing effect. These results correlated with results obtained for low viscosity formulations at $0.3 \mathrm{M} \mathrm{NaCl}$ salt concentration.

\section{Pharmacodynamic effects}

\section{High viscosity formulations}

The parameters for the hypocalcemic activity of the high viscosity formulations with and without DMPG are summarized in Table IV as Tmax (min), \% $\max _{\mathrm{d}}$ (maximal percent decrease), AUC (mg.min/dL) and D\% (total hypocalcemic activity). A review of the pharmacodynamic effect of sCT of lowering of calcium is illustrated in figures 10-12. 
Figure 9 THE INFLUENCE OF A SALT CONCENTRATION OF 0.3 M AND DMPG ON THE INTRANASAL ABSORPTION OF SALMON CALCITONIN

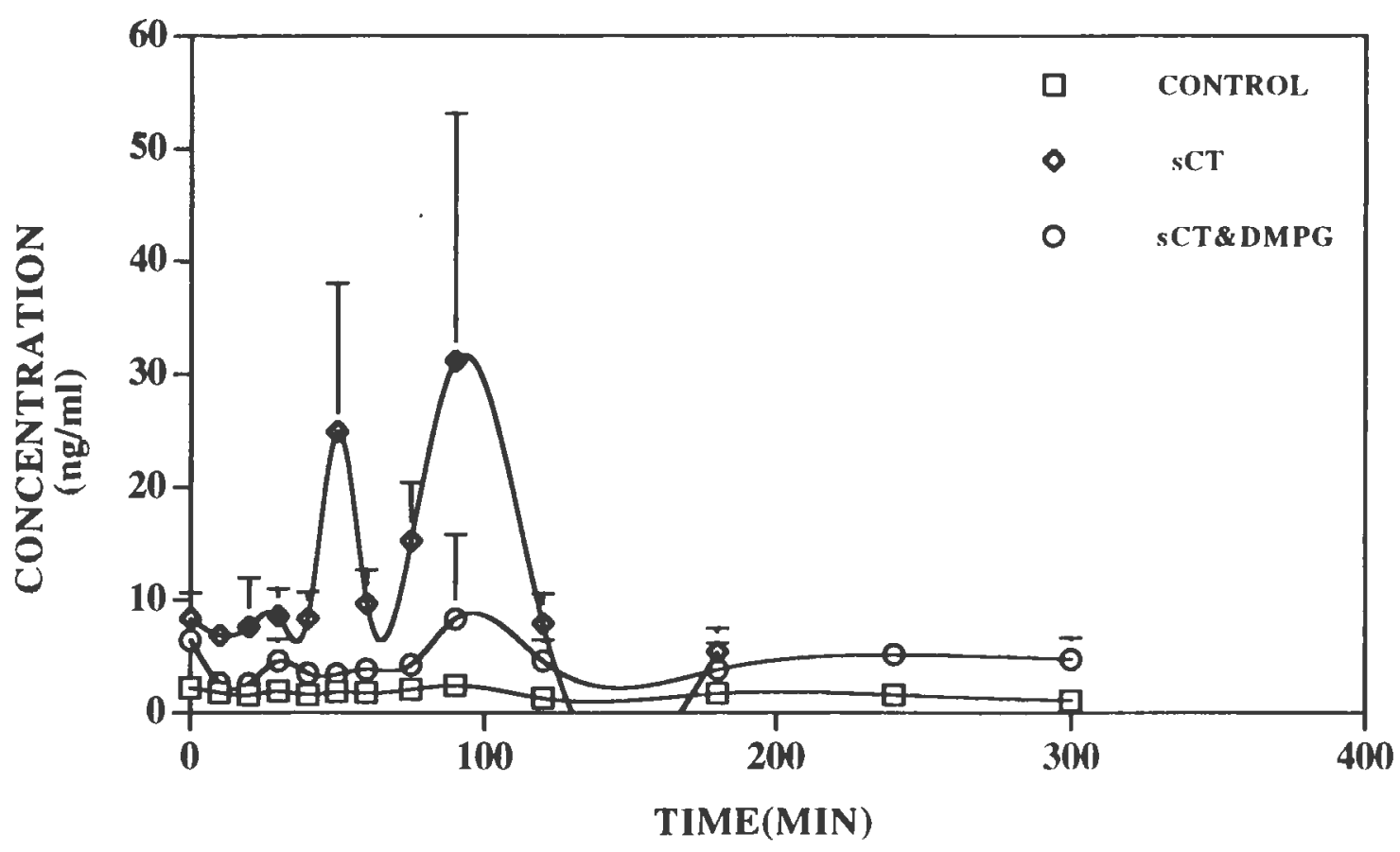


TABLE IV PHARMACODYNAMIC PARAMETERS OF HIGH VISCOSITY SALMON CALCITONIN FORMULATIONS AFTER INTRANASAL ADMINISTRATION INTO NEW ZEALAND RABBITS ( $\mathrm{N}=5$ ); DOSE $=2000 \mathrm{I}$. U.

\begin{tabular}{|c|c|c|c|c|}
\hline VARIABLE & $T \max (\min )$ & $\%$ Maxd & AUC (mg.min/dL) & $\% \mathrm{D}$ \\
\hline CONTROL & & & $4045.40 \pm 255.17$ & \\
\hline I.V (5 I.U.) & 30 & 28 & $2732 \pm 271.39 a$ & 32 \\
\hline \multicolumn{5}{|l|}{$\begin{array}{l}\text { INTRANASAL } \\
\text { SCT } \\
\text { DOSE } 2000 \text { I.U. }\end{array}$} \\
\hline $0.045 \mathrm{M}$ & 120 & 34.58 & 3154.47 & 22 \\
\hline $0.15 \mathrm{M}$ & 240 & 28.81 & $3242.83^{b}$ & 19 \\
\hline $0.3 \mathrm{M}$ & 90 & 23.52 & 3696.28 & 9 \\
\hline \multicolumn{5}{|c|}{$\begin{array}{c}\text { INTRANASAL } \\
\text { DMPG \& SCT } \\
\text { DOSE } 2000 \mathrm{I} . \mathrm{U} .\end{array}$} \\
\hline $0.045 \mathrm{M}$ & 90 & 28.36 & 3331 & 17 \\
\hline $0.15 \mathrm{M}$ & 180 & 27.09 & 3161.67 & 21 \\
\hline $0.3 \mathrm{M}$ & 75 & 29.01 & 3510.80 & 13 \\
\hline
\end{tabular}

a significantly different from control at $\mathrm{p}<0.05$

b significantly different in AUC for DMPG formulations at $0.15 \mathrm{M}$ at $\mathrm{p}<0.5$ 


\section{Effect of $0.045 \mathrm{M} \mathrm{NaCl}$}

The influence of DMPG on the calcium level after intranasal administration of $\mathrm{sCT}$ in the presence of $0.045 \mathrm{M} \mathrm{NaCl}$ and at a viscosity of $76 \mathrm{cps}$ is shown in figure 10 . The maximal decrease was $34.58 \%$ at 300 minutes and $28.36 \%$ at 90 minutes in the absence and presence of DMPG respectively. A total lowering of calcium of $22 \%$ for formulations containing sCT whereas a D\% of $17 \%$ for formulations incorporating DMPG in SCT was obtained. There was no significant difference on the calcium level in the absence or presence of DMPG at $0.045 \mathrm{M} \mathrm{NaCl}$ at a viscosity of $76 \mathrm{cps}$.

\section{Effect of $0.15 \mathrm{M} \mathrm{NaCl}$}

The influence of DMPG on the calcium level after intranasal administration of $\mathrm{sCT}$ in the presence of $0.15 \mathrm{M} \mathrm{NaCl}$ and at a viscosity of $76 \mathrm{cps}$ is shown in figure 11 . The $\% \operatorname{maxd}_{\mathrm{d}}$ was $28.81 \%$ at 240 minutes and $27.09 \%$ at 180 minutes in the absence and presence of DMPG respectively. The AUC was 3242.83 mg.min/dL with a D\% of $19 \%$ for formulations containing sCT and 3161.679 mg.min/dL with D\% of $21 \%$ for formulations containing DMPG and sCT. The comparison of AUC and a $\mathrm{D} \%$ of these two formulations demonstrated that there was no significant difference in the calcium level by high viscosity formulations at a salt concentration of $0.15 \mathrm{M}$ containing enhancer or without enhancer. These results were different from those obtained at a low viscosity of $1 \mathrm{cps}$ where there was a significant difference in the overall hypocalcemic activity of formulations with and without enhancer. The reason for this difference is not known.

\section{Effect of $0.3 \mathrm{M} \mathrm{NaCl}$}

The influence of DMPG on the calcium level after intranasal administration 
FIGURE 10 THE INFLUENCE OF A SALT CONCENTRATION OF 0.045 M AND DMPG ON THE CALCIUM LEVEL AFTER

INTRANASAL ADMINISTRATION OF SALMON CALCITONIN AT HIGH VISCOSITY

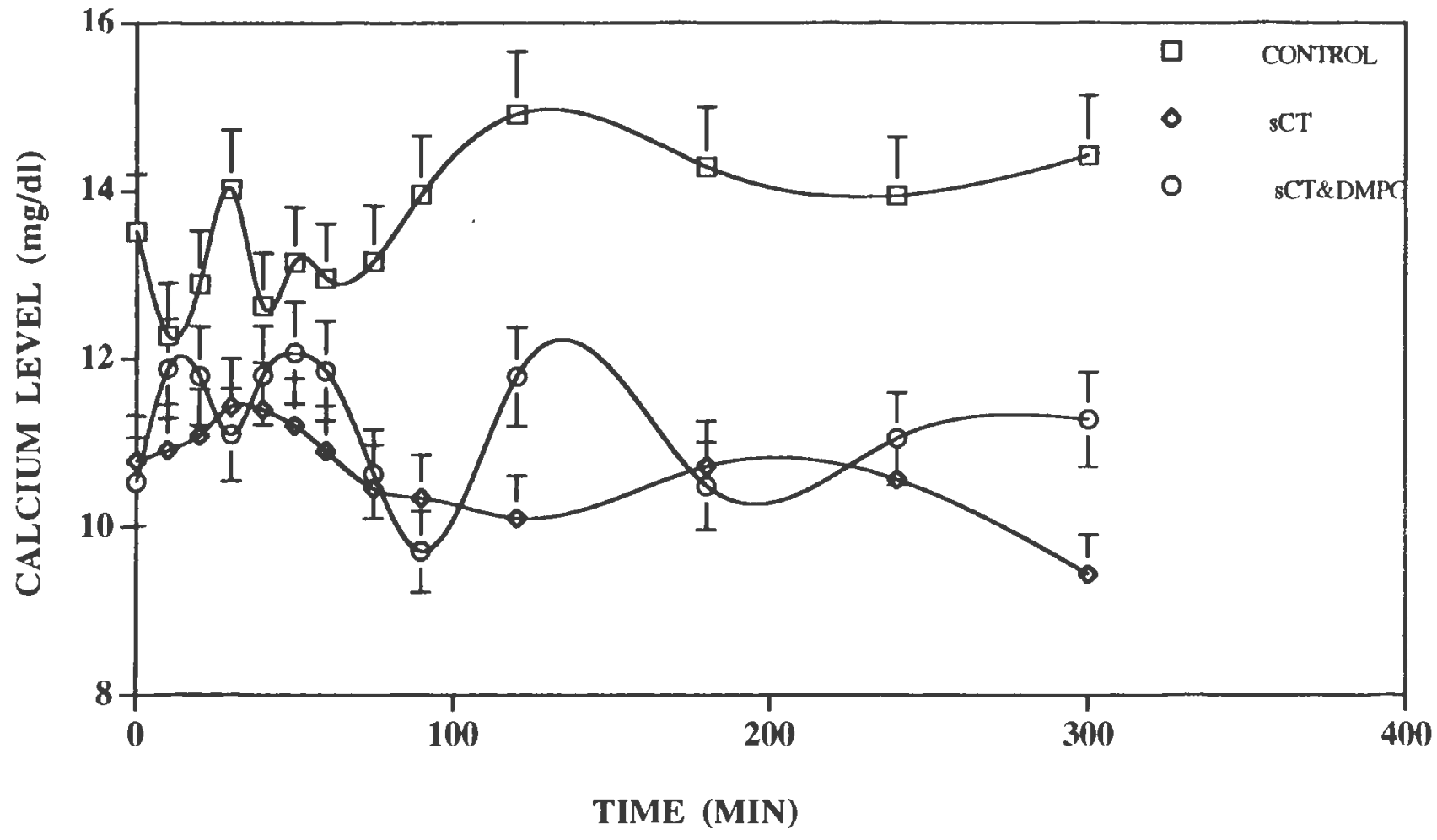


FIGURE 11 THE INFLUENCE OF A SALT CONCENTRATION OF 0.15 M AND DMPG ON THE CALCIUM LEVEL AFTER INTRANASAL ADMINISTRATION OF SALMON CALCITONIN AT HIGH VISCOSITY

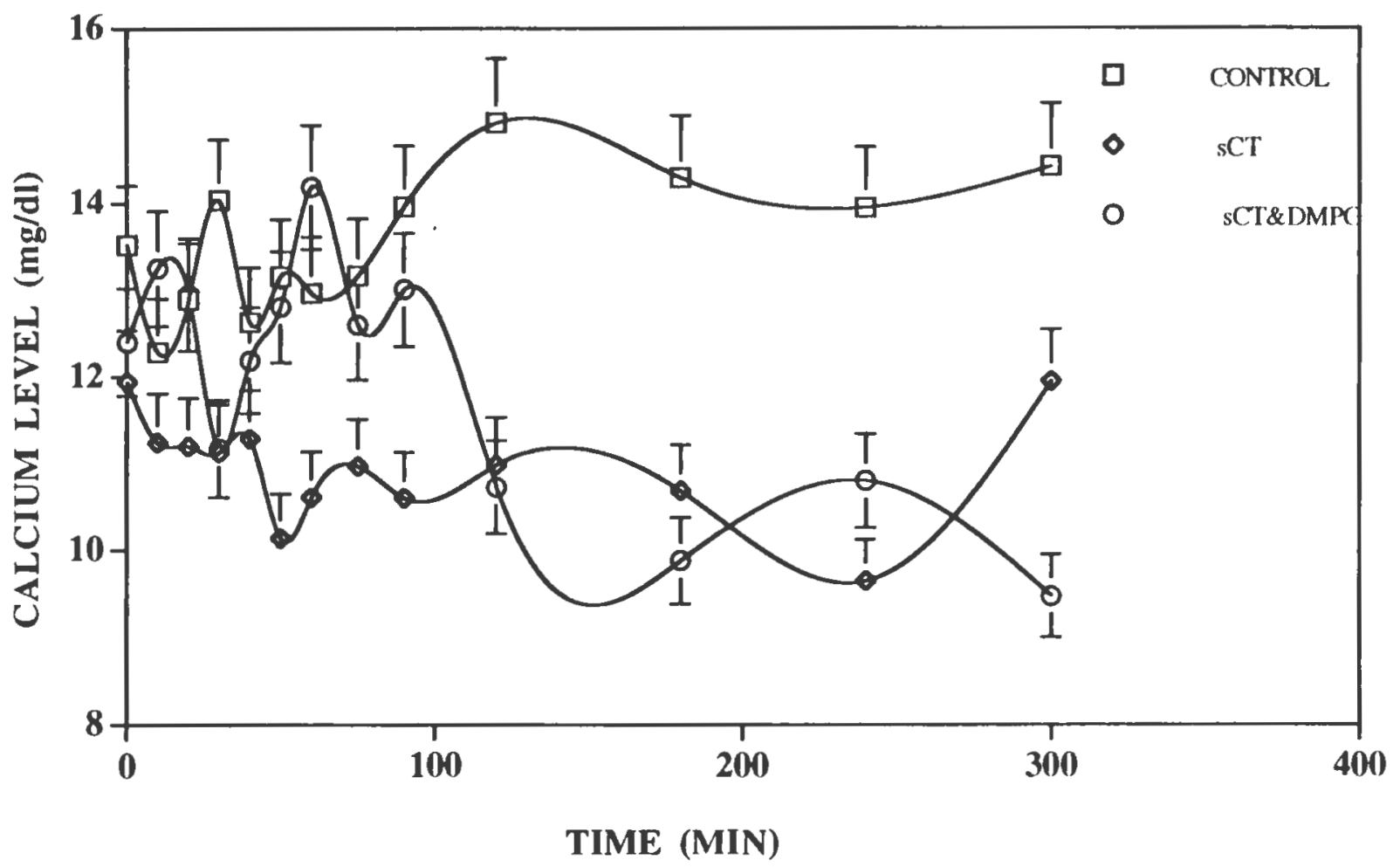


FIGURE 12 THE INFLUENCE OF A SALT CONCENTRATION OF 0.3 M AND DMPG ON THE CALCIUM LEVEL AFTER INTRANASAL ADMINISTRATION OF SALMON CALCITONIN AT HIGH VISCOSITY

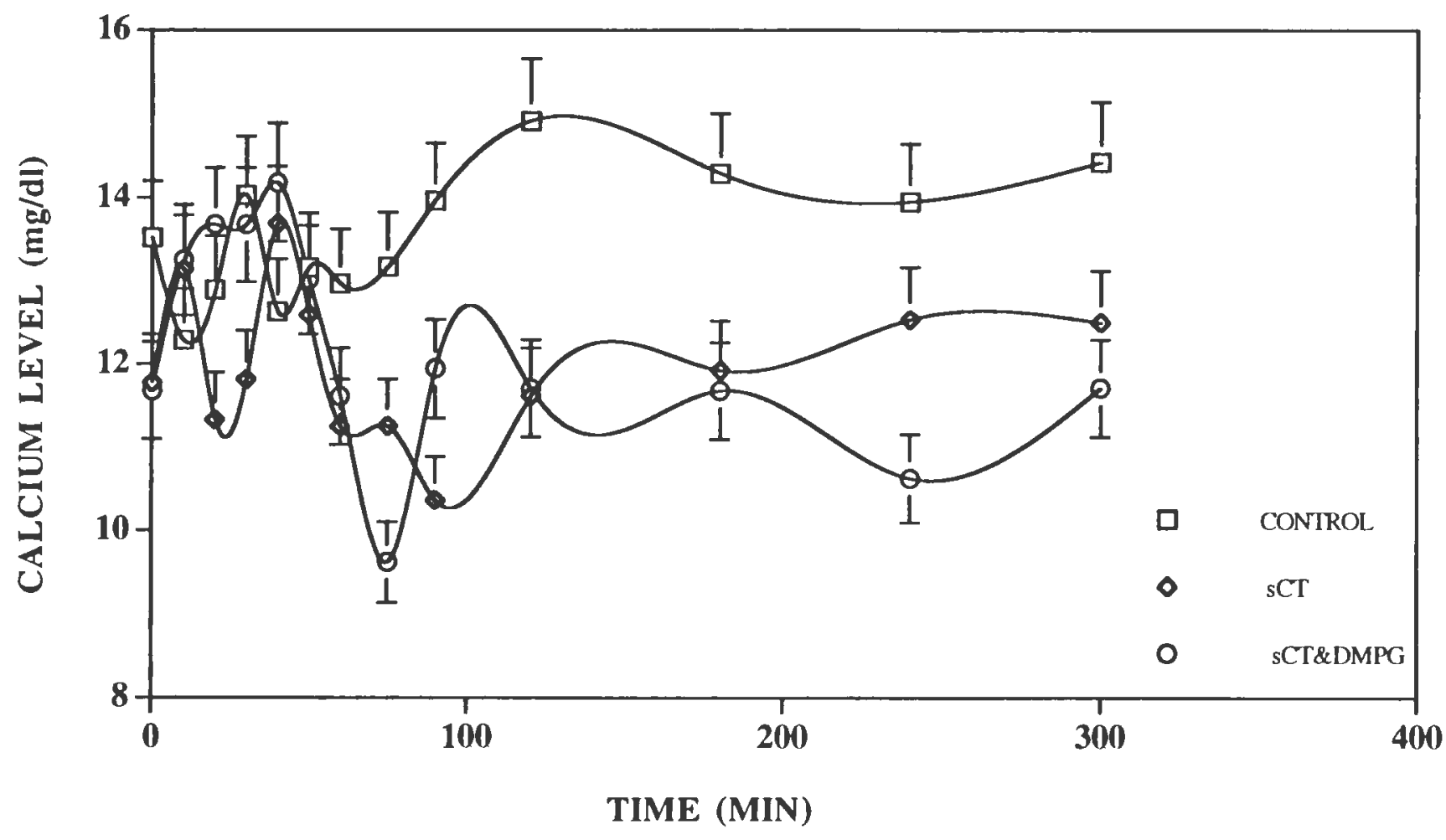


of $\mathrm{sCT}$ in the presence of $0.3 \mathrm{M} \mathrm{NaCl}$ and a viscosity of $76 \mathrm{cps}$ is shown in figure 12 . The $\% \operatorname{maxd}$ was $23.52 \%$ at 90 minutes and $29.01 \%$ at 75 minutes in the absence and presence of DMPG respectively. The AUC was 3696.28 $\mathrm{mg} \cdot \mathrm{min} / \mathrm{dL}$ with a $\mathrm{D} \%$ of $9 \%$ was calculated for formulations containing only sCT as compared to the AUC of $3510.801 \mathrm{mg} \cdot \mathrm{min} / \mathrm{dL}$ with a D\% of $13 \%$ obtained by formulations containing containing DMPG and sCT. Again there was no significant difference in the total calcium lowering effect of SCT in the absence and presence of DMPG ( $9 \%$ vs $13 \%)$.

The similarity in the extent of the hypocalcemic effect observed for the different formulations of SCT especially those which demonstrated significant differences in absorption of SCT may be attributed to the acute homeostatic mechanism between calcitonin and parathyroid hormone. The parathyroid hormone counteracts the effects of calcitonin once a critical level of hypocalcemia is attained. Thus the extent of the hypocalcemic effect is controlled by the hormonal balance. The acute control of blood calcium is accomplished by the feedback action of calcitonin and parathyroid hormone 63 . This complex regulation of blood calcium concentration makes it difficult to evaluate the efficacy of SCT delivery systems by observation of the hypocalcemic effect. Additionally the short half life of sCT makes it more difficult to correlate serum $\mathrm{SCT}$ and its biological effects 64 .

\section{Selection of the best formulations}

Response surface methodology was used as a optimization technique to select the levels of the variables that could best describe the most desirable attributes of the formulation. The response surface analysis plot demonstrated that a maxima was obtained, which suggests that there is a 
FIgure 13 THREE DIMENSIONAL SURFACE PLOT SHOWING MAXIMA FOR DMPG AND SALT CONCENTRATION WITH RESPECT TO AREA UNDER THE CURVE

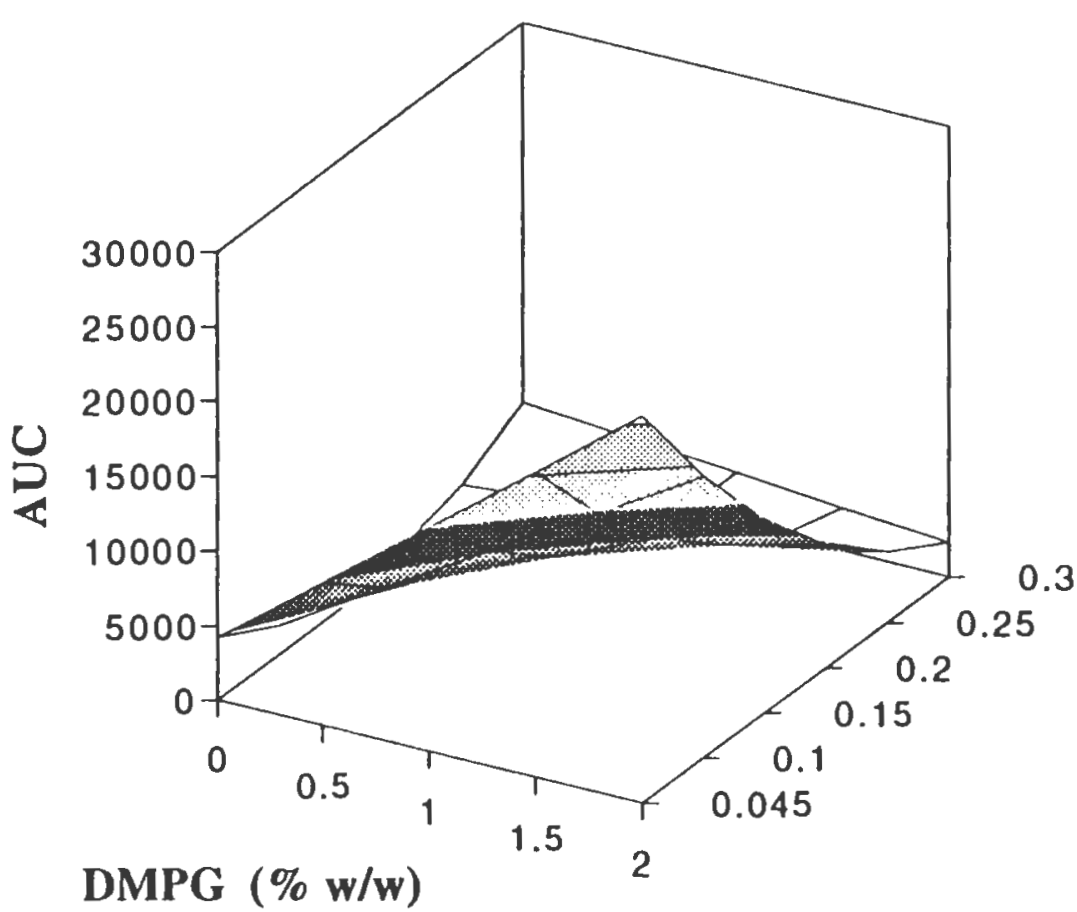

AREA UNIER CURVE A UC

(ng.min/ml)

$\square$ 25000-30000

20000-25000

15000-20000

10000-15000

5000-10000

$\sum \square \mathbf{0 - 5 0 0 0}$

DMPG $(\% \mathrm{w} / \mathrm{w})$

己 
optimum salt concentration to deliver DMPG. The three dimensional plot included concentration of $\mathrm{NaCl}$ on $\mathrm{X}$-axis, concentration of DMPG on $\mathrm{Y}$-axis and AUC on Z-axis. Figure 13 indicates an AUC of 25000-30000 ng.min/ml for $0.045 \mathrm{M}$ formulations with DMPG at a concentration of $2 \%$ and a AUC of 0 $50000 \mathrm{ng} \cdot \mathrm{min} / \mathrm{ml}$ for formulations with a $\mathrm{NaCl}$ of concentration $>0.25 \mathrm{M}$ and a DMPG of $0-0.5 \% w / w$ concentration. Thus the analysis suggests that the most effective formulation should contain DMPG at a salt concentration of $0.045 \mathrm{M}$ to provide the best absorption enhancing effect of DMPG on salmon calcitonin.

To overcome the low bioavailability of higher molecular weight polypeptides in intranasal delivery, it becomes necessary to include an absorption enhancer. However the choice of absorption enhancer is very important as it should be able to increase the uptake of the peptide, at the same time it should be safe, nontoxic in long term use and should not alter the physiology, histology of nasal cavity. This study not only investigated the role of DMPG in enhancing the absorption but also the effect of other formulation factors such as viscosity and salt concentration on the efficacy of this enhancer. Very little work has been done on phospholipids as absorption enhancers, especially acidic absorption enhancers. It is extremely important to study their effects after chronic use on ciliary beat freqency, histology and physiological functions before they can be approved as an excipient in the formulations meant for nasal delivery. 


\section{REFERENCES}

1. Lee, V. H. L., Enzymatic barriers to peptide and protein absorption and use of penetration enhancers to modify absorption. In Delivery Systems

for Peptide Drugs, Edited by Davis, S. S., Illum, S.S., Tomlinson, E., (1986) pp. 87-104, .

2. Hirai, S., Yashiki, T., Mima, H., Vaginal absorption of a potent luteinizing hormone -releasing hormone analog (leuprolide) in rats I : Absorption by various routes and absorption enhancement, J. Pharm. Sci., 71 (1982) 1367-1370.

3. Tengamnuay, P, and Mitra, A. K., Bile salt fatty acid mixed micelles a nasal absorption promoters of peptides. II In vivo nasal absorption of insulin in rats and effects of mixed micelles on the morphological integrity of the nasal mucosa., Pharm. Res., 7 (1990) 370-375.

4. Longnecker, J. P., Moses, A. C., Flier, J. S., Silver, R. D., Carey, M.C., and Dubovi, E. J., Effects of sodium taurodihydrofusidate on nasal absorption of insulin in sheep. J. Pharm. Sci., 76 (1987) 351-355.

5. Deruloo, M. J. M., Hermens, W. A. J. J., Romeyn, S. G., Verhoef, J. C., Merkus, F. W. H. M. Absorption Enhancement of Intranasally Administered Insulin by Sodium Taurodihydrofusidate in Rabbits and Rats. Pharm. Res., 6 (10) (1982) 853-856. 
6. Baldwin, P. A., Klingbeil, C.K., Garimm, C. J., Longnecker, J.P., The effect of sodium tauro-24-25, dihydrofusidate on the nasal absorption of human growth hormone in three animal models, Pharm. Res. 7(5) (1990) 547-552.

7. Mishima, M., Wakita, Y, and Nakano, Studies on the promoting effects of medium chain fatty acids salts on the nasal absorption of insulin in rats. J. Pharmacobio-Dyn., 10 (1990) 624-631.

8. Park, G. B., Shao, Z., Mitra, A.K., Acyclovir permeation enhancement across intestinal and nasal mucosae by bile salt - acylcarnitine mixed micelles, Pharm. Res.., 9 (10) (1990) 1262-1267.

9. Murakami, T., Yata, N., Tamauchi, J. Nakai, Yamazaki, M and Kamada, A., Studies on absorption promoters for rectal delivery preparations. I. Promoting efficacy of enamine derivative of amino acids for the rectal absorption of B- lactam antibiotics in rabbits, Chem. Pharm. Bull. 29 (1981) 1998-2004.

10. Kamada, A., Nishihata, T., Kimu, S., Yamamoto, M., and Yata, N., Study of enamine derivatives of phenylglycine as adjuvants for the rectal absorption of insulin, Chem., Pharm. Bull., 29 (1981) 2012-2019.

11. Sekine, M., Sasahara, K., Kojima, T., Hasegawa,K., and Okada, R., Improvement of bioavailability of poorly intestinally absorbed drugs from medium chain glyceride base. Enhancement of the rectal 
absorption of cefmetazole sodium in rabbits, Chem. Pharm., Bull., 32 (1984) 4189-4192.

12. Nishihata, T., Rytting, J. H., Higuchi, T., Caldwell, L., Enhanced rectal absorption of insulin and heparin in rats in the presence of nonsurfactant adjuvants, J. Pharm. Pharmacol., 33 (1980) 334-335.

13. Nishihata, T., Lee, C., Yamamoto, M., Rytting, J. H., and Higuchi, T., The effect of salicylate in the rectal absorption of phenylalanine and some peptides and the effects of these peptides on the rectal absorption of cefoxin and cefmetazole, J. Pharm. Sci., 73 (1984) 1326-1328.

14. Nishimura, K., Nozaki., Y., Yoshimi, A., Nakamura, S., Kitagawa, M., Kakeya, N., Kitao, K., Studies in the promoting effects of carboxylic acid derivatives on the rectal absorption of B-lactam antibiotics in rats, Chem. Pharm. Bull. 33 (1985) 282 -291.

15. Martin, G. P., Marriott., C., Kellaway, I. W., Direct effects of bile salts and phospholipids on the physical property of mucus, Gut, 19 (1978) 103.

16. Nishhata, T., Kim, S., Morishita, S., Kamada, A., Yata, N., and Higuchi, T., Adjuvant effects of glyceryl esters of acetoacetic acid on rectal absorption of insulin and insulin in rabbits, J. Pharm. Sci., 72 (1983) 280.

17. Nishihata, T., Okamura, Y., Kamada, A., Higuchi, T., Yagi, T., Kawamori, R., and Scichiri, M., Enhanced bioavailability of insulin after rectal 
administration with enamine as adjuvant in depancreatized dogs. J. Pharm. Pharmacol., 37 (1985a) 22.

18. Okada, H., Yamazaki, I., Ogawa, Y., Hirai, S., Yashiki, T., and Mima, H. J., Vaginal absorption of potent luteinzing hormone releasing hormone analog (leuprolid) in rats. II. Mechanism of absorption enhancement with organic acids. J. Pharm. Sci., 72 (1982) 75.

19. Yamashita, S., Saitoh, H., Nakainshi, K., Masada, M., Nadai, T., and Kimura, T., Characterization of enhanced intestinal permebility; electrophysiological study on the effects of diclofenac and ethylenedianinetetraacetic acid, J. Pharm. Pharmcol., 37 (1985) 512.

20. Sakai, K., Kutsuna, T. M., Nishino, T., Fufihara, Y., and Yata, N., Contribution of calcium ion sequestration by polyoxyethylated non-ionic surfactants to the enhanced colonic absorption of p-aminobenzoic acid, J. Pharm. Sci., 75 (1986) 387.

21. Kajii, H., Horie, T., Hayashi, M., and Awazu, S., Fluorescence study on the interaction of salicylate with rat small intestinal epithelal cells: possible mechanisms for the promoting effects of salicylate on drug absorption in vivo. Life Sci., 37 (1985) 523.

22. Muraushi, N., Nakajima, Y., Kinugawa, M., Muranishi, S., Sezaki, H., Mechanism for the inducement of the intestinal absorption of poorly absorbed drugs by mixed micelles II. Effects of the incorporation of 
various lipids on the permeability of liposomal membranes. Int. J. Pharm., 4 (1982) 281.

23. Muranushi, N., Takagi, N., Muranishi, S., and Sezak, H., Effect of fatty acids and monoglycerides on permeability of lipid bilayer. Chem. Phys. Lipis, 28 (1981) 269.

24. Okada, H., Yamazaki, I., Ogawa, Y., Hirai, S., Yashiki, T., and Mima, H. J., Vaginal absorption of a potent luteinizing hormone- releasing hormone analog (leuprolide) in rats. I. Absorption by various routes and absorption enhancement, J. Pharm. Sci., 72 (1982) 75.

25. Hirai, S., Yashiki, T., and Mima, H., Effect of surfactants on the nasal absorption of insulin in rats, Intl. J. Pharm., 9 (1981a) 165.

26. Su, K. S. E., Campanale, K. M., Mendelsohn, L. G., Kerchner, G. A., and Gries, C. L., Nasal delivery of polypeptides I: Nasal Absorption of enkephalins in rats, J.Pharm Sci., 74 (1985) 394.

27. Kim, S., Kamada, A., Higuchi, T., and Nishihata, T., Effects of enamine derivatives on the rectal absorption of insulin in dogs and rabbits, $\mathrm{J}$. Pharm. Pharmacol., 35 (1983) 100.

28. Nishihata, T., Higuchi, T., and Kamada, A., Salicylate-promoted permeation of cefoxition, Insulin and phenylalanine across red cell membrane, Possible mechanisms, Life Sci., 34 (1984a). 437. 
29. Hirai, S., Yashiki, T and Mima H., Mechanisms for the enhancement of the nasal absorption of insulin by surfactants, Int. J. Pharm. 9 (1984a) 173.

30. Taniguchi, K., Muranishi, S., and Sezaki, H., Enhanced intestinal permeability to macromolecules II. Improvements of the large intestinal absorption of heparin by lipid-surfactant mixed micelles in rat. Int. J. Pharm., 4 (1980) 219.

31. Kamada, ., Nishihata, T., Kim, S., Yamamoto, M., and Yata, N., Study of enamine derivatives of phenylglycine as adjuvants for the rectal absorption of insulin, Chem. Pharm. Bull., 29 (1980) 2012.

32. Hayashi, M., Hirasawam T., Muraoka, T., Shiga, M., and Awazum S., Comparison of water influx and sieving coefficient in rat jejunal, rectal and nasal absorption of antipyrine, Chem. Pharm. Bull., 33 (1985) 2149.

33 Bloom, W and Fawcett, D. W., A Textbook of Histology, W. B. Saunders CO., Philadelphia., (1968).

34. Pontiroli, A. E., Alberetto, M., Secchi, A., Dossi, G., Bosi, I., and Pozza, G., Insulin given intranasally induces hypoglycaemia in normal and diabetic subjects, Brit. Med. J., 284 (1982) 303.

35. Moses, A.C., Gorson, G. S., Carey, M. C., and Flier, J. S., Insulin administered intranasally as an insulin-bile salt erosol: effectiveness and reproducibility in normal and diabetic subjects. Diabetes, 32 (1977) 1040. 
36. Stanzani, L., Mascellanio, G., Corbelli, G. P., and Bianchini, P., Rectal absorption of some glycosaminoglycan sulphates and heparin in rats, J. Pharm. Pharmacol., 33 (1981)783.

37. Sithigorngul, P., Burton, Nishhata, T., and Caldwell, L., Effects of sodium salicylate on epithelial cells of the rectal mucosa of the rat: a light and electron microscopy study, Life. Sci., 33 (1983 1025.

38. Yagi, T., Hakui, N., Yamasaki, y., Kawamori, R., Shichiri, M., Abe, H., Kim, S., Miyake, M., Kamikwawa, K., Nishihata, T., and Kamada, A., Insulin suppository: enhanced rectal absorption of insulin using an enamine derivative as a new promoter., J. Pharm. Pharmacol. 37 (1985) 512.

39. Shao, Z., Krishnamoorthy, R., and Mitra, A. K., Cyclodextrins as nasal absorption promoters of insulin: Mechanistic Evaluations.

Pharm. Res., 9(9) (1992) 1157-1163.

40. Hermens, W. A. J. J., Hooymans, P. M., Verhoef, J. C., Merkus, F. W. H., Effects of absorption enhancers on human nasal tissue ciliary movement in vitro., Pharm. Res., 7 (2) (1990) 144-146.

41. Donovan, M.D., Flynn, G. L., and Amidon, G. L., The molecular weight dependence of nasal absorption : The effect of absorption enhancers. Pharm. Res., 7 (8) (1990) 808-815 
42. Stafford, R. E., and Dennis, E. A., Lysophospholipids as biosurfactants, Colloids and surfaces, 30 (1988). 47-64.

43. Tagesson, C., Franzen, L., Dahl, G, and Westrom, B., Lysophosphatidylcholine increases rat ileal permeability to macromolecules, Gut, 26 (1985) 369-377.

44. Illum, L., Farraj, N. F., Critchley, H., Johansen, B. R., and Davis, S. S.., Enhanced nasal absorption of insulin in rats using lysophosphatidylcholine, Int. J. Pharm., 57 (1989) 49-54.

45. Illum, L., Farraj, N. F., Davis, S. S., Johansen, B. R., and O'Hagen, D. T., Investigation of the nasal absorption of biosynthetic human growth in sheep - use of a bioadhesive microsphere delivery system, Int. J. Pharm. 63 (1990) 207-211.

46. O'Hagan, D. T., Critchley, H., Farraj, N. F.., Johansen, B. R.,, Davis, S. S., and Illum, L., Effects of various absorption enhancers on the nasal absorption of biosynthetic human growth hormone in the rat. Pharm. Res., 7 (1990) 772-776.

47. Epand, R., Epand, R. F., Orlowski, R. C., Flanigan, Everett, Stahl, Glenn, L., A comparison of the interaction of glucagon, human parathyroid hormone-(1-34)-peptide and calcitonin with dimyristoylphosphatidylglycerol and with dimyristoylphosphatidylcholine., Biophys. Chem, 23 (1-2) (1993) 39-48. 
48. Epand, R. M., Epand, R. F., Orlowski, R. C., Presence of an amphipathic helical segment and its relationship to biologica lpotency of calcitonin analogs., Int. J. Pept. Protein Res., 25(1) (1993) 105-111.

49. Epand, R. M., Epand, R. F., Stafford, A. R., Orlowski, R. C., Deletion sequences of salmon calcitonin that retain the essential biological and conformational features of the intact molecule., J. Med. Chem., 31(8) (1988) $1595-1598$.

50. Epand, R. M., Epand, R. F., Orlowski, R. C., Schlueter, R. J., Boni, L. T., Hui, S. W., Amphipathic helix and its relationship to the interaction of calcitonin with phospholipids., 22 (22) (1993) 5074-84.

51. Levy, R. S., Efficient Calcitonin Production, Biopharm, May (1993) 3639.

52. Lee, W. A., Permeation Enhancers for the nasal delivery of protein and peptide therapeutics, Biopharm, 3 (10) (1990) 22-25.

53. Harris, A.S., Ohlin, M., Svensson, E., Lethagen, S. and Nilsson, I. M., Effect of viscosity on the pharmacokinetics and biological response to intranasal desmopressin, J. Pharm. Sci., 471 (1992).

54 Harris, A.S., Ohlin, M., Svensson, E., Lethagen, S. and Nilsson, I. M., Effects of concentration and volume on nasal bioavailability and biological response to Desmopressin, J. Pharm. Sci., 77: 4 (1988) 337-339. 
55. Jager-Waldau, R., A Two Phase Flow Mechanical spray pump: A possible alternative to propellant driven MDI's. Journal of Biopharmaceutical Sciences, 3(1/2) (1992) 77-84.

56. SAS/STAT User's guide, Vol 2., GLM-VAR COMP, Version 6, 4th Edition, SAS Institute Inc., Cary, NC 27512, pp. 1457-1478

57. Lai, C. Y., CRC Crit. Rev. Biochem., 9 (1980) 171.

58. Law, P.Y., Harris, R. A., Loh, H.H., and Way, E. L., Evidence for the involvement of cerebroside sulfate in opiate receptor binding., J. Pharmacol. Exp. Therp. 207 (1978) 458.

59. Harris, A.S., Svensson, E., Wagner, Z.G., Moore, J. A., and Patton, J. A., Effect o viscosity on particle size, deposition and clearance of nasal delivery systems containing desmopressin.,Int. J. Pharm. Sci., 77 (1988) 405-408.

60. Pennington, A.K., Ratcliffe, J. H., Wilson, C.G., and Hardy, J. G., The influence of solution viscosity on nasal spray deposition and clearance., Int. J. Pharm., 43 (1988) 221-224.

61. Harris, A. S., Ohlin, M., Svensson, E., Letagen, S., and Nilsson, I. M., J. Pharm. Sci., 78 (1989) 470-471.

62. Harris, A.S., Nilsson, I. M., Wagner, Z.G., Alkner, U., J. Pharm. Sci., 75, 1085-1088, 1986. 
63. Morimoto, K., Morisaka, K., and Kamada, ., Enhancement of nasal absorption of insulin and calcitonin using polyacrylic acid gel, J. Pharm. Pharmacol., 37 (1985) 134-136.

64. Ziegler, R., Holz, G., Strrebl, W and Raue, R., Nasal applications of calcitonin in Paget's disease of bone, Acta Endoac. Suppl., 215, 54-55 (1978) 


\section{CONCLUSIONS}


1. A study of delivery devices and components which used the Malvern laser sizer to determine the qualitative and quantitative spray profile indicated that the currently available metered nasal devices were capable of dispensing low viscosity solutions as a fine spray and maintaining a Gaussian distribution. The devices also demonstrated an excellent total dose delivery and reproducibility for all types of solutions.

2. The nasal micron spray pump, a prototype device, that was developed for pulmonary drug delivery is very versatile and can be extremely valuable in nasal drug delivery. It is capable of generating a narrower droplet size distribution and a fine spray for viscous solutions which cannot be achieved with currently available spray pumps.

3. Among the formulation variables investigated, tonicity elicited a significant difference in achieving a higher concentration of salmon calcitonin in the serum and enhancing the bioavailability of salmon calcitonin.

4. Viscosity studied at the two levels indicated that although the droplet spray distribution was significantly affected, no significant improvement in the bioavailability of salmon calcitonin was found for solutions differing in viscosity. 
5. The use of dimyristoylphosphatidylglycerol, an acidic phospholipid, a novel permeation enhancer demonstrated an increase in the bioavailability of salmon calcitonin.

6. The absorption enhancing activity of dimyristoylphosphatidylglycerol when studied as a function of salt concentration indicated that a low salt concentration was required for the optimal activity.

7. The pharmacodynamic effect of salmon calcitonin of lowering of calcium indicated that although it was a useful parameter for indirectly measuring the efficacy of salmon calcitonin formulations, it did not correlate directly with the plasma concentration of the drug and was very difficult to interpret the results. This inconsistency was attributed to the fact that the hypocalcemic response is controlled by the parathyroid gland which correctively responds to calcitonin plasma concentration.

8. The low bioavailability of higher molecular weight polypeptides such as salmon calcitonin can be enhanced by a optimization of both formulation parameters and nasal administration device variables.

This investigation emphasized a need to study both formulation and devices variables to overcome low bioavailability. This approach is of tremendous value to the formulation scientist by increasing the probability of optimizing drug delivery and accelerating product development. 
SECTION III

160 


\section{APPENDIX A}

\section{TECHNIQUES USED FOR ANALYSIS}




\section{QUANTITATIVE DETERMINATTION OF SALMON CALCITONIN IN}

\section{SERUM}

\section{Double Antibody Radioimmunoassay}

\section{Principle}

Double antibody radioimmunoassay is a sequential competitve radioimmunoassay. The sample is first preincubated with anti-calcitonin serum. 125-I -labeled calcitonin then competes with the calcitonin in the serum samples for antibody sites. After incubation for a fixed time, separation of bound from free is achieved by the PEG- acclerated double antibody method. The antibody-bound fraction is precipitated by centrifugation under refrigerated conditions. The precipitated pellets are counted by a gamma counter.

\section{Reagents provided (Diagnostics Systems Limited, Webster, TX)}

1. Calcitonin Antiserum contains guinea pig as primary antibodies.

2. 125 I- Calcitonin

3. $125 \mathrm{I}$ - Calcitonin calibrators.

Six vials labeled $A$ through $E$ with 0 to $50 \mathrm{ng} / \mathrm{ml}$ concentration of salmon calcitonin.

4. Precipitating reagent

One vial of precipitating reagent consisting of guinea pig-antigoat gamma globulin in polyethlene glycol. 


\section{Calcitonin controls}

Two vials labeled calcitonin controls I and II containing calcitonin in a protein based matrix containing $2 \mathrm{mg} / \mathrm{ml}$ and $10 \mathrm{ng} / \mathrm{ml}$ as low and high control levels of salmon calcitonin.

All the samples except precipitating reagent were lyophilized. They were stored in refrigerator and were reconstituted with distilled water for 30 minutes before the use.

\section{Procedure}

Serum samples were incubated with calcitonin antiserum for $6 \mathrm{hrs}$ at $2-8^{\circ} \mathrm{C}$. After the first incubation, radiolabeled calcitonin was added and samples reincubated for $24 \mathrm{hrs}$ at $2-8^{\circ} \mathrm{C}$. Separation was achieved by the addition of precipitating reagent and was followed by a third incubation for $1 \mathrm{hr}$. THe samples were centrifuged for 30 minutes aat $3000 \mathrm{rpm}$ at $20 \mathrm{C}$. The supernatant was drained off, the rim of tubes wiped to eliminate radioactive contamination and precipitated pellets were counted in a gamma counter for 1 minute in terms of cpm (counts per minute) and analysis of each sample was performed in duplicate.

\section{Calculations}

To be able to calculate the concentration of calcitonin on serum samples, the first step was to calculate the total count, non-specific binding, maximum binding and $\% \mathrm{~B} / \mathrm{Bo}$. 
The cpm of 125 Iodinated Calcitonin was counted and termed as total counts. The nonspecific binding (NSB) was determined by using deionized water instead of serum samples and was subtracted from the readingt in cpm obtained for all serum samples,

\section{Net Count $=$ average $\mathrm{cpm}-$ average NSB $\mathrm{cpm}$}

Maximum binding was provided by zero $\mathrm{ng} / \mathrm{ml}$ of calcitonin standard. The counts obtained by $0 \mathrm{ng} / \mathrm{ml}$ and subtracted by non-specific binding was taken to be $100 \%$ and was called maximum binding.

Percent bound $(\mathrm{B} / \mathrm{BO})=\underline{\text { Net count }} \times 100$ Net maximum binding

The sigmoidal standard curve of $\mathrm{B} / \mathrm{Bo}$ vs $\log [\mathrm{sCT}]$, typical of competitive binding assays was linearized using the log transformation. Using the linear log graph paper, percent bound was plotted on the vertical axis against concentration on the horizontal axis for each of the nonzero calibrators. The best fit was determined using a non weighted least square regression analysis.

\section{Results}

The radioimmunoassay quantitation range was $100 \mathrm{pg} / \mathrm{ml}-5000 \mathrm{pg} / \mathrm{ml}$. The square of the coefficient of determination on this range for the $B / B$ oversus $\log [\mathrm{sCT}]$ plots was greater than 0.993 for all assays performed in duplicate. 


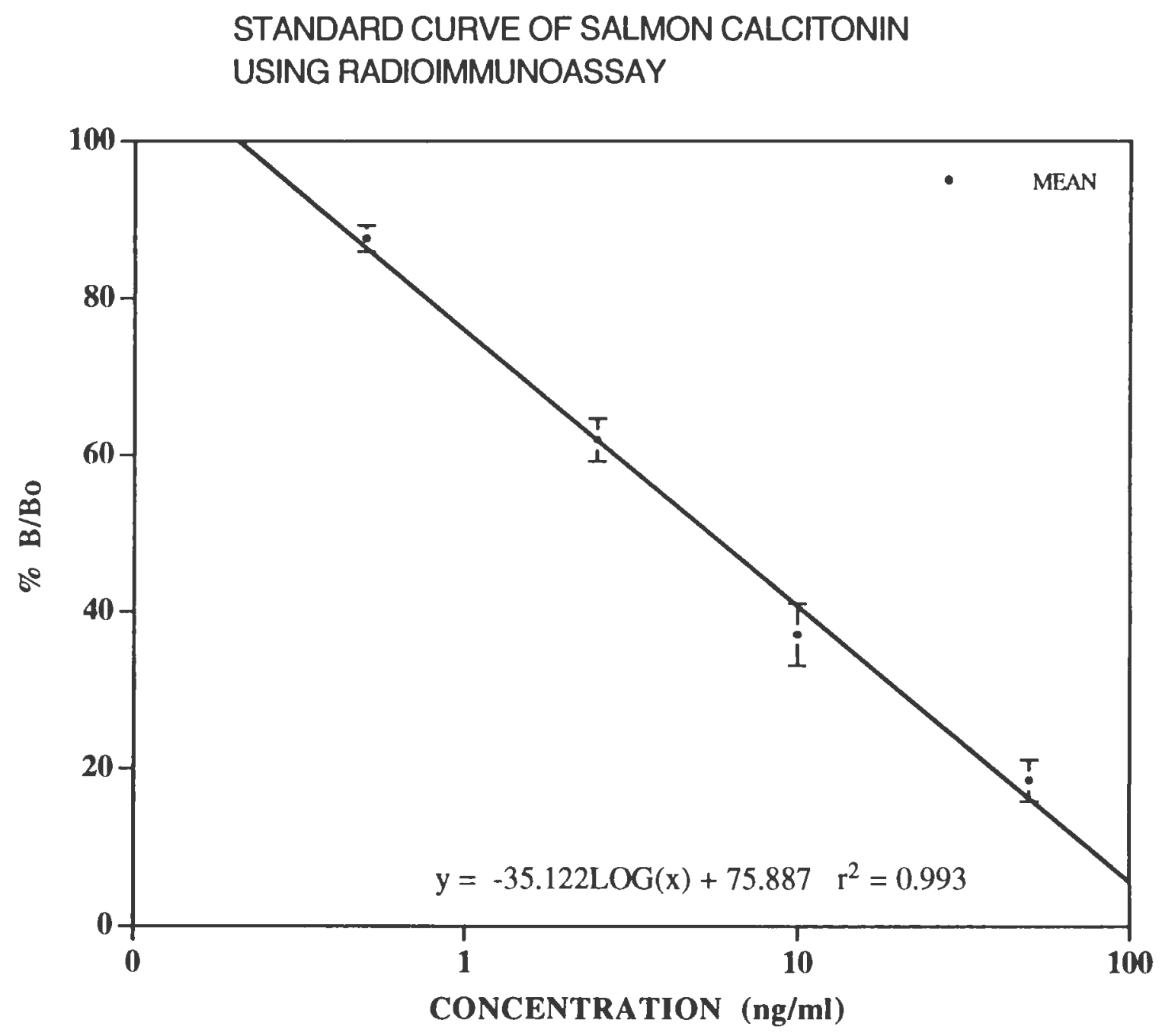




\title{
QUANTITATIVE DETERMINATION OF CALCIUM IN SERUM CALCIUM PLUS ${ }^{\circledR}$ PROCEDURE
}

\section{Principle}

The calcium plus ${ }^{\circledR}$ procedure developed by DMA, Houston, TX., utilizes a dye, arsenazo III which binds to calcium at an acid $\mathrm{pH}$. A bluish - purple complex is formed. The intensity of the color formed is measured by an increase in absorbance of the reaction mixture at $650 \mathrm{~nm}$.

\author{
Reagents Provided \\ Calcium plus $\mathbb{B}$ reagent \\ Control sera of concentration of calcium $10 \mathrm{mg} / \mathrm{dL}$
}

Composition of Calcium Plus Reagent

Arsenzo III $(0.136 \mathrm{mmol} / \mathrm{L})$

Buffer

Surfactant

Sodium azide

\section{Manual Procedure}

1. Add $2 \mathrm{ml}$ of calcium plus reagent into labeled test tubes.

2. Add $0.025 \mathrm{ml}$ of each control and samples to their respective test tubes.

3. Mix well

4. Use $0.025 \mathrm{ml}$ deionized water for reagent blank instead of sample or control.

5. Incubate for 2 minutes at the reaction temperature. 
6. Set the wavelength of the instrument at $650 \mathrm{~nm}$. Zero with the reagent blank.

7. Read and record absorbance of the samples and controls.

\section{Calculations}

Absorbance of unknown $\times$ Concentration of standard $=$ Calcium $(\mathrm{mg} / \mathrm{dL})$ Absorbance of standard

\section{RESULTS}

Serum calcium was quantified by uv spectroscopy and the range of the linearity was determined to be between $5 \mathrm{mg} / \mathrm{dL}-25 \mathrm{mg} / \mathrm{dL}$. The square of the coefficient of determination in this range for the absorbance (AUFS) versus concentration $(\mathrm{mg} / \mathrm{dL}$ ) was 0.999 for all the assays performed in duplicate during the course of study. 
STANDARD CURVE OF CALCIUM USING

ARSENAZO COMPLEX III MEASURED AT $650 \mathrm{~nm}$.

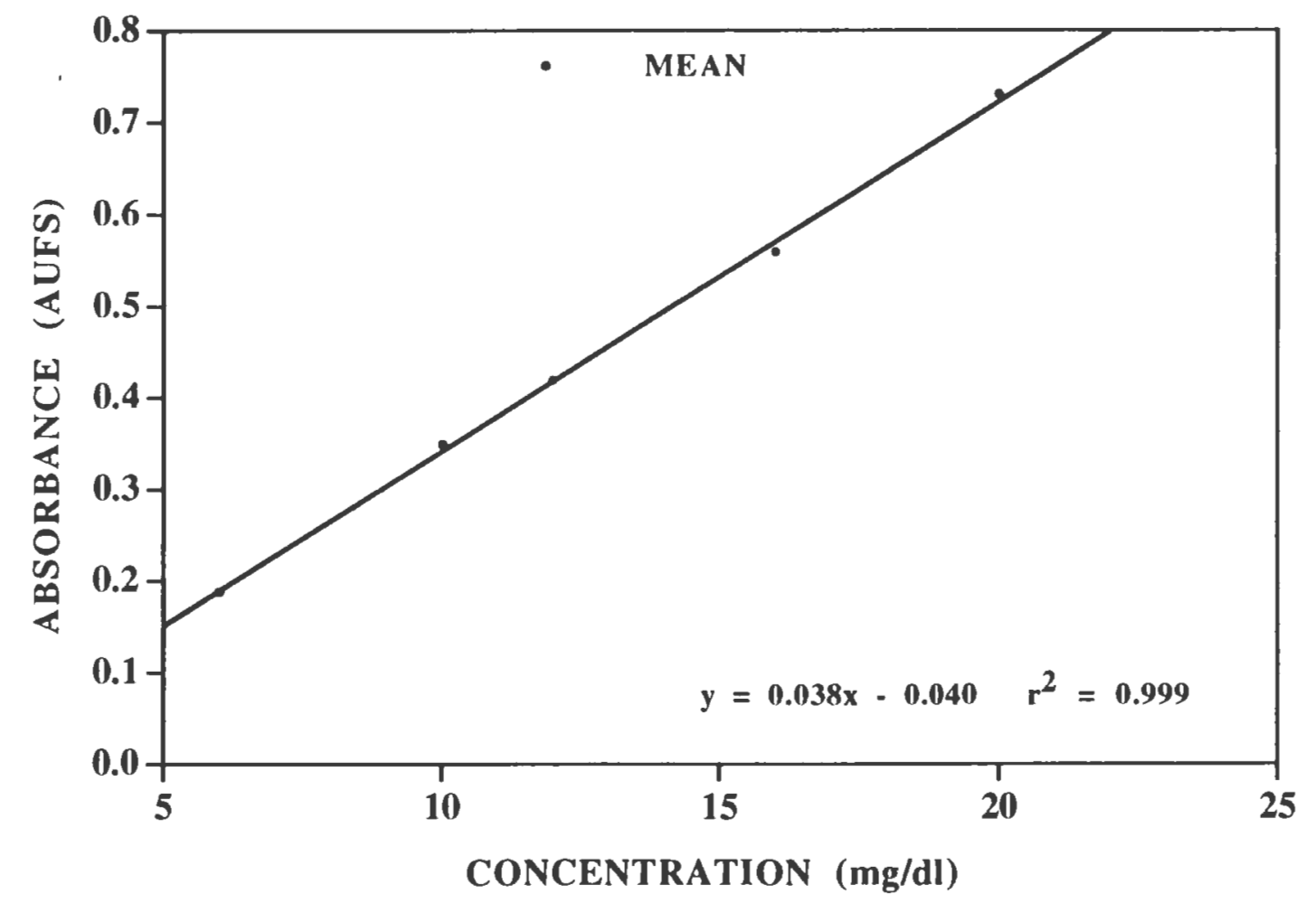




\section{APPENDIX B}

STATISTICAL DATA SUPPORTING MANUSCRIPT I 


\begin{tabular}{|c|c|c|c|c|}
\hline $\begin{array}{r}\text { STAT } \\
\text { FC }\end{array}$ & $\begin{array}{l}\text { ISTICAL ANA } \\
\text { ORMULATIOA }\end{array}$ & $\begin{array}{l}\text { ALYSIS OF MA } \\
\text { N VARIABLE - }\end{array}$ & $\begin{array}{l}\text { LVERN D } \\
\text { VISCOSIT }\end{array}$ & ATA \\
\hline & Analysis of & Variance Proce & dure & \\
\hline Dependent Variable & M50 & & & \\
\hline Source & $\begin{array}{l}\text { Sum of } \\
\text { Squares }\end{array}$ & $\begin{array}{l}\text { Mean } \\
\text { Square }\end{array}$ & $F$ Value & $\operatorname{Pr}>F$ \\
\hline Model & 6204.0566000 & 3102.0283000 & 126.56 & 0.0001 \\
\hline Error & 147.0588000 & 24.5098000 & & \\
\hline Corrected Total 8 & 6351.1154000 & & & \\
\hline R-Square & C.V. & Root MSE & $\mathrm{M} 50 \mathrm{Me}$ & ean \\
\hline 0.976845 & 7.138084 & 4.9507373 & 69.356667 & \\
\hline Dependent Variable: & M90 & & & \\
\hline Source & $\begin{array}{l}\text { Sum of } \\
\text { Squares }\end{array}$ & $\begin{array}{l}\text { Mean } \\
\text { Square }\end{array}$ & F Value & $\operatorname{Pr}>F$ \\
\hline Model & 90381.751489 & 45190.875744 & 229.02 & 0.0001 \\
\hline Error & 1183.945667 & 197.324278 & & \\
\hline Corrected Total 8 & 91565.697156 & & & \\
\hline R-Square & C.V. & Root MSE & M90 & Mean \\
\hline 0.987070 & 8.366806 & 14.047216 & 167.89222 & \\
\hline
\end{tabular}




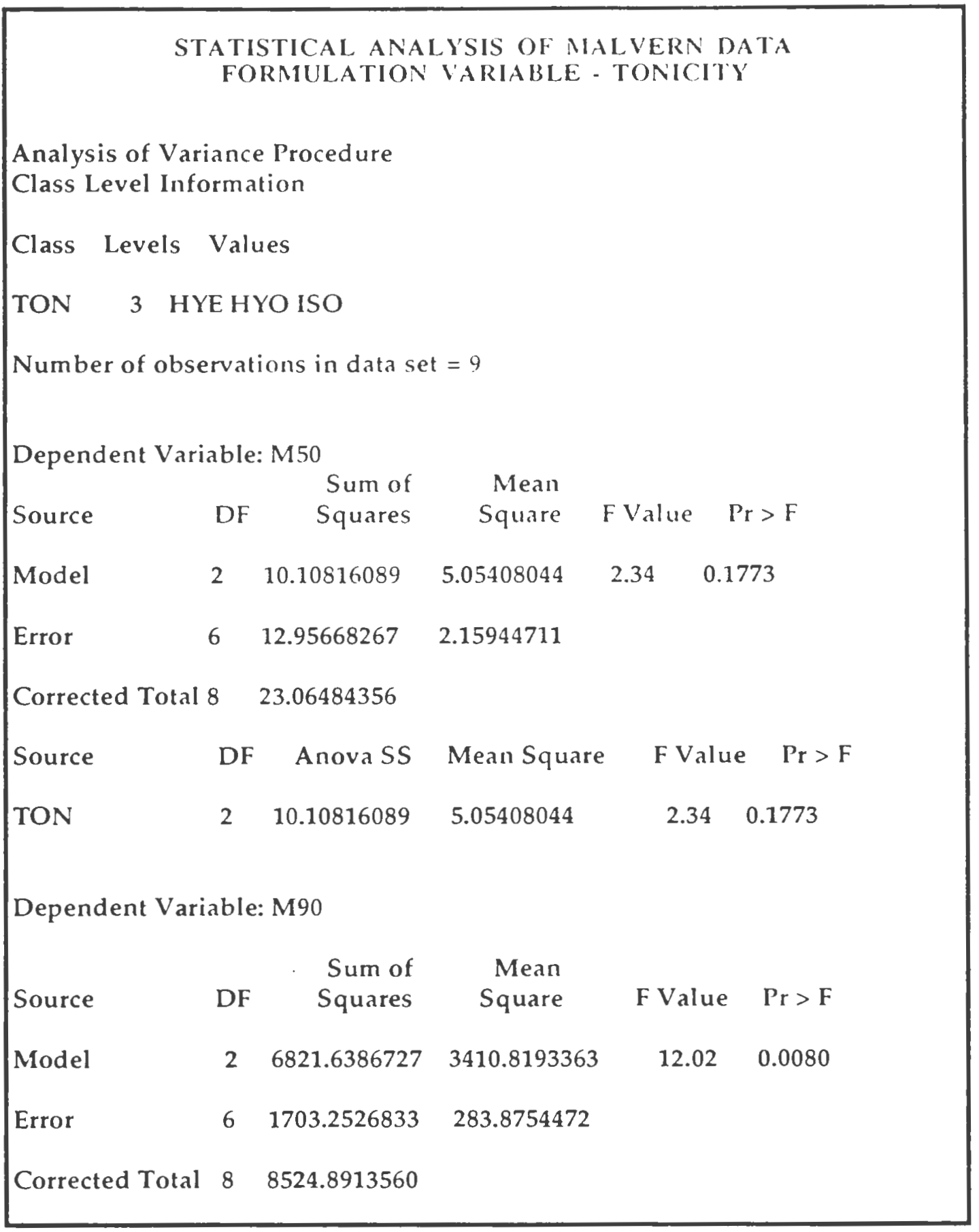




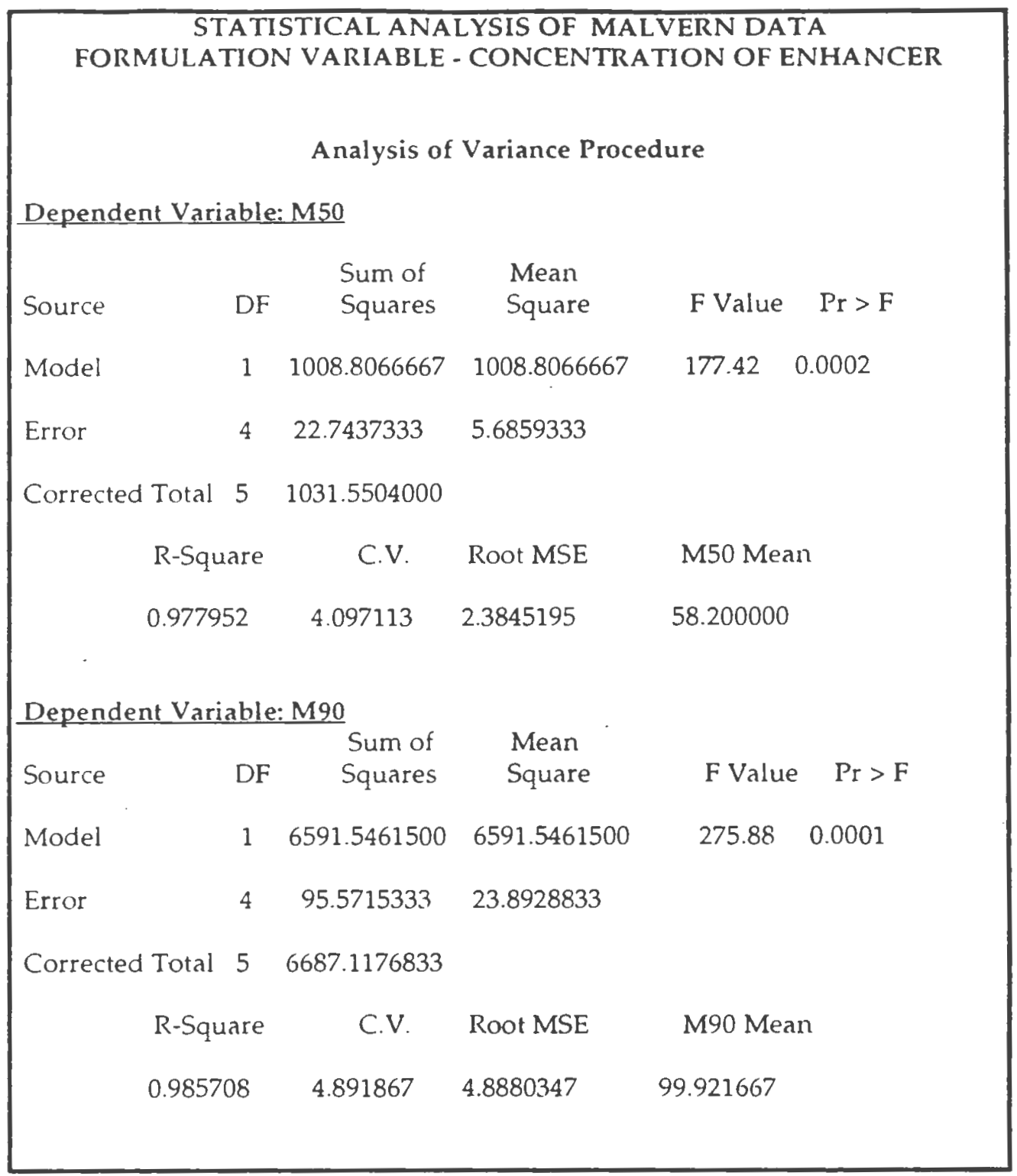




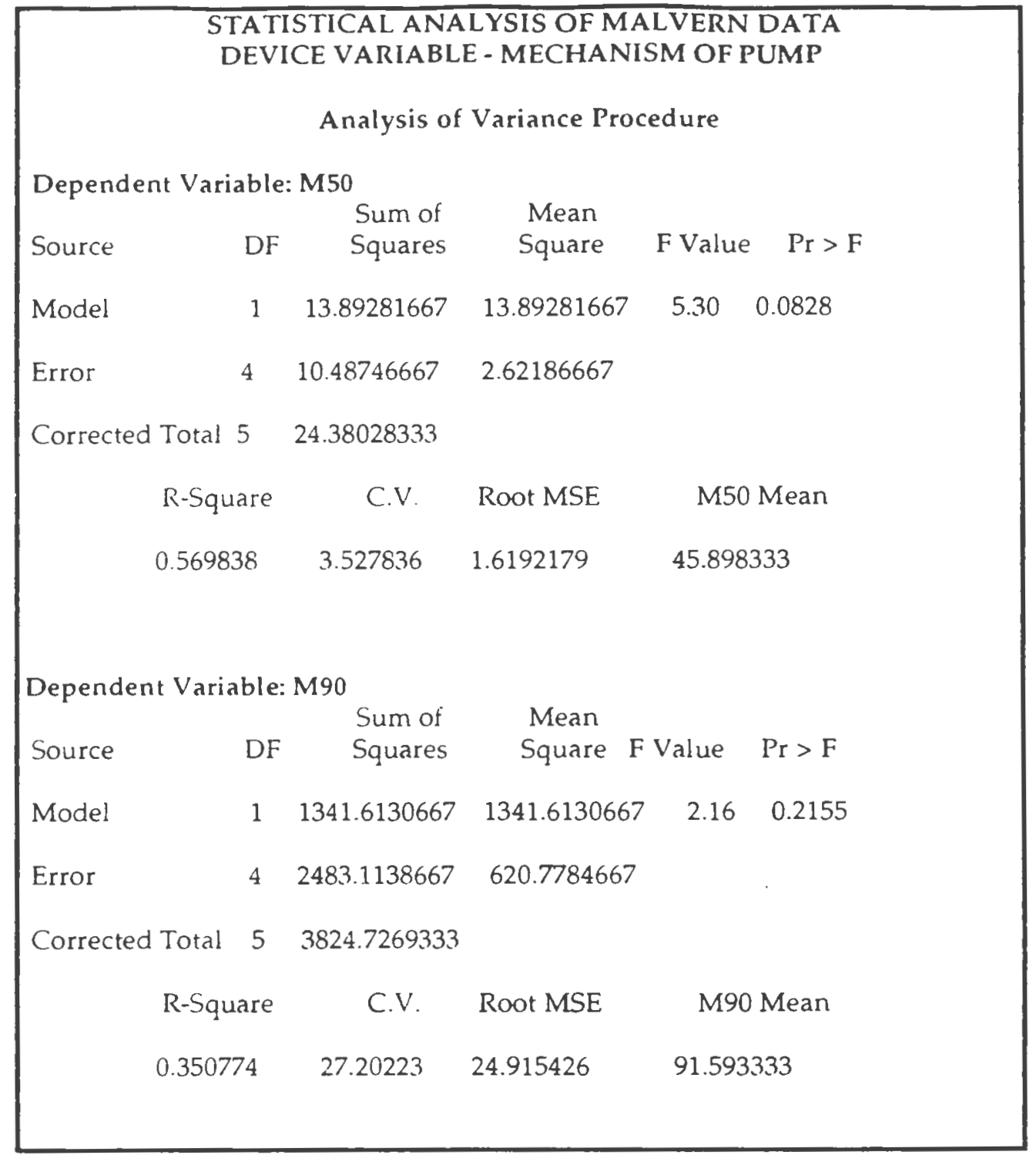




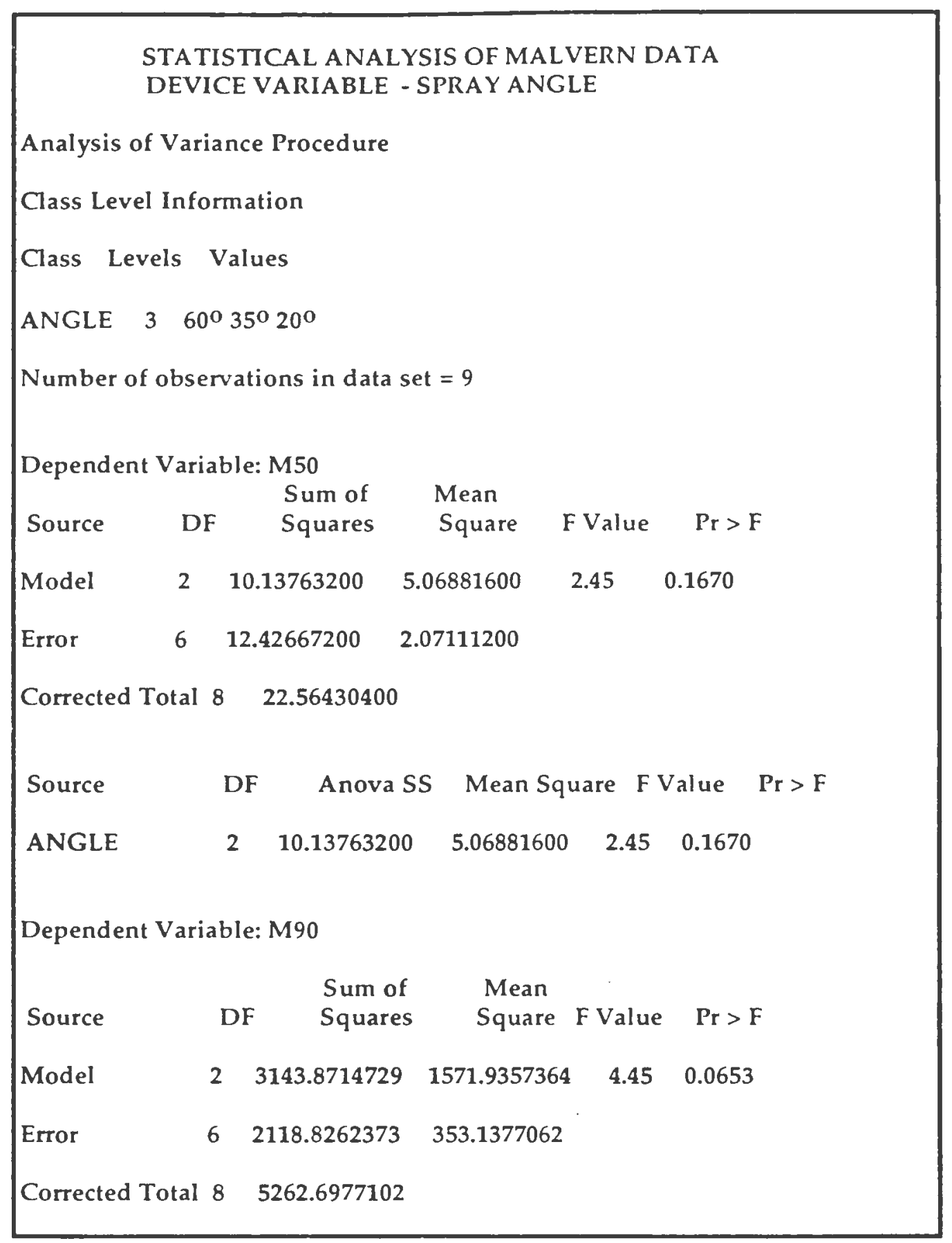




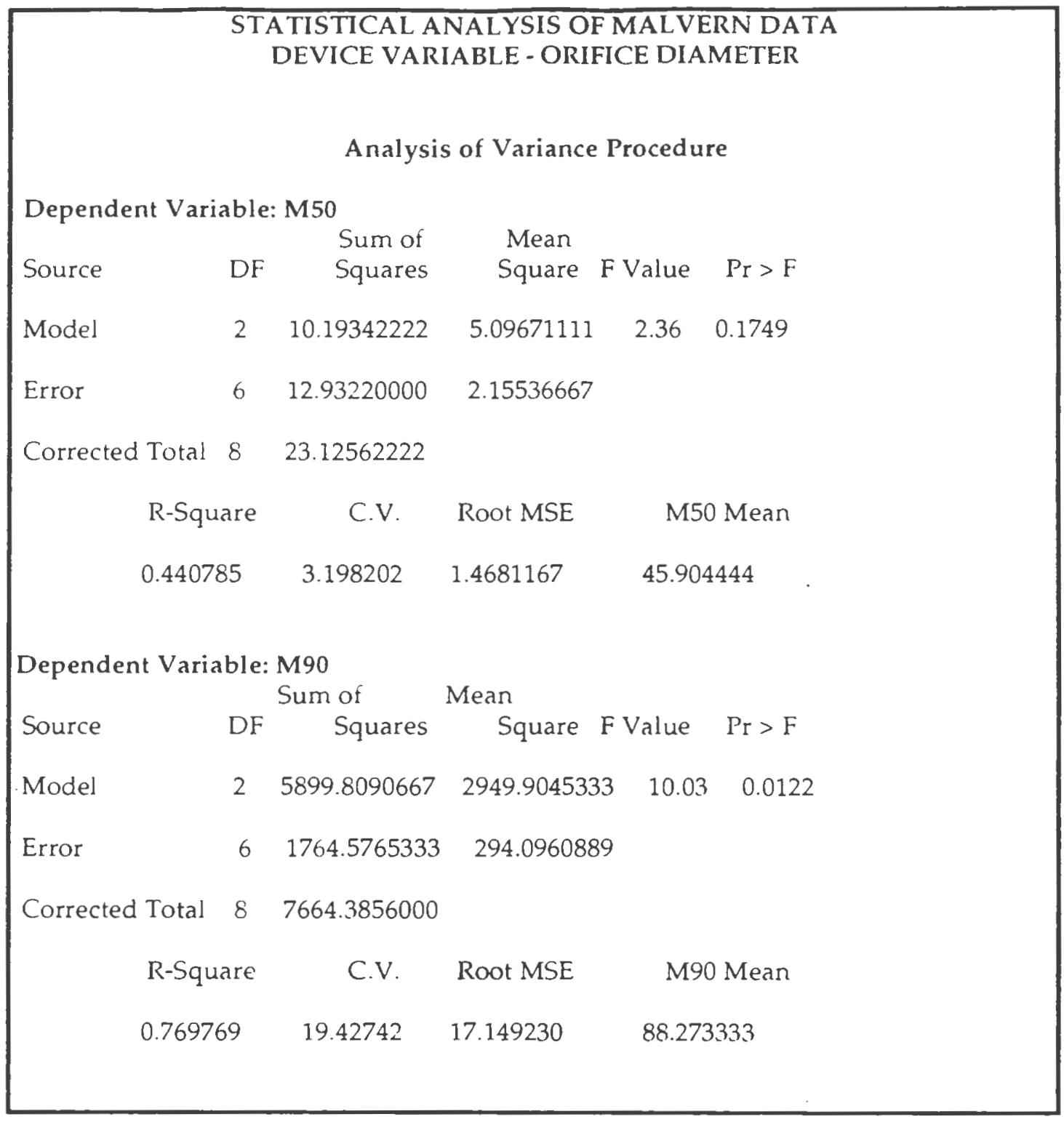




\section{APPENDIX C \\ STATISTICAL DATA SUPPORTING MANUSCRIPT I \& II}




\section{General Linear Models Procedure}

Scheffe's test for variable: $Y$

NOTE: This test controls the type I experimentwise error rate but generally has a higher type II error rate than REGWF

for all pairwise comparisons

$$
\text { A } \mid \text { pha }=0.05 d f=26 \text { MSE }=8012872
$$

Critical Value of $F=4.22520$

Minimum Significant Difference $=1939.5$

Means with the same letter are not significantly different.

$$
\text { Scheffe Grouping Mean N VIS }
$$

A $\quad 4775.8 \quad 18 \quad 1$

A $\quad 2957.8 \quad 18 \quad 76$ 
Scheffe's test for variable: $Y$

NOTE: This test controls the type I experimentwise error rate but generally has a higher type II error rate than REGWF for all pairwise comparisons

Alpha $=0.05 \mathrm{df}=26 \mathrm{MSE}=8012872$

Critical Value of $F=3.36902$

Minimum Significant Difference $=2999.7$

Means with the same letter are not significantly different.

Scheffe Grouping Mean N TON

$\begin{array}{llll}\text { A } & 6319 & 12 & 100\end{array}$

$\begin{array}{lllll}\text { A } & \text { B } & 3612 & 12 & 600\end{array}$

$\begin{array}{llll}\text { B } & 1760 & 12 & 300\end{array}$ 


\section{General Linear Models Procedure \\ Scheffe's test for variable:}

NOTE: This test controls the type I experimentwise error rate but generally has a higher type II error rate than REGWF for all pairwise comparisons

Alpha $=0.05 \mathrm{df}=26 \mathrm{MSE}=801287$

Critical Value of $F=4.22520$

Minimum Significant Difference $=1939.5$

Means with the same letter are not significantly different.

$$
\text { Scheffe Grouping Mean N DMPG }
$$

$\begin{array}{llll}\text { A } & 5331.1 & 18 & 1.0\end{array}$

$\begin{array}{llll}\text { B } & 2402.6 & 18 & 0\end{array}$




\section{General Linear Models Procedure}

T tests (LSD) for variable: $Y$

NOTE: This test controls the type I comparisonwise error rate not the experimentwise error rate.

$$
\begin{gathered}
\text { Alpha }=0.05 \mathrm{df}=26 \mathrm{MSE}=8012872 \\
\text { Critical Value of } \mathrm{T}=\mathbf{2 . 0 6} \\
\text { Least Significant Difference }=\mathbf{1 9 3 9 . 5}
\end{gathered}
$$

Means with the same letter are not significantly different.

$$
\text { TGrouping Mean } \quad \mathrm{N} \text { VIS }
$$

\begin{tabular}{rrrr} 
A & 4775.8 & 18 & 1 \\
A & 2957.8 & 18 & 76 \\
\hline
\end{tabular}




\section{General Linear Models Procedure}

$T$ tests (LSD) for variable: $Y$

NOTE: This test controls the type I comparisonwise error rate not the experimentwise error rate.

$$
\begin{gathered}
\text { Alpha }=0.05 \mathrm{df}=26 \mathrm{MSE}=8012872 \\
\text { Critical Value of } \mathrm{T}=2.06 \\
\text { Least Significant Difference }=2375.4
\end{gathered}
$$

Means with the same letter are not significantly different.

\begin{tabular}{cccc} 
TGrouping & Mean & N TON \\
A & 6319 & 12 & 100 \\
B & 3612 & 12600 \\
B & 1670 & 12300 \\
\hline
\end{tabular}




\section{General Linear Models Procedure}

T tests (LSD) for variable: $Y$

NOTE: This test controls the type I comparisonwise error rate not the experimentwise error rate.

$$
\begin{gathered}
\text { Alpha }=0.05 \mathrm{df}=26 \mathrm{MSE}=8012872 \\
\text { Critical Value of } \mathrm{T}=2.06 \\
\text { Least Significant Difference }=1939.5
\end{gathered}
$$

Means with the same letter are not significantly different.

$$
\text { TGrouping Mean N DMPG }
$$
A
$5331.1 \quad 18 \quad 1.0$

B 


\begin{tabular}{|c|c|c|c|}
\hline Source & DF & Type I SS & F Value \\
\hline VIS & 1 & 29745956.016 & 0.0650 \\
\hline DMPG & 1 & 77188149.634 & 0.0046 \\
\hline TON & 2 & 130842909.196 & 0.0018 \\
\hline DMPG*TON & 2 & 59202705.613 & 0.0387 \\
\hline VIS*TON & 2 & 62767100.747 & 0.0326 \\
\hline VIS*DMPG & 1 & 888473.395 & 0.7418 \\
\hline \multicolumn{4}{|c|}{ Dependent Variable: $Y$} \\
\hline Source & DF & Type II SS & F Value \\
\hline VIS & 1 & 29745956.016 & 0.0650 \\
\hline DMPG & 1 & 77188149.634 & 0.0046 \\
\hline TON & 2 & 130842909.196 & 0.0018 \\
\hline DMPG TON & 2 & 59202705.613 & 0.0387 \\
\hline VIS*TON & 2 & 62767100.747 & 0.0326 \\
\hline VIS*DMPG & 1 & 888473.395 & 0.7418 \\
\hline
\end{tabular}


Dependent Variable: $Y$

\begin{tabular}{lccccc} 
Source & DF & Type III SS & \multicolumn{2}{c}{ F Value } & $\operatorname{Pr}>$ F \\
VIS & 1 & 29745956.016 & 3.71 & 0.0650 \\
DMPG & 1 & 77188149.634 & 9.63 & 0.0046 \\
TON & 2 & 130842909.196 & 8.16 & 0.0018 \\
DMPG*TON & 2 & 59202705.613 & 3.69 & 0.0387 \\
VIS*TON & 2 & 62767100.747 & 3.92 & 0.0326 \\
VIS*DMPG & 1 & 888473.395 & 0.11 & 0.7418 \\
& & & & \\
Dependent Variable: & & & & \\
Source & DF & Type IV SS & F Value & $\operatorname{Pr}>$ F \\
VIS & 1 & 29745956.016 & 3.71 & 0.0650 \\
DMPG & 1 & 77188149.634 & 9.63 & 0.0046 \\
TON & 2 & 130842909.196 & 8.16 & 0.0018 \\
DMPG*TON & 2 & 59202705.613 & 3.69 & 0.0387 \\
VIS*TON & 2 & 62767100.747 & 3.92 & 0.0326 \\
VIS*DMPG & 1 & 888473.395 & 0.11 & 0.7418
\end{tabular}


PROC GLM;

CLASS VIS DMPG TON;

MODEL $Y=$ VIS DMPG TON DMPG*TON TON*VIS VIS*DMPG/SS1 SS2 SS3 SS4;

MEANS VIS DMPG TON/SCHEFFE;

MEANS VIS DMPG TON/LSD;

RUN;

PROC RSREG;

MODEL Y $=$ VIS DMPG TON/PREDICT;

RIDGE MAX;

RUN;

DATA A; DMPG $=1$;

VIS $=-20$;

DO I = 1 TO 5;

TON = 0;

VIS $=$ VIS +20 ;

DO J = 1 TO 6 ;

$\mathrm{TON}=\mathrm{TON}+100$

$Y=7610.88-17.01^{*} \mathrm{VIS}+13237^{*} \mathrm{DMPG}-39.68^{*} \mathrm{TON}+16.76^{*} \mathrm{DMPG}^{*} \mathrm{VIS}$

$-0.034^{*}$ TON*VIS $-24.07 *$ TON*DMPG + 0.058*TON*TON;

OUTPUT;

END;

END;

PROC PRINT; 


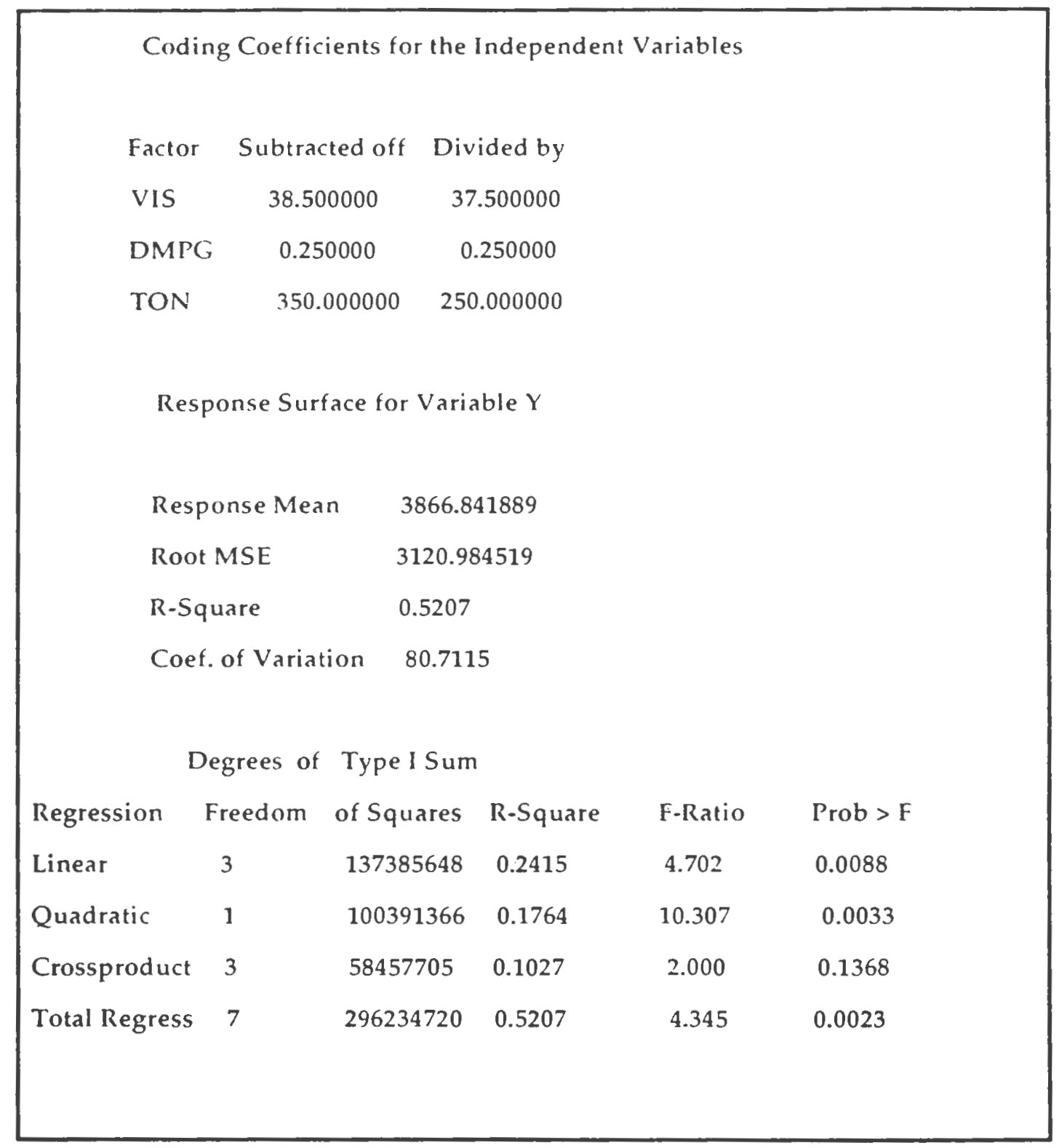




\begin{tabular}{|c|c|c|c|c|}
\hline \multirow[b]{3}{*}{ Parameter } & \multicolumn{4}{|l|}{ Degrees } \\
\hline & of & Paramete & Standard & $\mathrm{T}$ for $\mathrm{H} 0$ : \\
\hline & Freedom & Estimate & Error & Parameter $=0$ \\
\hline INTERCEPT & 1 & 7610.872353 & 32403.66856 & 3.166 \\
\hline VIS & 1 & -17.017080 & 29.852014 & -0.570 \\
\hline DMPG & 1 & \multicolumn{2}{|c|}{$13237 \quad 4503.851317$} & 2.939 \\
\hline TON & 1 & -39.680564 & 13.970208 & -2.840 \\
\hline VIS*VIS & 0 & 0 & . & \\
\hline DMPG*VIS & 1 & 16.757132 & 55.484169 & 0.302 \\
\hline DMPG*DMPG & 0 & 0 & . & \\
\hline TON*VIS & 1 & -0.034236 & 0.067505 & -0.507 \\
\hline TON*DMPG & 1 & -24.075277 & 10.125811 & -2.378 \\
\hline TON*TON & 1 & 0.059433 & 0.018513 & 3.210 \\
\hline \multicolumn{5}{|c|}{ Parameter Estimate from Coded } \\
\hline Parameter & \multicolumn{4}{|c|}{ Prob $>|\mathrm{T}| \quad$ Data } \\
\hline INTERCEPT & 0.0037 & \multicolumn{2}{|c|}{1250.697729} & \\
\hline VIS & 0.5732 & \multicolumn{2}{|c|}{-930.395314} & \\
\hline DMPG & 0.0065 & \multicolumn{2}{|c|}{1363.966125} & \\
\hline TON & 0.0083 & \multicolumn{2}{|c|}{-1353.585583} & \\
\hline VIS*VIS & . & \multicolumn{2}{|l|}{0} & \\
\hline DMPG*VIS & 0.7649 & \multicolumn{2}{|c|}{157.098111} & \\
\hline DMPG*DMPG & . & 0 & & \\
\hline
\end{tabular}




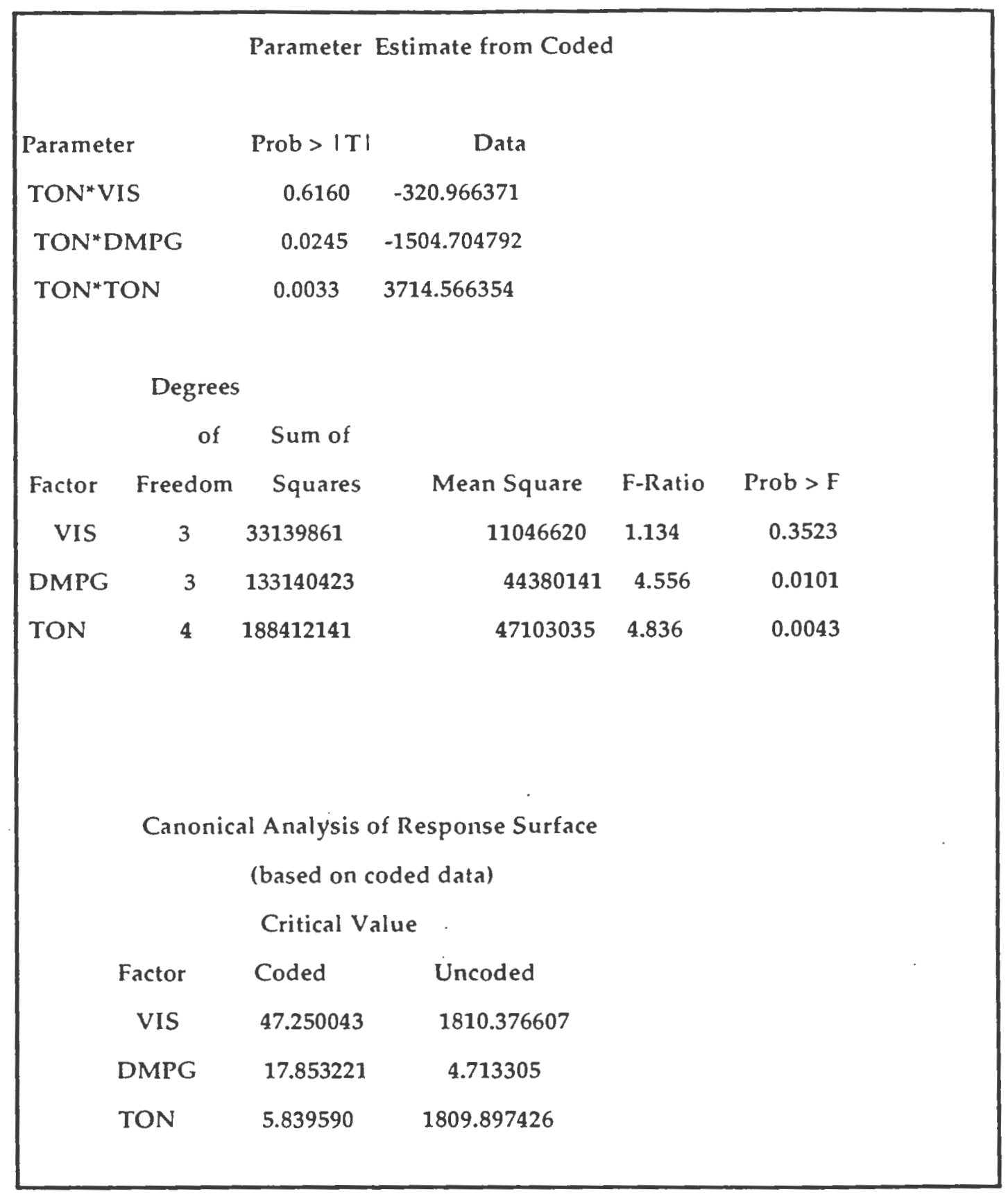




\begin{tabular}{|c|c|c|c|}
\hline \multirow{2}{*}{$\begin{array}{l}\text { Coded } \\
\text { Radius }\end{array}$} & \multicolumn{3}{|c|}{ Uncoded Factor Values } \\
\hline & VIS & DMPG & TON \\
\hline 0.0 & 38.500000 & 0.250000 & 350.000000 \\
\hline 0.1 & 37.221271 & 0.263987 & 331.113469 \\
\hline 0.2 & 36.525396 & 0.274531 & 308.467457 \\
\hline 0.3 & 36.167287 & 0.282944 & 284.441931 \\
\hline 0.4 & 35.990575 & 0.290160 & 259.959596 \\
\hline 0.5 & 35.917028 & 0.296676 & 235.327136 \\
\hline Coded & & ded Facto & Values \\
\hline Radius & VIS & DMPG & TON \\
\hline 0.6 & 35.906673 & 0.302752 & 210.650463 \\
\hline 0.7 & 35.937585 & 0.308538 & 185.968059 \\
\hline 0.8 & 35.996872 & 0.314121 & 161.293960 \\
\hline 0.9 & 36.076490 & 0.319558 & 136.632759 \\
\hline 1.0 & 36.171171 & 0.324886 & 111.985288 \\
\hline
\end{tabular}




\begin{tabular}{|c|c|c|c|c|c|c|}
\hline \multicolumn{7}{|c|}{ SIMULATED DATA FOR RESPONSE SURFACE ANALYSIS } \\
\hline OBS & DMPG & VIS & I & TON & J & Y \\
\hline 1 & 0.5 & 0 & 1 & 100 & 1 & 9637.88 \\
\hline 2 & 0.5 & 0 & 1 & 200 & 2 & 6206.38 \\
\hline 3 & 0.5 & 0 & 1 & 300 & 3 & 3934.88 \\
\hline 4 & 0.5 & 0 & 1 & 400 & 4 & 2823.38 \\
\hline 5 & 0.5 & 0 & 1 & 500 & 5 & 2871.88 \\
\hline 6 & 0.5 & 0 & 1 & 600 & 6 & 4080.38 \\
\hline 7 & 0.5 & 20 & 2 & 100 & 1 & 9397.28 \\
\hline 8 & 0.5 & 20 & 2 & 200 & 2 & 5897.78 \\
\hline 9 & 0.5 & 20 & 2 & 300 & 3 & 3558.28 \\
\hline 10 & 0.5 & 20 & 2 & 400 & 4 & 2378.78 \\
\hline 11 & 0.5 & 20 & 2 & 500 & 5 & 2359.28 \\
\hline 12 & 0.5 & 20 & 2 & 600 & 6 & 3499.78 \\
\hline 13 & 0.5 & 40 & 3 & 100 & 1 & 9156.68 \\
\hline 14 & 0.5 & 40 & 3 & 200 & 2 & 5589.18 \\
\hline 15 & 0.5 & 40 & 3 & 300 & 3 & 3181.68 \\
\hline 16 & 0.5 & 40 & 3 & 400 & 4 & 1934.18 \\
\hline 17 & 0.5 & 40 & 3 & 500 & 5 & 1846.68 \\
\hline 18 & 0.5 & 40 & 3 & 600 & 6 & 2919.18 \\
\hline 19 & 0.5 & 60 & 4 & 100 & 1 & 8916.08 \\
\hline 20 & 0.5 & 60 & 4 & 200 & 2 & 5280.58 \\
\hline
\end{tabular}




\begin{tabular}{|llllllll|}
\hline \multicolumn{6}{l}{ SIMULATED DATA FOR RESPONSE SURFACE ANALYSIS } & & \\
OBS & DMPG & VIS & I & TON & J & Y \\
21 & 0.5 & 60 & 4 & 300 & 3 & 2805.08 \\
22 & 0.5 & 60 & 4 & 400 & 4 & 1489.58 \\
23 & 0.5 & 60 & 4 & 500 & 5 & 1334.08 \\
24 & 0.5 & 60 & 4 & 600 & 6 & 2338.58 \\
25 & 0.5 & 80 & 5 & 100 & 1 & 8675.48 \\
26 & 0.5 & 80 & 5 & 200 & 2 & 4971.98 \\
27 & 0.5 & 80 & 5 & 300 & 3 & 2428.48 \\
28 & 0.5 & 80 & 5 & 400 & 4 & 1044.98 \\
29 & 0.5 & 80 & 5 & 500 & 5 & 821.48 \\
30 & 0.5 & 80 & 5 & 600 & 6 & 1757.98 \\
& & & & & & & \\
\hline
\end{tabular}


BIBLIOGRAPHY 
Aoki, F. Y., Crawley, J. C. W., "Distribution and removal of human serum albumin-tecnetium $99 \mathrm{~m}$ instilled intranasally.," British Journal of Pharmacology.. 3 (1976) 869-879.

Baldwin, P. A., Klingbeil, C. K., Garimm, C. J. and Longnecker, J. P., "The effect of sodium tauro-24-25, dihydrofusidate on the nasal absorption of human growth hormone in three animal models," Pharmaceutical Research., 7(5) (1990) 547-552.

Balin, B. J., Broadwell, R. D., Salcman, M., and El- Kalliny, M. "Avenues for entry of peripherally administered protein to the central nervous system in mouse, rat and squirrel monkey," Lournal of Computational Neurology.. 251 (1986) 260.

Banga, A. K. and Chien, Y. W., "Iontophoretic delivery of drugs: fundamentals, developments and biomedical application.," Џournal of Controlled Release. 7 (1988) 1.

Burnette, R. R. and Marerro, D., "Comparison between the iontophoretic and passive transport of thyrotropin releasing hormones across excised nude mouse skin.,"Journal of Pharmaceutical Sciences. 75 (1986) 738-743.

Chien, Y. W., Lelawongs, P., Siddiqui, O., Sun, Y. and Shi, W. M., "Facilitated transdermal delivery of therapeutic peptides and proteins by iontophoretic delivery device.," Lournal of Controlled Release., 13 (1990) 263. 
Chien, Y. W., Su, K. S. E. and Chang, S., (Eds), Physicochemical Biopharmaceutical and Toxicophysiological Considerations in Nasal Systemic Drug Delivery. Published by Marcel Dekker, (1989) pp. 53

Chien, Y. W., Su, K. S. E. and Chang, S., (Eds), Physicochemical Biopharmaceutical and Toxicophysiological Considerations in Nasal Systemic Drug Delivery.. Marcel Dekker., Inc., NY., (1989) pp. 64

Chien, Y. W., Su., K. S. E., Chang, S., (Eds.,) Nasal Systemic Drug Delivery, Physicochemical, Biopharmaceutical and Toxicophysiological Considerations. Marcel Dekker, Inc., NY., (1989) pp 49.

Chiou, C. Y. and Chang, M. S., "Systemic delivery of enkephalin.,"Life Sciences.. 43 (1988) 509.

Chiou, G. C. Y., Chuang, C. Y., and Chang, M. S., "Reduction of blood glucose concentration with insulin eye drops.," Diabetes Care. 11 (1988) 750.

Chiou, G. C., and Ching, Y. C., "Improvement of systemic absorption of insulin through eyes with absorption enhancers.," Lournal of Pharmaceutical Sciences. 78 (1989) 815.

Chiou, G. C., and Chuang, C. Y. and Chang, M.S., "Reduction of blood glucose concentrations with insulin eye-drops.," Diabetes Care.,11 (1988) 750.

Chiou, G.C. and Chuang, C. Y., "Treatment of hypoglycemia with glucagon eyedrops.," Lournal of Ocular Pharmacology.. 4 (1989) 179. 
Christiansen, C., Christiensen, M. S. Larsen, N. E., Transbol, I. B., "Pathophysiological mechanisms of estrogen effect on bone metabolism. Dose-response relationships in early postmenopausal women.," Iournal of Clinical Endocrinology and Metabolism. 55 (1982) 1124-1130.

Clark, A. R., "Invitro Assessment of spacer devices.," Presented at Respiratory Drug Delivery II, Keystone, CO., (1990) March 26-30

Clissod, S. P., Fitton, A., Chrisp, Paul., "Intranasal salmon calcitonin-A review of its pharmacological properties and potential utilities in metabolic bone disorders associated with aging.," Drugs and Aging. 1 (5) (1991) 405-423.

Collens, W.S. and Goldziehr, "Absorption of insulin by the nasal mucous membrane.," Proceedings of Society of Experimental Biology. 29 (1932) 756.

Crooks, P., "Lung Peptidases and their activities.," Presented at respiratory drug delivery II, Keystone, CO., (1990) March 26-30.

Curatolo, W., "The lipoidal permeability barriers of the skin and alimentary tract.," Pharmaceutical Research., 4 (1987) 271.

Davis, S. S., "Advanced Delivery Systems for Peptides and ProteinsPharmaceutical Considerations.," In Delivery Systems for Peptide Drugs. Edited by Davis, S., Illum, L., and Tominson. Plenum Press, (1986) pp 45-49,. 
Davis, S. S., "Advanced Delivery Systems for Peptides and ProteinsPharmaceutical Considerations.," In Delivery Systems for Peptide Drugs, Edited by Davis, S., Illum, L., and Tominson. Plenum Press (1986) pp 76-79.

Davis, S. S., "Advanced Delivery Systems for Peptides and ProteinsPharmaceutical Considerations.," In Delivery Systems for Peptide Drugs, Edited by Davis, S., Illum, L., and Tomlinson., E., Plenum Press (1986) pp 1.

Davis, S. S., "Advanced Delivery Systems for Peptides and ProteinsPharmaceutical Considerations.," In Delivery Systems for Peptide Drugs. Edited by Davis, S., Illum, L., and Tomlinson., E., Plenum Press, (1986) pp 265275.

De Boer, A. G., Van Hoogdalem, E. J., Heijligers-Feijen, C. D., Verhoef, J. C. and Breimer, D. D., "Rectal Absorption enhancement of peptide drugs.," Journal of Controlled. Release.. 13 (1990) 241.

deLeede, L. G. J. et al., "Rectal and intravenous propranol infusion to steady state: Kinetics and $\beta$ receptor blockade.," Clinical Pharmacology and Therapeutics., 35 (1984) 148-155.

deLeede, L. G. J., et al., "Enhancement of rectal absorption of insulin using salicylate in dogs.," Lournal of Pharmacokinetics and Biopharmaceutics., 10 (1982) 525-537.

Deruloo, M. J. M., Hermens, W. A. J. J., Romeyn, S. G., Verhoef, J. C., Merkus, F. W. H. M., "Absorption Enhancement of Intranasally Administered Insulin 
by Sodium Taurodihydrofusidate in Rabbits and Rats.," Pharmaceutical Research., 6 (10) (1982) 853-856.

Donovan, M. D., Flynn, G. L. and Amidon, G. L., "The molecular weight dependence of nasal absorption: The effect of absorption enhancers.," Pharmaceutical Research. 7(8) (1990) 808-815

Dua, R, Zia, H., Needham, T., "Evaluation of formulation and device variables on nasal spray characteristics.," Manuscript in Preparation (1995).

Epand, R. M., Epand, R. F., Orlowski, R. C., "Presence of an amphipathic helical segment and its relationship to biological potency of calcitonin analogs.,"International Journal of Peptides and Protein Research. 25(1) (1993) 105-111.

Epand, R. M., Epand, R. F., Stafford, A. R., Orlowski, R. C., "Deletion sequences of salmon calcitonin that retain the essential biological and conformational features of the intact molecule.," Iournal of Medicinal Chemistry..31(8) (1988) 1595-1598.

Epand, R., Epand, R. F., Orlowski, R. C., Flanigan., E, Stahl, Glenn, L., "A comparison of the interaction of glucagon, human parathyroid hormone-(134) peptide and calcitonin with dimyristoylphosphatidylglycerol and with dimyristoylphosphatidylcholine.," Biophysical Chemistry.. 23 (1-2) (1993) 3948. 
Evans, W. S., Borges, J. L. C., Kaiser, D. L., Vance, M. L., Seller, R. P., Macleod, R. M., Vale, W., Rivier, J. and Thorner, M. O., "Intranasal administration of human pancreatic tumor GH-releasing factor-40 stimulates $\mathrm{GH}$ release in normal men.," Lournal of Clinical Endocrinology and Metabolism., 57 (1983) 1081-1084.

Gansslen, M., "Ueber, inhalation van insulin.," Klin Schnschr., 4 (1925) 71.

Gizurason, S., "Animal models for intranasal drug delivery studies.," Acta Pharmaceutical Nordic. 2(2) (1990) 105-122.

Grossman, A., Fabbri, A., Goldberg, P. L. and Nesser, G. M., "Two new modes of desmopressin administration.," British Medical Journal., 280 (1980) 1215.

Hanskiss, J. and Hadhazy, C.S., "Resorption von insulin and asthmolysin von der nasenschleimhaut.," Acta. Med. Acad.Sci-Hung. 12 (1958) 107.

Hanson, M., Gazdick, G., Cahill, J., Augustine, M., "Intranasal delivery of the peptide, salmon calcitonin.," In Davis et al, (Eds.,) Delivery systems for peptide drugs.. Plenum Press, New York (1986) pp. 232-242.

Hardy, J. G., Lee, S. W., Wilson, C. G., "Intranasal drug delivery by spray and drops.," Journal of Pharmacy and Pharmacology. 37 (1985) 294-297.

Harris, A. S., "Biopharmaceutical aspects of the intranasal administration of peptides.," in Delivery Systems for Peptide Drugs, Davis, S. S., Illum, L., and Tomlinson, E., Eds., Plenum Press, NewYork, (1986) pp 191. 
Harris, A. S., Ohlin, M., Lethagen, S. and Nilsson, I. M., "Effects of concentration and volume on nasal bioavailability and biological response to Desmopressin.," Lournal of Pharmaceutical Sciences.,77(4) (1988) 337-348.

Harris, A.S., Svensson, E., Lethagen, S., and Nilsson, "Effect of viscosity on Particle Size, Deposition and Clearance of Nasal Delivery Systems Containing Desmopressin.," Lournal of Pharmaceutical Sciences..,77(5) (1988) 405-408.

Hayashi, M., Hirasawam T., Muraoka, T., Shiga, M., and Awazum S., "Comparison of water influx and sieving coefficient in rat jejunal, rectal and nasal absorption of antipyrine.," Chemical and Pharmaceutical Bulletin., 33 (1985) 2149.

Hendricks, C., and Gabel, R. A. "Use of intranasal oxytocin in obstetrics I. Laboratory evaluation.," American Journal of Obstetrics and Gynecology. 79 (1960) 780 .

Hermens, W. A. J. J., Hooymans, P. M., Verhoef, J. C., Merkus, F. W. H., "Effects of absorption enhancers on human nasal tissue ciliary movement in vitro.," Pharmaceutical Research., 7 (2) (1990) 144-146.

Heubner, W., deJough, S.E., and Laquer, E., "Ueber inhalation von insulin.," Klin Schnshr. 3 (1924) 2342.

Hirai, S., Yashiki, T and Mima H., "Mechanisms for the enhancement of the nasal absorption of insulin by surfactants.," International Journal of Pharmaceutics., 9 (1984a) 173. 
Hirai, S., Yashiki, T., and Mima, H., "Effect of surfactants on the nasal absorption of insulin in rats.," International Journal of Pharmaceutics., 9 (1981a) 165.

Hirai, S., Yashiki, T., Mima, H., "Effect of surfactants on the nasal absorption on insulin on rats.," Lournal of Pharmaceutical Sciences., 9 (1981) 165-172.

Hirai, S., Yashiki, T., Mima, H., "Vaginal absorption of a potent luteinizing hormone -releasing hormone analog (leuprolide) in rats I : Absorption by various routes and absorption enhancement.," Iournal of Pharmaceutical Sciences. 71 (1982) 1367-1370.

Hughes, B.L., Allen, D. L., Dorato, M.A and Wolff, R.K., "Effects of delivery devices on nasal deposition and mucociliary clearance in rhesus monkey.," Lournal of Aerosol Science and Technology.. 18 (1993) 241-249

Hussain, A. A., Hirai, S and Bawarshi, R., "Nasal absorption of natural contraceptives steroids in rats-Progesterone absorption.," Iournal of Pharmaceutical Sciences. 70 (1981) 466.

Hussain, A. A., Hirai, S., Kashihara, T., Batenhorst, R., et al., "Nasal Absorption of propranolol in humans., Lournal of Pharmaceutical Sciences., 69 (1989) 1240.

Hussain, A. A., Kimura, R., and Huang, C. H., "Nasal absorption of testosterone in rats.," \ournal of Pharmaceutical Sciences., 73 (1984) 1300. 
Illum, L., Farraj, N. F., Critchley, H., Johansen, B. R. and Davis, S. S., "Enhanced nasal absorption of insulin in rats using lysophosphatidylcholine.," International Journal of Pharmaceutics., 57 (1989) 49-54.

Illlum, L., Farraj, N. F., Davis, S. S., Johansen, B. R. and O'Hagen, D. T., "nvestigation of the nasal absorption of biosynthetic human growth in sheep - use of a bioadhesive microsphere delivery system.," International Journal of Pharmaceutics. 63 (1990) 207-211.

Illum, L., "Microspheres as a potential controlled release nasal drug delivery systems" in Delivery systems for peptide drugs.,Davis, S. S., Illum, L. and Tomlinson, E., Plenum Press, New York, (1980) pp. 205-210.

Jager--Waldau, R., "A Two Phase Flow Mechanical Spray Pump: A possible alternative to propellant driven MDI's.," Lournal of Biopharmaceutical Sciences. 3(1/2) (1992) 77-84

Juhasz, J., Lenaerts, V., and Ong, H., "Poloxamer gels for peptide delivery- in vitro studies.," Lournal of Controlled Release.. 13 (1990) 322.

Kajii, H., Horie, T., Hayashi, M. and Awazu, S., "Fluorescence study on the interaction of salicylate with rat small intestinal epithelal cells: possible mechanisms for the promoting effects of salicylate on drug absorption in vivo.,"Life Sciences., 37 (1985) 523. 
Kamada., Nishihata, T., Kim, S., Yamamoto, M. and Yata, N., "Study of enamine derivatives of phenylglycine as adjuvants for the rectal absorption of insulin.,"Chemical and Pharmaceutical Bulletin., 29 (1980) 2012.

Kamada, A., Nishihata, T., Kimu, S., Yamamoto, M. and Yata, N., "Study of enamine derivatives of phenylglycine as adjuvants for the rectal absorption of insulin.," Chemical and Pharmaceutical Bulletin., 29 (1981) 2012-2019.

Kari, B., "Control of blood glucose levels in alloxan-diabetic rabbits by iontophoresis of Insulin.," Diabetes., 35 (1986) 217-221.

Keenan, J. and Chamberlain, M. A. "Nasal mucosal absorption of tetracosactrin as indicated by rise in plasma flurogenic corticosteroids.," British Medical Journal. 4 (1969) 407-408.

Kim, S., Kamada, A., Higuchi, T. and Nishihata, T., "Effects of enamine derivatives on the rectal absorption of insulin in dogs and rabbits.," Lournal of Pharmacy and Pharmacology., 35 (1983) 100.

Kurose, H., Seino, Y., Shima, M., Tanaka, H., Ishiiida, M. et al, "Intranasal absorption of salmon calcitonin.," Calcified Tissue International..441 (1987) 249-251.

Law, P.Y., Harris, R. A., Loh, H.H., and Way, E. L., "Evidence for the involvement of cerebroside sulfate in opiate receptor binding.," Lournal of Pharmacology and Experimental Therpeutics., 207 (1978) 458. 
Lee, V. H. L., Carson, L. W., Dodda-Kashi, S. and Stratford, R. E., "Metabolic permeation barriers to the ocular absorption of topically applied enkephalins in albino rabbits.," Lournal of Ocular Pharmacology.. 4 (1989) 179.

Lee, V. H. L., "Enzymatic barriers to peptide and protein absorption and use of penetration enhancers to modify absorption.," In Delivery Systems for Peptide Drugs, Edited by Davis, S. S., Illum, S.S., Tomlinson, E., (1986) pp. 87104, .

Lee, V. H. L., "Mechanisms and facilitation of corneal drug penetration., Lournal of Controlled Release. 11 (1991) 79-84.

Lee, V. H. L., "Peptide and Protein Drug Delivery Systems.," Biopharm. 1(3) (1988) 24-31.

Lee, W. A., "Permeation Enhancers for the nasal delivery of protein and peptide therapeutics.," Biopharm., 3 (10) (1990) 22-25.

Lee, W.A., Ennis, R.D., Longnecker, J.P., and Bengtsson, P., "The bioavailability of intranasal salmon calcitonin in healthy volunteers with and without a permeation enhancer.," Pharmaceutical Research., 11(5) 1994.

Levy, R. S., "Efficient Calcitonin Production.,"_Biopharm., May (1993) 36-39.

London, D. L., Butt, W. R., Lynch, S. S., Marshall, J. C., Robinson, W. R. and Stephanson, J. M., "Hormonal response to intranasal luteinizing hormone 
releasing hormone.," Journal of Clinical and Endocrinology Metabolism.. 37 (1973) 829-831.

Longnecker, J. P., Moses, A. C., Flier, J. S., Silver, R. D., Carey, M. C., Dubov, E. J., "Effects of sodium taurodihydrofusidate on nasal absorption of insulin in sheep.," Iournal of Pharmaceutical Sciences. 76(5) (1987) 351- 355.

Longnecker, J. P., Moses, A. C., Flier, J. S., Silver, R. D., Carey, M.C. and Dubovi, E. J., "Effects of sodium taurodihydrofusidate on nasal absorption of insulin in sheep.," Lournal of Pharmaceutical Sciences. 76 (1987) 351-355.

Major, R. H., "The intranasal application of insulin, experimental and clinical experiences.," American Journal of Medical Science., 192 (1936) 257.

Martin, G. P., Marriott., C., Kellaway, I. W., "Direct effects of bile salts and phospholipids on the physical property of mucus.," Gut, 19 (1978) 103.

Merkle, H., Anders, R., Wermerskirchen, A., Rachs, S., and Wolany, G., "Buccal routes of peptides and protein drug delivery" in Peptide and Protein Drug Delivery., Lee, V. H. L., Ed., Marcel Dekker, New York (1991) Chap.11.

Milhaud, G., Tsieng-Ming, Nesralla, H., Moukhtar, M.S., Perault-Staub, A. M., "Studies on the mode of action and the therapeutic use of thyrocalcitonin" in Taylor, S. F., (Eds.)Calcitonin, Heinemann, London (1967) pp. 347, 
Miller, L., Kolaskie, C.J., Smith, G. A., and Riviere, J., "Transdermal iontophoresis of gonadotrophin releasing hormone (LHRH) and two analogues.," Lournal of Pharmaceutical Sciences., 79 (1990) 490.

Mishima, M., Wakita, Y, and Nakano, "Studies on the promoting effects of medium chain fatty acids salts on the nasal absorption of insulin in rats.," Journal of Pharmacobiodynamics. 10 (1990) 624-631.

Mohamadi, M., Becker, K. L., and Bivins, L. E., "Paradoxical Effects of Salmon Calcitonin on serum calcium: Studies on intact and Thyroparathroidectomized men and dogs.," Acta Endocrinologica., 79 (1975) 700-708.

Morimoto, K., et al., "Enhanced rectal absorption of [Asu 1,7]-eel calcitonin in rats using polyacrylic acid aqueous gel base.," Journal of Pharmaceutical Sciences. 73 (1984) 1366-1368.

Morimoto, K., Morisaka, K., and Kamada, "Enhancement of nasal absorption of insulin and calcitonin using polyacrylic acid gel.," Lournal of Pharmacy and Pharmacology., 37 (1985) 134-136.

Morvola, M., Reinikaine, A., Heliovaara, M., Huikari, A. J., "The effects of some sweetening agents and osmotic pressure on the intestinal absorption of sulfafurazole in the rat.," Lournal of Pharmacy and Pharmacology.s31 (1979) 615. 
Moses, A. M., "Synthetic lysine vasopressin nasal spray in the treatment of diabetes insipidus," Lancet, 1 (1964) 422.

Moses, A.C., Gorson, G. S., Carey, M. C. and Flier, J. S., "Insulin administered intranasally as an insulin-bile salt erosol: effectiveness and reproducibility in normal and diabetic subjects.,"Diabetes, 32 (1977) 1040.

Muller, K., Osler, M., "Induction of labor, a comparison of intravenous, intranasal and transbuccal oxytocin.," Acta Obstetrics. Gynecology. Scandanavia., 46 (1967) 59-67.

Murakami, T., Yata, N., Tamauchi, J. Nakai, Yamazaki, M and Kamada, A., 'Studies on absorption promoters for rectal delivery preparations. I. Promoting efficacy of enamine derivative of amino acids for the rectal absorption of $B$ - lactam antibiotics in rabbits.," Chemical and Pharmaceutical Bulletin. 29 (1981) 1998-2004.

Muranushi, N., Takagi, N., Muranishi, S. and Sezak, H., "Effect of fatty acids and monoglycerides on permeability of lipid bilayer.," Chemical Physical Lipids.. 28 (1981) 269.

Muraushi, N., Nakajima, Y., Kinugawa, M., Muranishi, S., Sezaki, H., "Mechanism for the inducement of the intestinal absorption of poorly absorbed drugs by mixed micelles II. Effects of the incorporation of various lipids on the permeability of liposomal membranes.," International Journal of Pharmaceutics. 4 (1982) 281. 
Salzman, R., Manson, J. E., Griffing, G. T., Kimmerle, R., Ruderman, N., et al., "Intranasal aerosolizedd insulin, mixed meal studies and long term use in type I diabetes.," New England Journal of Medicine, 312 (1985) 1078-1084 .

Sekine, M., Sasahara, K., Kojima, T., Hasegawa, K., and Okada, R., "Improvement of bioavailability of poorly intestinally absorbed drugs from medium chain glyceride base : Enhancement of the rectal absorption of cefmetazole sodium in rabbits.," Chemical and Pharmaceutical Bulletin., 32 (1984) 4189-4192.

Shao, Z., Krishnamoorthy, R., and Mitra, A. K., "Cyclodextrins as nasal absorption promoters of insulin: Mechanistic Evaluations.," Pharmaceutical Research., 9 (9) (1992) 1157-1163.

Siddiqui, O., et al ., "Facilitated transdermal transport of insulin.," Lournal of Pharmaceutical Sciences., 76 (1987) 341-345.

Sithigorngul, P., Burton, Nishhata, T., and Caldwell, L., "Effects of sodium salicylate on epithelial cells of the rectal mucosa of the rat: a light and electron microscopy study.," Life Sciences._33 (1983) 1025.

Srinivasan, V., Su, M. H., Higuchi, W. I., and Behl, C. R., "Iontophoresis of polypeptides: effects of ethanol pretreatment of human skin.," Iournal of Pharmaceutical Sciences. 79 (1990) 588.

Stafford, R. E., and Dennis, E. A., "Lysophospholipids as biosurfactants.," Colloids and surfaces., 30 (1988). 47-64. 
Pontiroli, A. E., Secchi, A., and Alberetto, M., "Alternative routes of peptide hormone administration.," Special Topics Endocrinology. Metabolism. 7 (1985) 77.

Pujara, C. P., Shao, Z., Duncan, M. R., and Mitra, A. K., "Effects of formulation variables on nasal epithelial cell integrity: Biochemical evaluations.," International Journal of Pharmaceutics., 114 (1995) 197-203.

Rytting, H., "Rectal route of peptide and protein drug delivery.," in Peptide and Protein Delivery, Lee, V. H. L., Ed., Marcel Dekker, New York., (1989) pp 579.

Saffran, M., et al., "A new approach to the oral administration of insulin and other peptide drugs.," Science. 233 (1986) 1081-1084.

Saikiya, Y., Miyauchi., Y., Tsuemura, Y. "Influence of osmotic Pressure and Viscosity on intestinal Drug Absorption. II Quinine Concentration profile in plasma after oral administration of variousQuinine solutions to Rats.," Chemical and Pharmaceutical Bulletin., 29 (1981) 1470-1472

Sakai, K., Kutsuna, T. M., Nishino, T., Fufihara, Y., and Yata, N., "Contribution of calcium ion sequestration by polyoxyethylated non-ionic surfactants to the enhanced colonic absorption of p-aminobenzoic acid.", Journal of Pharmaceutical Sciences.. 75 (1986) 387. 
Ohwaki, T., Ando, H., Watanabe, S. and Miyake, Y., "Effects of dose, pH, and osmolarity on nasal absorption of secretin in Rats.," Lournal of Pharmaceutical Science., 74 (1985) 550-552.

Okada, H., Yamazaki, I., Ogawa, Y., Hirai, S., Yashiki, T., and Mima, H. J., "Vaginal absorption of a potent luteinizing hormone- releasing hormone analog (leuprolide) in rats. I. Absorption by various routes and absorption enhancement.," Lournal of Pharmaceutical Sciences.. 72 (1982) 75.

Park, G. B., Shao, Z. and Mitra, A.K., "Acyclovir permeation enhancement across intestinal and nasal mucosae by bile salt-acylcarnitine mixed micelles.," Pharmaceutical. Research.s 9 (10) (1990) 1262-1267.

Pennington, A.K., Ratcliffe, J. H., Wilson, C.G., and Hardy, J. G., "The Influence of solution viscosity on nasal spray deposition and clearance.," International Journal of Pharmaceutics. 43 (1988) 221-224.

Pontiroli, A. E., Alberetto, M., Secchi, A., Dossi, G., Bosi, I., and Pozza, G., "Insulin given intranasally induces hypoglycaemia in normal and diabetic subjects.," British Medical Journal.,284 (1982) 303.

Pontiroli, A. E., Perfetti, M.G., Fattor, B., Pozza, G., "Effect of intranasal growth hormone releasing hormone and corticotrophic- releasing hormone administration improved bioavailabilty by means of sodium-glycoholate.," Journal of Clinical Metabolism., 68 (1989b) 821-824. 
Mygind, N., and Vesterhauge, S. "Aerosol distribution in the nose.," Rhinologye 11 (1978) 79-84.

Nagai, T., Nishimoto, Y., Nambu, N., Suzuki, Y. and Sekine, K., "Powder dosage forms of Insulin for nasal administration.," Lournal of Controlled Release., 1(1984) 15-22.

Newman, S. P., Clark, A. R., Talasee, N., and Clarke, S. W., "Pressurized inhaler deposition in the human lung with and without an "open" space device, using a simple radiolabelling technique.," Thorax., 44 (1989) 706.

Nishhata, T., Kim, S., Morishita, S., Kamada, A., Yata, N., and Higuchi, T., "Adjuvant effects of glyceryl esters of acetoacetic acid on rectal absorption of insulin and insulin in rabbits.," Journal of Pharmaceutical Sciences., 72 (1983) 280.

Nishihata, T., et al., "Enhancement of rectal absorption of insulin in dogs using salcylate in dogs.," Journal of Pharmacy and Pharmacology.. 35 (1983) 148-151.

Nishihata, T., Higuchi, T., and Kamada, A., "Salicylate-promoted permeation of cefoxition, Insulin and phenylalanine across red cell membrane: Possible mechanisms.," Life Sciences., 34 (1984a) 437.

Nishihata, T., Lee, C., Yamamoto, M., Rytting, J. H. and Higuchi, T., "The effect of salicylate in the rectal absorption of phenylalanine and some peptides 
and the effects of these peptides on the rectal absorption of cefoxin and cefmetazole.," Journal of Pharmaceutical Sciences., 73 (1984) 1326-1328.

Nishihata, T., Okamura, Y., Kamada, A., Higuchi, T., Yagi, T., Kawamori, R., and Scichiri, M., "Enhanced bioavailability of insulin after rectal administration with enamine as adjuvant in depancreatized dogs.," Lournal of Pharmacy and Pharmacolgy. 37 (1985a) 22.

Nishihata, T., Rytting, J. H., Higuchi, T., Caldwell, L., "Enhanced rectal absorption of insulin and heparin in rats in the presence of non-surfactant adjuvants.," Lournal of Pharmacy and Pharmacology.. 33 (1980) 334-335.

Nishimura, K., Nozaki., Y., Yoshimi, A., Nakamura, S., Kitagawa, M., Kakeya, N., Kitao, K., "Studies in the promoting effects of carboxylic acid derivatives on the rectal absorption of $\beta$-lactam antibiotics in rats.," Chemical and Pharmaceutical Bulletin. 33 (1985) 282291.

O'Hagan, D. T., Critchley, H., Farraj, N. F., Johansen, B. R., Davis, S. S. and Illum, L., "Effects of various absorption enhancers on the nasal absorption of biosynthetic human growth hormone in the rat.," Pharmaceutical Research., 7 (1990) 772-776.

Oberdorster, G., "Alveolar clearance of inhaled particles and drugs.," Aerosol Age, January (1991) 34 . 
Stanzani, L., Mascellanio, G., Corbelli, G. P., and Bianchini, P., "Rectal absorption of some glycosaminoglycan sulphates and heparin in rats.," Lournal of Pharmacy and Pharmacology..33 (1981)783.

Su, K. D. E.., Oeswein, J. Q., and Campanale, K. M., "Intranasal administration of human zinc insulin in rats:Absorption and possible mechanisms.," A. Journal of Pharmaceutical Academic Pharmeutical Sciences., 15 (1985) 89.

Su, K. S. E., Campanale, K. M., Mendelsohn, L. G., Kerchner, G. A., and Gries, C. L. , "Nasal delivery of polypeptides. I Nasal absorption of enkephalins in rats.," Lournal of Pharmaceutical Sciences. 74 (1985) 394-398.

Su, K. S. E., Howey, D. C., Campanale, K. M., and Oeswein, J. Q., "Intranasal admininstration of human sodium insulin in rats, dogs and humans: Absorption and possible mechanisms.," Diabetes. 35 (1986) A 64.

Su, K.S. E., "Nasal route of peptide and protein drug delivery.," in Peptide and Protein Drug Delivery Lee, V. H. L., Ed., Marcel Dekker, NewYork, (1991) Chapter. 13.

Tagesson, C., Franzen, L., Dahl, G, and Westrom, B., "Lysophosphatidylcholine increases rat ileal permeability to macromolecules.," Gut., 26 (1985) 369-377.

Taniguchi, K., Muranishi, S., and Sezaki, H., "Enhanced intestinal permeability to macromolecules II. Improvements of the large intestinal 
absorption of heparin by lipid-surfactant mixed micelles in rat.," International Lournal of Pharamceutical Sciences.. 4 (1980) 219.

Tengamnuay, P, and Mitra, A. K., "Bile salt fatty acid mixed micelles: a nasal absorption promoters of peptides. II In vivo nasal absorption of insulin in rats and effects of mixed micelles on the morphological integrity of the nasal mucosa.," Pharmaceutical Research. 7 (1990) 370-375.

Tyle, P., "Iontophoretic devices for drug delivery.," Pharmaceutical Research., 3 (1986) 318-326.

Vance, M. L., Evans, W. S., Kaiser, D. L., Burke, R. L., Rivier, J. et al., "The effect of intravenous subcutaneous, and intranasal GH-RH analog on growth hormone secretion in normal men: dose response relationship.," Clinical Pharmacology and Therapeutics., 40 (1986) 627-633.

Wearley, L. L., "Recent Progress in Protein and Peptide Delivery by Noninvasive Routes.," Critical Reviews in Therapeutic Drug Carrier Systems.. 8(4) (1991) 331-394.

Woodyatt, R.T., "The clinical use of insulin.," Lournal of Metabolism Research., 2 (1922) 793.

Yagi, T., Hakui, N., Yamasaki, y., Kawamori, R., Shichiri, M., Abe, H., Kim, S., Miyake, M., Kamikwawa, K., Nishihata, T., and Kamada, A., "Insulin suppository: enhanced rectal absorption of insulin using an enamine 
derivative as a new promoter.," Lournal of Pharmacy and Pharamcology. 37 (1985) 512.

Yamamoto, ., Luo, A. M., Dodda-Kashi, S., and Lee, V. H. L., "The ocular route for systemic insulin delivery in the albino rabbit.," Journal of Pharmacy and Experimental Therapeutics, 249 (1989) 249.

Yamashita, S., Saitoh, H., Nakainshi, K., Masada, M., Nadai, T., and Kimura, T., "Characterization of enhanced intestinal permebility; electrophysiological study on the effects of diclofenac and ethylenedianinetetraacetic acid.," Iournal of Pharmacy and Pharmacology 37 (1985) 512.

Ziegler, R., Holz, G., Strrebl, W and Raue, R., "Nasal applications of calcitonin in Paget's disease of bone.," Acta Endocrinology Supplement., 215 (1978) 54-55 